Life Sciences Contributions Royal Ontario Museum

Variation in the Jaw Musculature of the Avian Family Vireonidae

Ronald I. Orenstein Jon C. Barlow

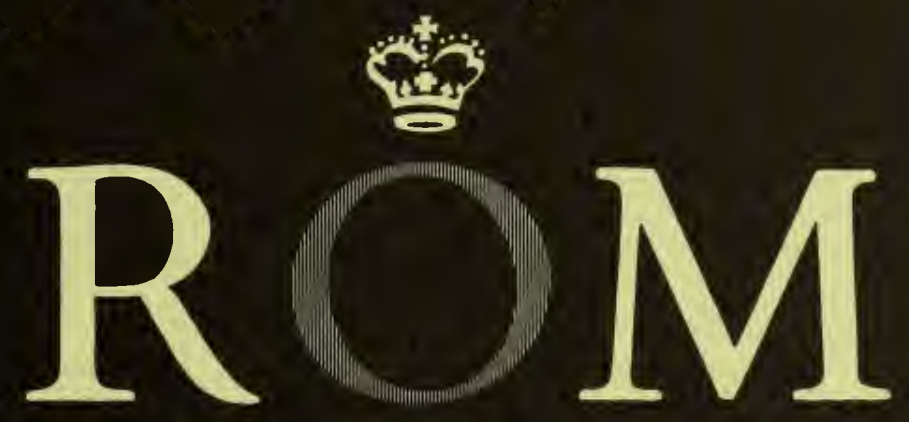




\section{ROYAL ONTARIO MUSEUM LIFE SCIENCES PUBLICATIONS INSTRUCTIONS TO AUTHORS}

Authors are to prepare their manuscripts carefully according to the following instructions. Failure to do so will result in the manuscript's being returned to the author for revision. All manuscripts are considered on the understanding that if accepted they will not be offered for publication elsewhere.

1. GENERAL Papers for publication are accepted from ROM staff members, Research Associates, or from researchers reporting on work done with ROM collections. In exceptional cases, monographic works on the flora and/or fauna of Ontario will be considered for publication by authors not affiliated with the ROM. Authors are expected to write clearly and concisely, and to omit all material not essential for an understanding of the main theme of the paper.

2. FORMAT Manuscripts are to be typed double-spaced (including captions, synonomies, literature cited, and tables)

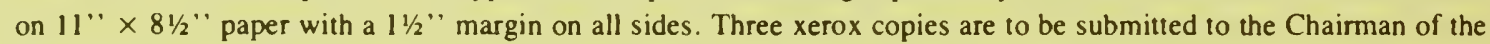
Editorial Board, and the original retained by the author(s). A separate sheet is to be submitted giving author(s) names, affiliation, title of publication, series in which it is to appear, number of typed pages, number of tables, and number of figures. Manuscripts should normally be organized in the following order: Table of Contents, Ahstract, Introduction, Materials and Methods, Results, Discussion, Conclusions, Summary (if paper is long), Acknowledgements, Literature Cited, and Appendices. Authors are encouraged to include foreign language translations of the Summary where appropriate. Headings of sections are to be left-justified to the text margin. The first line of the first paragraph in each new section should not be indented. Text-figures are referred to as "Fig. l". Literature cited in the text is in the form "Jones (1972)" or "(Jones, 1972)" or "(Smith, 1960:71-79, fig. 17)".

3. STANDARD SOURCES The primary source for decisions on format and style is A Guide for Contributors and Editors of ROM Life Sciences Publications, available from the Chairman of the Editorial Board. Otherwise, consult CBE (AlBS) Style Manual (3rd Edition). Other standard sources are as follows: for English spelling (Concise Oxford Dictionary), for Canadian place names and coordinates (Gazetteer of Canada), and for spelling of geographic names (Times [London] Atlas)

4. ABSTRACT All papers are preceded by a short and factual abstract, about 3 per cent as long as the text, but not longer than 400 words. The abstract is to be followed by four to six keywords enclosed in brackets

5. TAXONOMY The name of a taxon is given in full in headings, where it appears for the first time, or when the name begins a paragraph. Use authority and date if appropriate, with first mention of each taxon and not thereafter. Taxonomic papers follow the layout in Life Sciences Contribution 99, particularly the synonomies.

6. LITERATURE CITED References in the text cite author and date and are enclosed in parentheses (Smith, 1978). Complete references are listed in alphabetical order by author at the end of the paper. When there are two or more citations for an author, the works are listed chronologically. Names of journals are not abbreviated. Consult Life Sciences Contributions beginning with 117 for correct bibliographic form.

7. TABLES All tables are numbered consecutively in arabic numerals in numerical order of their first mention in the text. Mark the appropriate text location of each table with a marginal notation. Each table is typed on a separate sheet. Avoid footnotes etc., to tables by building them into the title.

8. FIGURES All figures are numbered consecutively in arabic numerals. Component photographs or drawings are labelled sequentially in upper case letters. Mark the appropriate text location of each figure with a marginal notation. The intended reduction for figures is ideally one and a half to two times. All labelling on figures is in blue pencil and not inked or letraset. Halftones must be photographic prints of high contrast on glossy paper. Authors are to submit $10^{\prime \prime} \times 8^{\prime \prime}$ copies with the MS and retain originals until they are requested. Figure captions are to appear grouped together on a separate page at the end of the MS 
LIFE SCIENCES CONTRIBUTIONS

ROYAL ONTARIO MUSEUM

NUMBER 128

RONALD I. ORENSTEIN JON C. BARLOW

\section{Variation in the}

Jaw Musculature of the Avian Family Vireonidae 


\section{ROYAL ONTARIO MUSEUM \\ PUBLICATIONS IN LIFE SCIENCES}

The Royal Ontario Museum publishes three series in the Life Sciences: LIFE SCIENCES CONTRIBUtions, a numbered series of original scientific publications including monographic works.

LIFE SCIENCES OCCASIONAL PAPERS, a numbered series of original scientific publications, primarily short and usually of taxonomic significance.

LIFE SCIENCES MISCELLANEOUS PUBLICATIONS, an unnumbered series of publications of varied subject matter and format.

All manuscripts considered for publication are subject to the scrutiny and editorial policies of the Life Sciences Editorial Board, and to review by persons outside the Museum staff who are authorities in the particular field involved.

\section{LIFE SCIENCES EDITORIAL BOARD}

Senior Editor: C. McGOWAN

Editor: P. H. voN BITTER

Editor: R. WINTERBOTTOM

RONALD I. ORENSTEIN is a Postdoctoral Associate of the Department of Omithology, Royal Ontario Museum. JON C. BARLOW is Curator, Department of Ornithology, Royal Ontario Museum, and Professor, Department of Zoology, University of Toronto.

\section{Canadian Cataloguing in Publication Data}

Orenstein, Ronald I. (Ronald Isaac), 1946-

Variation in the jaw musculature of the avian

family Vireonidae

(Life sciences contributions, ISSN 0384-8159; no. 128)

Bibliography: $\mathrm{p}$.

ISBN 0-88854-276-3

1. Vireos - Anatomy. 2. Jaws - Muscles. 3. Birds Anatomy. I. Barlow, Jon C., 1935- II. Royal

Ontario Museum. III. Title. IV. Series.

$\begin{array}{lll}\text { QL696.P2945073 598.8'71 } & \text { C81-094596-7 }\end{array}$

Publication date: 22 May 1981

ISBN 0-88854-276-3

ISSN 0384-8159

(C) 1981, The Royal Ontario Museum

100 Queen's Park, Toronto, Canada M5S 2C6

PRINTED AND BOUND IN CANADA AT THE UNIVERSITY OF TORONTO PRESS 


\section{Contents}

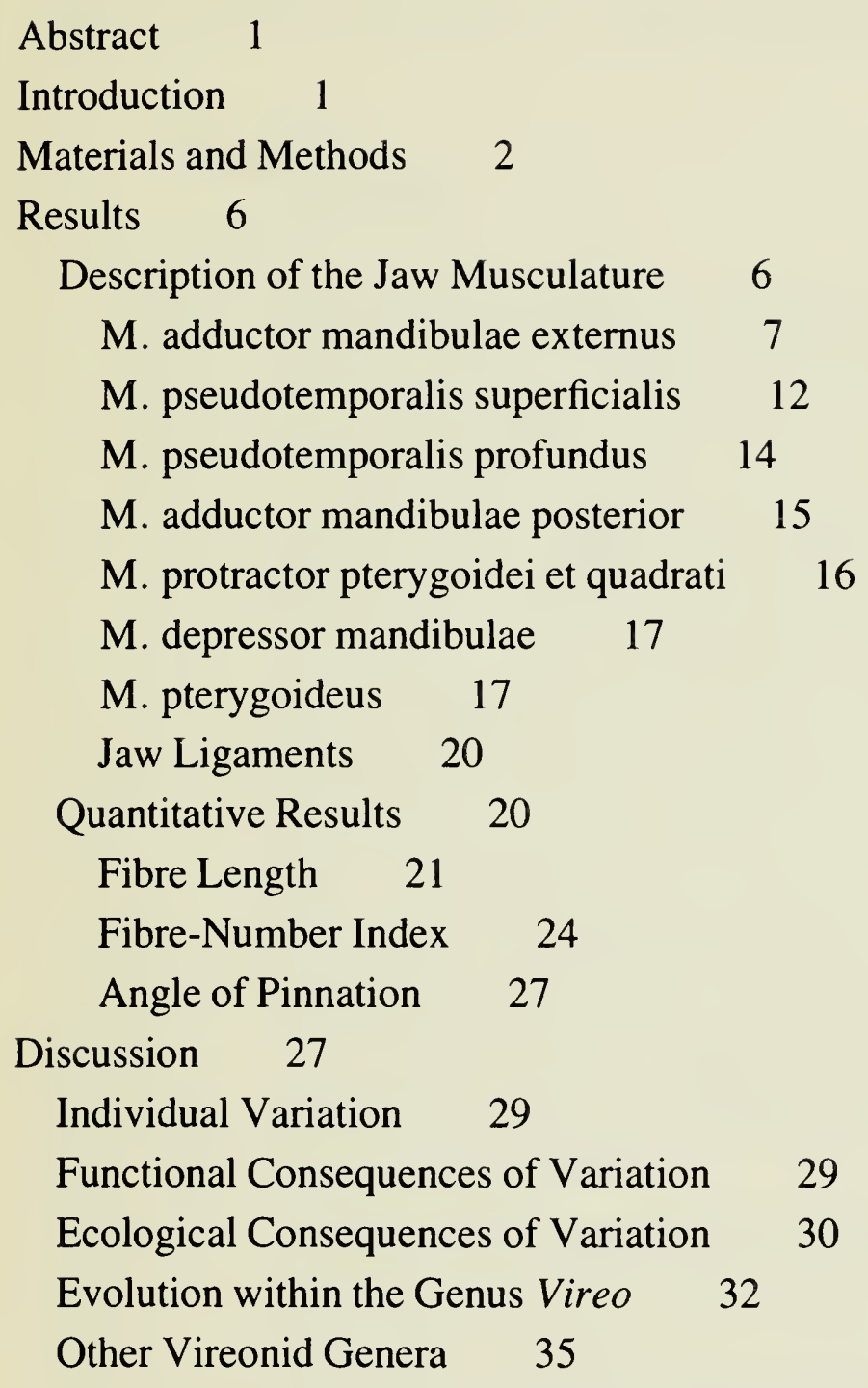

Taxonomic Significance of the Jaw Musculature $\quad 36$ Acknowledgements 37

Literature Cited $\quad 38$

Appendix $1 \quad 43$

Abbreviations Used in Figs. 1-15

Figs. 1-15 46 
Digitized by the Internet Archive in 2011 with funding from University of Toronto 


\title{
Variation in the Jaw Musculature of the Avian Family Vireonidae
}

\begin{abstract}
This study examines variation of the jaw musculature within a single genus, Vireo (including Neochloe, Lawrencia, and Laletes), and in the related genera Hylophilus, Cyclarhis, and Vireolanius (including Smaragdolanius).

Dissections of the jaw musculature, with measurements of fibre length, fibre number, and angle of pinnation, were performed on 100 preserved specimens representing 46 species and subspecies of Cyclarhis, Vireo, Hylophilus, and Vireolanius. The jaw musculature in the Vireonidae studied shows little variability in the basic pattern of tendon arrangements, origins, and insertions, except in $\mathrm{Mm}$. adductor mandibulae externus caudalis and pterygoideus dorsalis lateralis. The major interspecific variations in Vireo involve changes in fibre length and number. Differences in relative fibre lengths in the large adductor muscles were found between the subgenera Vireo and Vireosylva, with $V$. hypochryseus similar to Vireosylva. Cyclarhis and Vireolanius had relatively stronger jaw musculature but were otherwise similar to Vireo. Hylophilus spp. had significantly larger depressor musculature than the other genera studied.

Such variations in the jaw musculature may be related to variations in other aspects of the feeding apparatus, and to foraging behaviour and food type. We believe that foraging site may have been more important in the evolution of interspecific differences than the habitat separation proposed by Hamilton (1962).
\end{abstract}

\section{Introduction}

During the past three decades, there has been a resurgence of interest in the bearing of avian anatomy on taxonomy (Bock, 1969, 1974). Osteological and myological characters have been employed to determine relationships within an order (Hudson, 1948), or affinities of obscure taxa (Berger, 1969; Mann et al., 1978). Beecher (1950, 1951a, $1951 \mathrm{~b}, 1953)$ used the jaw musculature as a basis for radical taxonomic proposals, including a reorganization of the Oscines. Most subsequent studies have been confined to a few species (Merz, 1963), or have stressed functional adaptations (Zusi, 1967). The detailed study of the Geospizinae by Bowman (1961) was the first to concentrate on variation of the jaw musculature within genera of Oscines. Richards and Bock (1973) analysed the feeding apparatus in a single small genus, Loxops. More recently, Burton (1974a, 1974b) has surveyed the jaw musculature of the Charadrii and the Callaeidae. 
The present study examines variation in the jaw musculature within a large, relatively homogeneous genus, Vireo. Representatives of the other vireonid genera, Hylophilus, Vireolanius (including Smaragdolanius), and Cyclarhis, were also examined. The primary aims of this study were as follows:

1. To determine the extent and nature of quantitative and qualitative variation in the jaw musculature, with respect to origins, insertions, tendon number and arrangement, fibre length, and fibre number.

2. To discover any relationship between such variation and foraging behaviour, including habitat selection and foraging site selection. In particular, to determine if the division of Vireo into species groups based on foraging preference (Hamilton, 1958, 1962) could be supported by myological evidence.

3. To evaluate the myological evidence for recognizing the subgenera Vireo and Vireosylva, and in particular for the proper allocation of the Golden Vireo ( $V$. hypochryseus) of Mexico. This species has been placed in both Vireo (Ridgway, 1904; Blake, 1968) and Vireosylva (Hamilton 1958, 1962).

4. To evaluate the myological evidence for the affinities of Cyclarhis and Vireolanius. This aim could only be realized in a limited way as no outgroup comparisons were made (cf. Raikow, 1978).

The large number of taxa considered, the small sample sizes in many cases, and the extent of individual variation found rendered detailed analyses of skull kinetics and force vectors as undertaken by Richards and Bock (1973), or the use of free-body diagrams and torque analyses (Bock, 1966, 1968, 1974), unfeasible, although we realize their importance in interpreting muscular functions. We assume for the purposes of discussion that among such a homogeneous assemblage as the genus Vireo the actions of individual muscles and fibres do not vary appreciably.

\section{Materials and Methods}

Detailed dissections of the jaw musculature were performed by the first author on 100 specimens preserved in alcohol, representing 46 species and subspecies of Cyclarhis, Vireo, Hylophilus, and Vireolanius (Table 1). Additional specimens of representative forms were dissected early in the study to acquire familiarity with the birds' anatomy. All specimens were decapitated, and the skin removed from the head. Further dissection was confined to the left side of the specimen so as not to completely destroy the jaw musculature, although some points were checked on the right side. After the position of insertion of $\mathrm{M}$. branchiomandibularis had been noted, the left eye, left jugal bar, tongue, hyoid apparatus, and skin of the palate were removed. Fascia, portions of the optic nerve, the intrinsic musculature of the eye, and major blood vessels were removed on the side dissected.

The specimen was placed for several minutes in a solution used for staining muscle fibres (Bock and Shear, 1972): iodine $\left(\mathrm{I}_{2}\right)$, potassium iodide (KI), and water in a 1:2:100 ratio. As only superficial fibres are stained by this technique, it was necessary to repeat the immersion of the specimen several times during the dissection. 


\section{Table 1 Specimens dissected during this study.}

The code names given here, used in computer analyses, are used as abbreviations in some figures. The other abbreviations used in this table are as follows:

1 designates specimens obtained after the univariate analysis was performed

a not included in quantitative analyses

b subspecific identification uncertain

c specimen dissected is either the nominate race or H. o. pallidipectus

$R$ specimen(s) in the Royal Ontario Museum

C specimen(s) loaned by the Carnegie Museum

Y specimen(s) loaned by the Peabody Museum, Yale

$\mathrm{K}$ specimen(s) loaned by the University of Kansas

$\mathrm{N}$ specimen(s) loaned by the National Museum of Natural History

\begin{tabular}{|c|c|c|c|}
\hline $\begin{array}{l}\text { Code } \\
\text { Name }\end{array}$ & Species & $\begin{array}{l}\text { Number } \\
\text { Dissected }\end{array}$ & $\begin{array}{c}\text { Source of } \\
\text { Material }\end{array}$ \\
\hline
\end{tabular}

\begin{tabular}{|c|c|c|c|}
\hline CGUJ & $\begin{array}{l}\text { Cyclarhis gujanensis (spp.?) } \\
\text { (Rufous-browed Peppershrike) }\end{array}$ & 1 & $\mathrm{C}$ \\
\hline CGIN & C. g. insularis & 2 & $\mathrm{C}$ \\
\hline VMEL & $\begin{array}{l}\text { Vireolanius melitophrys } \\
\text { (Chestnut-sided Shrike-vireo) }\end{array}$ & $1^{1}$ & $\mathrm{R}$ \\
\hline VPUL & V. pulchellus (Emerald Shrike-vireo) & $1^{1}$ & $\mathrm{R}$ \\
\hline VBRE & Vireo brevipennis (Slaty Vireo) & $1^{1}$ & $\mathrm{R}$ \\
\hline VHHU & V. huttoni huttoni (Hutton's Vireo) & 2 & $\mathrm{R}$ \\
\hline VHST & V.h. stephensi & 2 & $\mathrm{R}$ \\
\hline VATR & V. atricapillus (Black-capped Vireo) & 2 & $\mathrm{R}$ \\
\hline VGRI & V. griseus (ssp.?) (White-eyed Vireo) & $1^{\mathrm{a}}$ & $\mathrm{R}$ \\
\hline VGNO & $V \cdot g$. noveboracensis & 1 & $\mathrm{R}$ \\
\hline VGMA & V. g. maynardi & 3 & $\mathrm{R}$ \\
\hline VPSE & V. pallens semiflavus (Mangrove Vireo) & 4 & $\mathrm{R}$ \\
\hline VCRI & V. caribaeus (St. Andrew Vireo) & $1^{1}$ & $\mathrm{R}$ \\
\hline VBAI & V. bairdi (Cozumel Vireo) & 3 & $\mathrm{C}(2), \mathrm{Y}(1)$ \\
\hline VGUN & V. gundlachii (Cuban Vireo) & $1^{1}$ & $\mathrm{R}$ \\
\hline VCCR & $\begin{array}{l}\text { V. crassirostris crassirostris } \\
\text { (Thick-billed Vireo) }\end{array}$ & $1^{1}$ & $\mathrm{R}$ \\
\hline VBAR & V. bellii arizonae (Bell's Vireo) & 1 & $\mathrm{R}$ \\
\hline VBME & V.b. medius & 1 & $\mathrm{R}$ \\
\hline VBBE & V.b. bellii & 1 & $\mathrm{R}$ \\
\hline VVIC & V. vicinior (Gray Vireo) & 4 & $\mathrm{R}$ \\
\hline VNEL & V. nelsoni (Dwarf Vireo) & $1^{1}$ & $\mathrm{R}$ \\
\hline VHHY & V. hypochryseus hypochryseus (Golden Vireo) & 6 & $\mathbf{R}$ \\
\hline VMOD & V. modestus (Jamaican Vireo) & $1^{1}$ & $\mathrm{R}$ \\
\hline VNAN & V. nanus (Flat-billed Vireo) & $1^{1}$ & $\mathrm{R}$ \\
\hline VLAT & V. latimeri (Puerto Rican Vireo) & 2 & $\mathrm{C}$ \\
\hline VOSB & V. osburni (Blue Mountain Vireo) & $1^{1}$ & $\mathrm{R}$ \\
\hline VCAR & V. carmioli (Yellow-winged Vireo) & $1^{1}$ & $\mathrm{R}$ \\
\hline VSSO & V. solitarius solitarius (Solitary Vireo) & 2 & $\mathrm{R}$ \\
\hline VSPL & V.s.plumbeus & 6 & $\mathrm{R}$ \\
\hline
\end{tabular}


Table 1 continued

\begin{tabular}{|c|c|c|c|}
\hline $\begin{array}{l}\text { Code } \\
\text { Name }\end{array}$ & Species & $\begin{array}{l}\text { Number } \\
\text { Dissected }\end{array}$ & $\begin{array}{l}\text { Source of } \\
\text { Material }\end{array}$ \\
\hline VSCA & V.s. cassinii & 1 & $\mathrm{R}$ \\
\hline VFLA & V. flavifrons (Yellow-throated Vireo) & 2 & $\mathrm{R}$ \\
\hline VPHI & V. philadelphicus (Philadelphia Vireo) & 3 & $\mathrm{R}$ \\
\hline VOOL & V. olivaceus olivaceus (Red-eyed Vireo) & $7,3^{\mathrm{a}}$ & $\mathrm{R}$ \\
\hline VOFL & V.o. flavoviridis ("Yellow-green Vireo") & 6 & $\mathrm{R}$ \\
\hline VOVI & V.o.vividior & 2 & $\mathrm{C}$ \\
\hline $\mathrm{VOCH}$ & V.o.chivi & $2^{\mathrm{b}}$ & $\mathrm{C}$ \\
\hline VOGR & V. o. gracilirostris & $1^{1}$ & $\mathrm{~N}$ \\
\hline VMMA & V. magister magister (Yucatan Vireo) & 4 & $\mathrm{C}(2), \mathrm{K}(2)$ \\
\hline VMCA & V.m. caymanensis & $2^{1}$ & $\mathrm{R}$ \\
\hline VABA & $\begin{array}{l}\text { V. altiloquus barbadensis } \\
\text { (Black-whiskered Vireo) }\end{array}$ & 1 & $\mathrm{~K}$ \\
\hline VGGI & V. gilvus gilvus (Warbling Vireo) & 1 & $\mathrm{R}$ \\
\hline VGSW & V.g.swainsoni & 1 & $\mathrm{R}$ \\
\hline HOPI & $\begin{array}{l}\text { Hylophilus poicilotis (ssp.?) } \\
\text { (Rufous-crowned Greenlet) }\end{array}$ & 2 & Y \\
\hline HPEC & $H$. pectoralis (Ashy-headed Greenlet) & 1 & $\mathrm{C}$ \\
\hline HAUR & $\begin{array}{l}\text { H. aurantiifrons (ssp.?) } \\
\text { (Golden-fronted Greenlet) }\end{array}$ & 2 & $\mathrm{C}$ \\
\hline HFLA & H. flavipes (ssp.?) (Scrub Greenlet) & 1 & $\mathrm{C}$ \\
\hline $\mathrm{HOCH}$ & H. ochraceiceps (Tawny-crowned Greenlet) & $1^{\mathrm{c}}$ & $\mathrm{C}$ \\
\hline HDDE & $\begin{array}{l}\text { H. decurtatus decurtatus } \\
\text { (Gray-headed Greenlet) }\end{array}$ & $2,1^{\mathrm{a}}$ & $\mathrm{R}$ \\
\hline
\end{tabular}

Dissections were performed with a Wild M5 dissecting microscope equipped with a drawing tube. $10 \times$ eyepieces and a $25 \times$ objective were used for most dissection, although some drawings were made using the $12 \times$ objective. Microdissecting instruments (set \#8-870, Fisher Scientific Company) were used for all work.

Each muscle or muscle section was studied and removed before proceeding further (Table 2). Drawings were made at regular intervals, and the pattern of gross fibre arrangement and tendons noted. Measurements of fibre lengths, estimated to $0.1 \mathrm{~mm}$, were made by comparison with a scale viewed through the drawing tube. As fibre lengths are affected by preservation, these measurements must be considered approximations to the resting length in life. Angles of pinnation were measured to within 1 degree on a tracing of the muscle. Owing to artifacts of preservation, however, these data exhibited too much variation to be useful. Muscles were stripped of all fibres and the fibres were removed in bundles of approximately equal diameter. The total number of such bundles for a muscle provided an index of fibre number. This index is admittedly crude and difficult to reproduce. The judgement of the size of a bundle of fibres is subject to error. This technique, however, is more practical when dealing with large numbers of specimens, as here, than an attempt to count fibres in histological cross-sections of the entire muscle, and can be utilized on a specimen used for other aspects of dissection. Of other methods of estimating muscle size, excision for 
Table 2 Quantitative characters used in analysis of the jaw musculature, with code names used in this study.

A. Fibre Lengths (All lengths taken on selected fibres, usually in the central portion of the muscle)

1. FLAT Length of fibres in $M$. adductor mandibulae externus rostralis lateralis

2. FTEM Length of fibres in $\mathrm{M}$. adductor mandibulae externus rostralis temporalis

3. FVME Length of fibres in M. adductor mandibulae externus rostralis medialis arising from the tendon of origin of $\mathrm{M}$. adductor mandibulae externus ventralis

4. FIME Length of fibres in $\mathrm{M}$. adductor mandibulae externus rostralis medialis arising from its medial tendon of origin

5. FAVE Length of longest (rostralmost) fibres in M. adductor mandibulae externus ventralis

6. FPVE Length of shortest (caudalmost) fibres in M. adductor mandibulae externus ventralis

7. FACD Length of fibres inserting on the rostral face of the tendon of insertion in $M$. adductor mandibulae externus caudalis

8. FPCD Length of fibres inserting on the caudal face of the tendon of insertion of $M$. adductor mandibulae externus caudalis

9. FOPS Length of fibres in the lateral lobe of M. pseudotemporalis superficialis

10. FMPS Length of fibres in the middle lobe of $M$. pseudotemporalis superficialis

11. FIPS Length of fibres in the medial lobe of $\mathbf{M}$. pseudotemporalis superficialis

12. FPPR Length of fibres in M. pseudotemporalis profundus

13. FADP Length of longest (lateralmost) fibres in $\mathrm{M}$. adductor mandibulae posterior

14. FPRP Length of longest fibres in $\mathrm{M}$. protractor pterygoidei

15. FPRQ Length of shortest fibres in M. protractor quadrati

16. FLDM Length of longest (lateralmost) fibres in M. depressor mandibulae

17. FSDM Length of shortest (caudomedial) fibres in M. depressor mandibulae

18. FDLT Length of fibres in M. pterygoideus dorsalis lateralis

19. FEVM Length of lateral fibres in M. pterygoideus ventralis medialis

20. FIVM Length of medial fibres of M. pterygoideus ventralis medialis arising from the palate

21. FPVM Length of caudomedial fibres in $\mathbf{M}$. pterygoideus ventralis medialis arising from its medial tendon of origin

22. FADM Length of fibres in M. pterygoideus dorsalis medialis anterior

23. FPDM Length of fibres in M. pterygoideus dorsalis medialis posterior

B. Fibre-Number Indices

1. NTEM M. adductor mandibulae externus rostralis temporalis and lateralis (combined)

2. NMED M. adductor mandibulae externus rostralis medialis

3. NVEN M. adductor mandibulae externus ventralis

4. NCDL M. adductor mandibulae externus caudalis

5. NAME M. adductor mandibulae externus (total)

6. NPPR M. pseudotemporalis profundus

7. NADP M. adductor mandibulae posterior

8. NPPQ M. protractor pterygoidei et quadrati

9. NDEP M. depressor mandibulae

10. NDLT M. pterygoideus dorsalis lateralis (not including "ventralis lateralis")

11. NPVM M. pterygoideus ventralis medialis

12. NADM M. pterygoideus dorsalis medialis anterior

13. NPDM M. pterygoideus dorsalis medialis posterior

14. NPTE M. pterygoideus (total) 
volumetric analysis is extremely difficult to apply to the complex and often very small jaw muscles (Bowman, 1961), and in a preserved specimen the analysis is affected by stretching or distortion of the fibres. In any case, this technique, and those using dry or wet weights, give measurements of overall muscle size, not of fibre number or physiological cross-sectional area, which are the only gross muscle parameters directly related to force development (Gans and Bock, 1965; Bock, 1974: 176).

Mean, range, and standard error were determined for quantitative measurements at the species or subspecies level, and at the generic or subgeneric level. Cube root of weight was employed as a correction factor for all taxa with available weight data, although for a non-linear measurement such as fibre number a correction factor of a $2 / 3$ power may have been more appropriate. Values for fibre length/cube root of weight and fibre-number index/cube root of weight were treated with analysis of variance (ANOVA) and, where applicable, Gabriel's simultaneous sums of squares test (SSSTP; see Sokal and Rohlf, 1969: 237). Eleven taxa of Vireo and two of Vireolanius were received after the univariate analysis was completed, but as only one specimen of each was available (except for Vireo magister caymanensis [2]), the analysis was not repeated. Because of the small sample sizes for many taxa, often one or two specimens only, multivariate analyses performed on the 46 muscle characters yielded confused results and are not reported here. Complete results of univariate and multivariate analyses are on file at the Department of Ornithology, Royal Ontario Museum.

Although differences in fibre orientation may be an important aspect in a study of muscle variation, we felt that such differences could not safely be described in preserved specimens of varying age drawn from many sources.

We have preferred to use Richards and Bock (1973) rather than the Nomina Anatomica Avium (Baumel et al., 1979) as a basis for our nomenclature. Names of jaw muscles differ little between the two works, except that Baumel et al. (1979) use "M. adductor mandibulae caudalis" for the $\mathbf{M}$. adductor mandibulae posterior. There are many differences in osteological nomenclature between the two. Baumel et al.'s (1979) coverage of the skull omits many details and its synonymy is incomplete. Richards and Bock (1973) is clearly the superior guide for cranial nomenclature. We have, however, followed Baumel et al. (1979) for directional terminology, using "rostral", "caudal", "medial", and "lateral" instead of "anterior", "posterior", "internal", and "external" respectively. The latter terminology has, for consistency, been retained in muscle names to conform with Richards and Bock (1973).

\section{Results}

\section{Description of the Jaw Musculature (Figs. 1-15)}

The only published description of the jaw musculature in the Vireonidae is that of Beecher (1953). Although Beecher examined several species of Vireo, Hylophilus, Cyclarhis, and Smaragdolanius (= Vireolanius), he gives few comparative details and his descriptions have not proved useful (cf. Bock, 1974). W. J. Bock (pers. comm.) has studied the jaw musculature of Vireo altiloquus.

The probable actions of the seven pairs of jaw muscles have been described elsewhere (Beecher, 1951a; Bowman, 1961; Richards and Bock, 1973; Burton, 
1974a). To simplify, the Mm. adductor mandibulae externus, pseudotemporalis superficialis, pseudotemporalis profundus, adductor mandibulae posterior, and pterygoideus close the jaws, either by elevating the lower mandible, depressing the upper, or both; the $\mathrm{M}$. depressor mandibulae depresses the lower mandible; and the M. protractor pterygoidei et quadrati elevates the upper mandible. The only detailed laboratory studies on the operation of the avian feeding apparatus have been those of Zweers on Anas platyrhynchos (Zweers, 1974; Zweers et al., 1977).

We found few species-specific characters in the jaw muscles of the vireos. Individual variation was extensive, with asymmetry, particularly with respect to tendon size and fibre number, in certain specimens. In most cases, however, the positions of origin and insertion of major tendons exhibited little variation.

In the ensuing descriptions, if variant states were found in only some specimens of a species or subspecies, the number of specimens exhibiting these states is indicated in parentheses. Forms represented by a single specimen are noted with an asterisk $\left({ }^{*}\right)$. For an explanation of the abbreviations used in Figs. 1-15, see page 45.

\section{M. adductor mandibulae externus}

A large and complex muscle, subdivided into three main parts: the Pars rostralis, the Pars ventralis, and the Pars caudalis, with intermediate fibres difficult to assign.

\section{Pars Rostralis}

The Pars rostralis is further subdivided into the Partes temporalis, lateralis, and medialis.

\section{a. Pars rostralis temporalis (Figs. 1-5: amert)}

The temporalis arises fibrously from the temporal fossa of the braincase and part of the surface of the zygomatic process. Its dorsal and ventral limits are the temporal and subtemporal cristae respectively. Insertion is by a heavy tendon attaching to the surangular process of the mandible. This tendon extends caudodorsally into the temporal fossa where it fans out, largely in a paramedial plane. Most fibres insert on its medial surface.

Variations. In most species examined, the rostral and dorsal surfaces of the temporal crista give rise to a superficial aponeurosis of origin. Fibres arising from the medial surface of this aponeurosis insert on the lateral surface of the fan-shaped expansion of the tendon of insertion. This aponeurosis is tenuous and difficult to examine, but its extent may be gauged from the number of fibres inserting on the lateral face of the tendon of insertion. In Vireo it is present in all forms except V. atricapillus, bellii arizonae*, b. medius*, huttoni stephensi ( 1 of 2$)$, nanus*, nelsoni*, $h$. hypochryseus (4 of 6), olivaceus flavoviridis (1 of 6), philadelphicus, and gilvus. In one specimen of $V$. gilvus, a very small proportion of the fibres inserts on the lateral face of the tendon. One specimen of $V . h$. hypochryseus has a large superficial aponeurosis on the left side only. $V$. carmioli* has only a few fibres inserting on the ventral edge of the lateral face of the tendon of insertion. The area of the tendon of insertion receiving superficial fibres is greatest in the heavy-billed Vireo vicinior and 
V. osburni*, as well as in Cyclarhis and Vireolanius spp. ${ }^{*}$ In Hylophilus a welldeveloped superficial aponeurosis of origin is found only in ochraceiceps*. In this species the aponeurosis is dense and arises almost entirely from the postorbital process. A very small number of fibres in $H$. pectoralis* arise from a weak superficial aponeurosis (see Text-fig. 1:31).
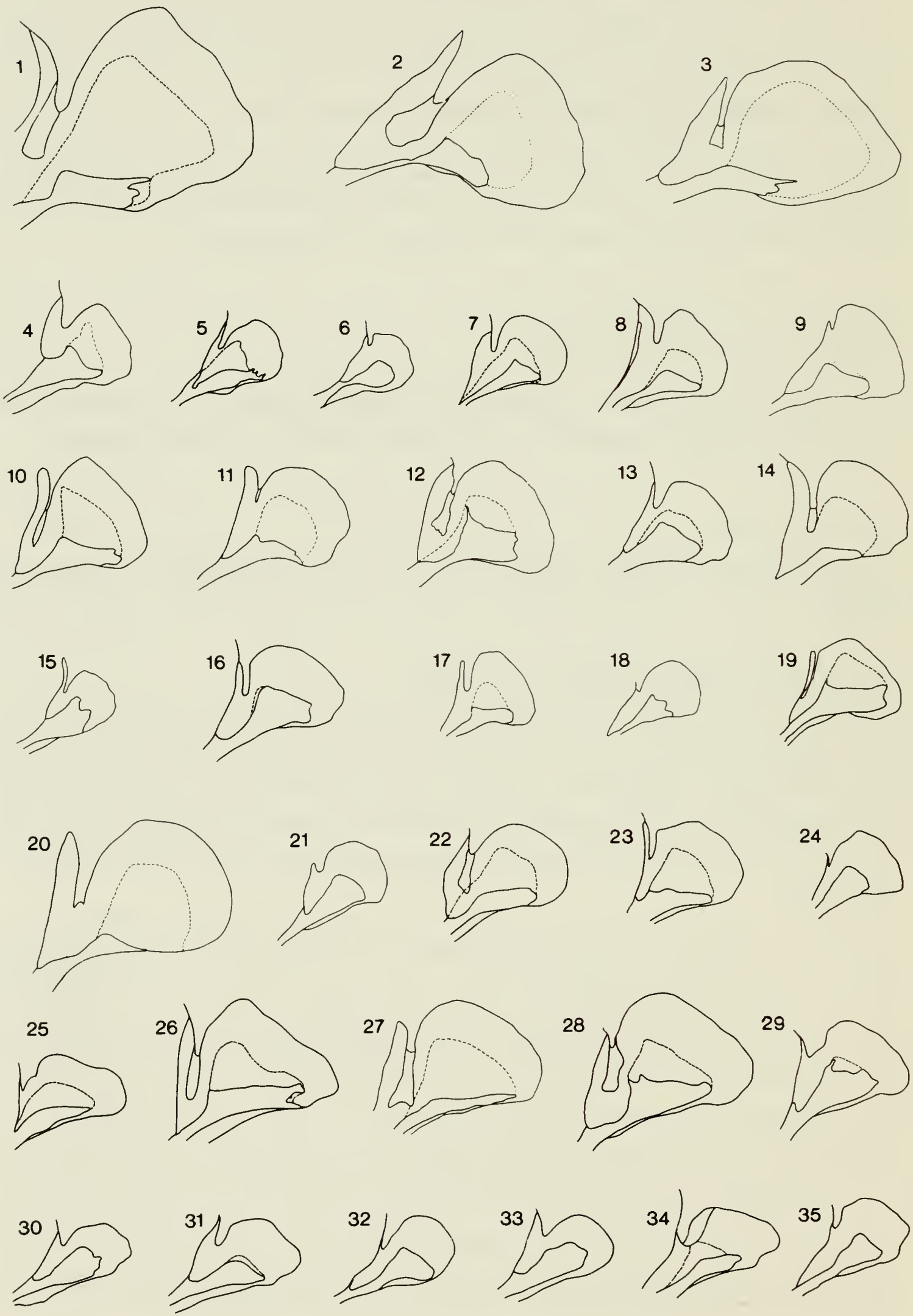
The rostral edge of the tendon of insertion normally curves mediad caudal to the postorbital process, and fibres arising from that process insert on the tendon's lateral surface. On some individuals (e.g., one Vireo griseus maynardi) the tendon curved laterad instead, and in one specimen of $V$. bairdi it curved laterad slightly, then mediad. In Hylophilus decurtatus and $H$. ochraceiceps* infolding is marked, and the temporal fossa is deepened at the point of the medial extension of the tendon.

In Cyclarhis gujanensis the area of the temporal fossa has been diminished as a result of the more dorsal position of the subtemporal crista (see Pars caudalis). Ventral fibres of the temporalis take origin from a large aponeurosis running ventrally from the subtemporal crista, covering the dorsal portion of the Pars caudalis. Although both Vireo osburni* and Vireolanius spp.* exhibit a similar dorsal shift of the subtemporal crista, they have no additional aponeurosis of insertion for the temporalis.

The extent of the temporal fossa varies greatly among species in Vireo (Figs. 1-5), but because of the complexities described its area is a poor indicator of the fibre number of the temporalis. In Hylophilus, depth of the fossa may be a more important correlate of muscle size than its area, which varies little.

\section{b. Pars rostralis lateralis (Figs. 1-5: amerl)}

Fibres of the lateralis arise from the medial surface of a fan-shaped tendon of origin lying in a roughly paramedial plane and attaching to the base of the zygomatic process. More rostrally fibres arise from the lateral surface of the tendon of origin of the Pars ventralis. Fibres insert on the medial surface of a tendon which joins the tendon of insertion of the Pars rostralis temporalis just before it inserts on the mandible.

Variations. Fibres may arise from the lateral surface of the tendon of origin. Normally they arise from the anteroventral portion of the tendon, but in some forms (e.g., Cyclarhis gujanensis) a few such fibres arise from its dorsal half. The extent and complexity of this condition varies. In Vireo h. huttoni (1 of 2), griseus (ssp.?*), nanus* ${ }^{*}$, caribaeus $*$, osburni*, altiloquus barbadensis*, g. gilvus (1 of 2), Vireolanius melitophrys*, and Hylophilus ochraceiceps* the tendon is not enlarged and fibres arise from the ventral portion of its lateral surface. In Vireo gundlachii* and V.m. magister

Text-fig. 1 Lateral view of the M. adductor mandibulae externus rostralis temporalis, showing the area of the tendon of insertion having fibres inserting on its lateral surface. The area of the tendon visible superficially is indicated by a heavy line; the dashed line indicates its true caudal boundary. See Figs. 1-5 for relative scale.

1. Cyclarhis gujanensis insularis (Carnegie 1077), 2. Vireolanius melitophrys (ROM 112919), 3. V. pulchellus (ROM 112335), 4. Vireo brevipennis (ROM 109629) (the dotted line indicates damage), 5. V. h. huttoni (ROM 106037), 6. V. atricapillus (ROM 104450), 7. V. griseus maynardi (KU 3889), 8. V. pallens semiflavus (ROM 104312), 9. V. caribaeus (ROM 113085), 10. V. bairdi (Yale 6363), 11. V. gundlachii (ROM 110416), 12. V. c. crassirostris (ROM 111904), 13. V. b. bellii (KU 40376), 14. V. vicinior (ROM 99458), 15. V. nelsoni (ROM 109360), 16. V. h. hypochryseus (Rом 105617), 17. V. modestus (ROм 109764), 18. V. nanus (ROM 112421), 19. V. latimeri (Carnegie 830), 20. V. osburni (ROM 113173), 21. V. carmioli (ROM 113302), 22. V. solitarius plumbeus (ROM 100591), 23. V. flavifrons (ROM 102921), 24. V. philadelphicus (ROM 97690), 25. V. o. olivaceus (ROM 103089), 26. V. m. magister (KU 40814), 27. V. magister caymanensis (ROM 109363), 28. V. altiloquus barbadensis (KU 522976), 29. V. g. gilvus (Rом 98218), 30. Hylophilus poicilotis (Yale 2924), 31. H. pectoralis (Carnegie 1349), 32. H. aurantiifrons (Carnegie 362), 33. H. flavipes (Carnegie 96), 34. H. ochraceiceps (Carnegie 917), 35. H.d. decurtatus (RОм 104309). 
the ventral portion of the tendon is produced rostrally to form a tonguelike extension. In $V$. bairdi (1 of 3), flavifrons ( 1 of 2), magister caymanensis, and Vireolanius pulchellus*, this extension is oriented horizontally, reaching medially to the tendon of origin of the Pars ventralis. In this condition the original lateral surface faces ventrally. Except in Vireo flavifrons the medial (formerly ventral) leading edge of the tendon is weakly fused to the tendon of origin of the Pars ventralis.

In Hylophilus aurantiifrons ( 1 of 2 ) the ventral portion of the tendon of origin is folded medially but not enlarged. Cyclarhis gujanensis is similar to Vireo gundlachii*, but fibres arise from the external surface of both the dorsal and ventral surfaces of the tendon. In one specimen most of the tendon's outer surface gave rise to fibres. In all forms with fibres arising as described in this section, such fibres insert on the internal surface of the tendon of insertion with the remainder of the lateralis.

\section{c. Pars rostralis medialis (Figs. 1-5: amerm)}

The medialis has two areas of origin. In the first, fibres arising from the rostral edge of the postorbital process, the caudal wall of the orbit, and the dorsolateral surface of the tendon of origin of the Pars ventralis, insert on the underside of a flattened tendon attached to the rostral tubercle of the surangular process of the mandible. This tendon lies in a roughly paramedial plane medial to the mandible but curves laterally at its dorsal edge. The second group of fibres originate from a broad, paramedially flattened tendon arising from the caudal wall of the orbit internal to the first area of origin. They insert on the dorsomedial face of the tendon of insertion. The tendons of insertion of the medialis and temporalis are weakly fused at their edges.

Variations. The medial tendon of origin of the medialis gives origin to fibres from both its surfaces, rather than only from its external surface, in Vireo atricapillus (1 of 2), V. bellii arizonae*, Vireolanius melitophrys*, and Cyclarhis gujanensis. The additional fibres arise from the extreme distal end of the medial surface of the tendon, and insert rostral to fibres from the lateral surface of the tendon. In Cyclarhis gujanensis the most ventral of these fibres insert directly onto the medial surface of the mandible.

The dorsal horizontally oriented portion of the tendon of insertion forms a broad exposed area in most forms. In Vireo bellii, olivaceus, m. magister, altiloquus barbadensis*, and gilvus, and in Hylophilus aurantiifrons and H.d. decurtatus, only the caudodorsal end is much exposed, the tendon lying almost entirely in a paramedial plane (Text-fig. 2).

In Vireo latimeri, bairdi, gundlachii*, c. crassirostris*, vicinior, solitarius plumbeus, osburni*, altiloquus barbadensis*, and magister (both ssp.), and in both Vireolanius and Cyclarhis, a small tendon of origin from the postorbital process gives rise to medialis fibres rostrally and to temporalis fibres caudally. All of these species except Vireo latimeri have a large and bulky Pars rostralis. Probably most other species have fascia separating the two parts at this point.

\section{Pars ventralis (Figs. 1-5: amev)}

The Pars ventralis arises from the tip of the zygomatic process by a broad tendon fanning out rostroventrally. Most of this tendon is flattened in a paramedial plane and passes external to the mandible. At its dorsal edge, however, a flange passes medially 

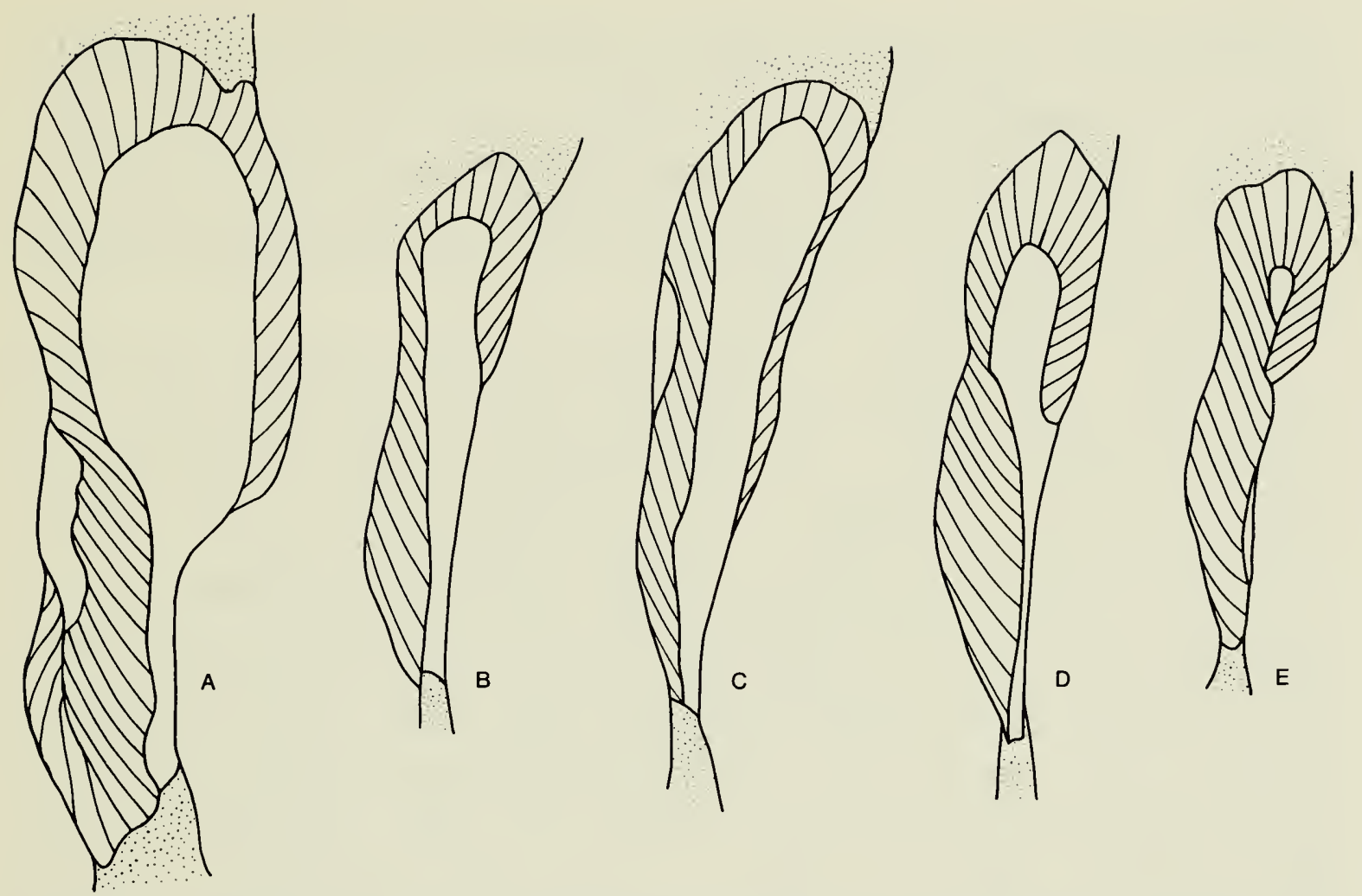

Text-fig. 2 Rostrodorsal view of M. adductor mandibulae externus rostralis medialis in several species, showing variation in the extent of exposed surface of the tendon of insertion. The Pars rostralis temporalis and Pars rostralis lateralis have been removed. See Figs. 6-12 for relative scale.
A Cyclarhis gujanensis insularis (Carnegie 1077)
B Vireo griseus maynardi (KU 3889)
C Vireo flavifrons (ROM 102921)
D Vireo altiloquus barbadensis (KU 52296)
E Hylophilus aurantiifrons (Carnegie 362)

dorsal to the mandible and caudal to the tendons of insertion of the Pars rostralis. Most ventralis fibres insert fleshily on the lateral surface of the mandible, others on its dorsal edge caudal to the insertion of the Pars rostralis medialis.

Variations. Most ventralis fibres arise from the edge or medial surface of the tendon of origin and insert fleshily, but a few of the most rostrodorsal fibres may take origin from the lateral surface. In Vireo brevipennis*, gundlachii*, osburni*, and Vireolanius melitophrys*, single specimens of Vireo atricapillus, griseus noveboracensis*, pallens semiflavus, bairdi, and flavifrons, and two specimens each of Vireo m. magister, V. altiloquus barbadensis, and Cyclarhis gujanensis, additional fibres arise from the lateral surface of the tendon along its ventral leading edge and insert on the medial surface of an aponeurosis running dorsally from the ventromandibular crista. The specimen of Vireo atricapillus with this condition also has additional fibres in the Pars rostralis medialis (see above).

\section{Pars Caudalis (Figs. 1-5: amec)}

The Pars caudalis inserts on the caudal tubercle of the surangular process by a broad tendon flattened in a transverse plane and usually produced caudad at its external edge. Fibres inserting on the dorsal portion of the rostral surface of this tendon arise from the 
subtemporal fossa, and those inserting on its ventral portion arise from the zygomatic process and the caudomedial surface of the tendon of origin of the Pars ventralis. Fibres inserting on the caudal surface take origin fleshily from the subtemporal fossa and the otic process of the quadrate, and from a tendon of origin arising from the otic process at the quadrate hinge and extending ventrally. A few of the ventralmost fibres may insert on the mandible just caudal to the attachment of the tendon of insertion, a condition difficult to demonstrate with certainty.

Variations. In most species of Vireo, fibres arise only from the rostromedial surface of the tendon of origin, but fibres do arise from the ventral portion of its caudolateral surface in Vireo c. crassirostris*, caribaeus*, pallens semiflavus ( 2 of 4), bairdi (1, possibly 2 of 3 ), vicinior ( 1 of 4$)$, solitarius plumbeus (1 of 6$)$, olivaceus flavoviridis (1 of 6), g. gilvus ( 1 of 2 ), and magister caymanensis (1 of 2$)$.

In Vireo osburni*, Cyclarhis gujanensis, Vireolanius pulchellus*, and $V$. melitophrys*, the caudalis is large and complex, with a considerable dorsal extension medial to the Pars rostralis temporalis and an associated dorsal shift of the subtemporal crista. Fibres arise from the entire caudal surface of the tendon of origin. The tendon of insertion is much expanded, with a second aponeurotic sheet passing caudal to the tendon of origin, partly fused with the remainder of the tendon of insertion at its lateral edge (completely fused in Vireolanius). In Vireolanius pulchellus* the tendon of origin passed rostrolaterad rather than caudomediad to the tendon of insertion. In all these species, a caudal tendon of origin, which may be partially continuous medially with the original tendon of origin, gives rise to fibres inserting on the caudal face of the additional flange of the tendon of insertion. In Vireo osburni* this tendon of origin is tenuous and small. The caudalmost fibres in the muscle arise from the skull. In this species the Pars caudalis is extensive medially with many fibres arising from the zygomatic process (Text-fig. 3).

In Hylophilus the structure of the caudalis differs slightly from that in Vireo. Fibres arise from almost the entire caudolateral face of the tendon of origin. To receive these fibres the tendon of insertion is produced caudad on the medial as well as the lateral side, except in H. flavipes* and H.d. decurtatus. In H. poicilotis and H.pectoralis* the medial flange almost entirely surrounds the tendon of origin.. In $H$. ochraceiceps* the tendon of origin is produced rostrally on both the medial and lateral edge (Textfig. 4).

\section{M. pseudotemporalis superficialis (Figs. 6-12: pss)}

This is a complex, roughly fan-shaped muscle arising from a fossa in the caudal wall of the orbit and inserting tendinously onto the pseudotemporalis tubercle of the mandible. We found no fleshy insertion as in cardueline finches and Loxops (Richards and Bock, 1973). The relationships of the tendons involved are complex and subject to much variation. There are normally two aponeuroses of origin, both arising from parallel dorsoventral cristae in the fossa. Fibres arise from both surfaces and from the skull wall, giving the muscle its characteristic three-lobed appearance. A third aponeurosis is usually present at the lateral edge of the fossa, with fibres arising from its medial surface. Fibres insert on a trifid tendon of insertion sending one flange to each of the muscle's three lobes. This muscle has very short fibres, longest in the inner lobe. The flanges of the tendon of insertion run almost the full length of the muscle, so that the 


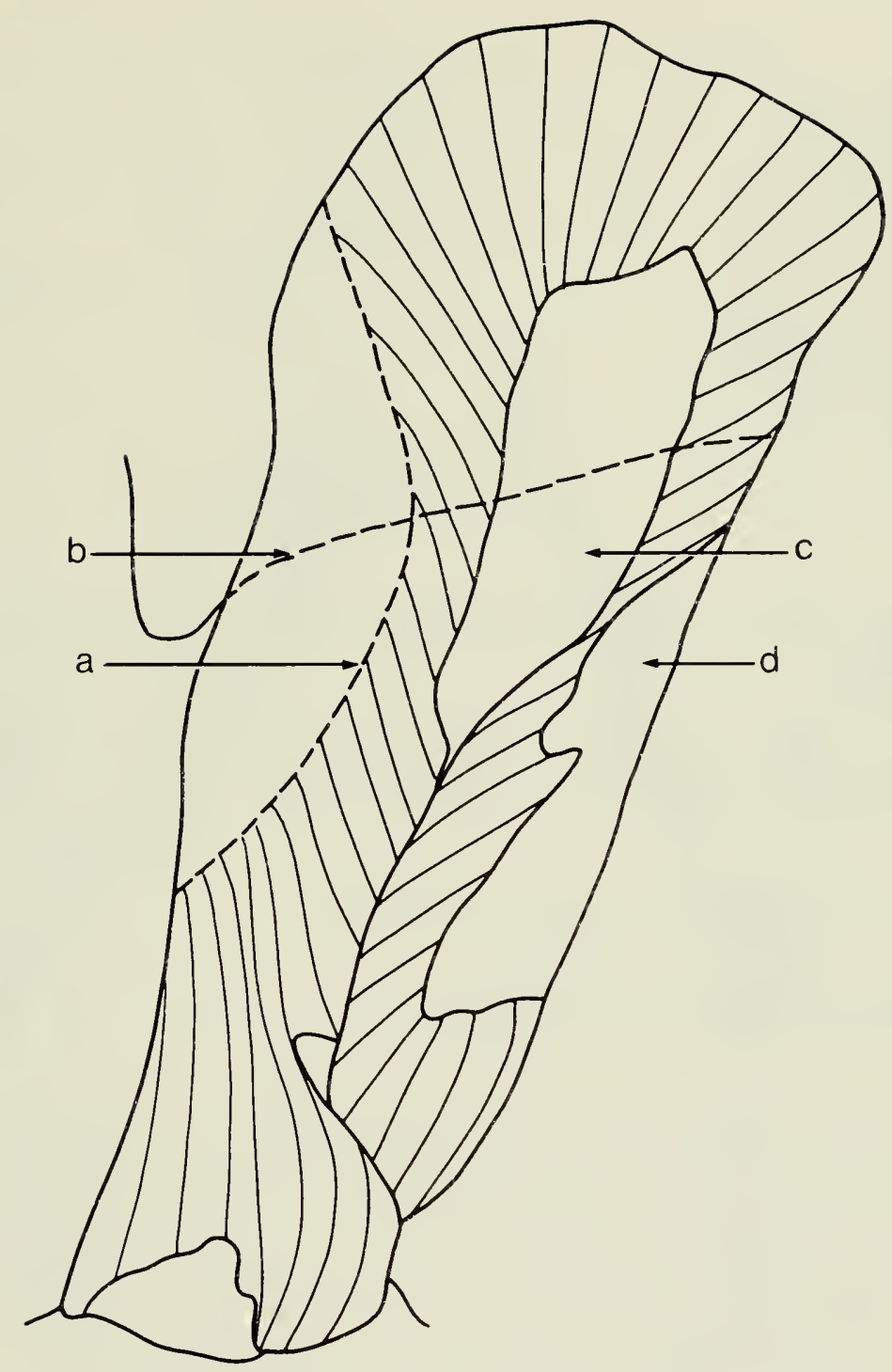

Text-fig. 3 Lateral view of M. adductor mandibulae externus caudalis in Cyclarhis gujanensis insularis (Carnegie 1077). Other portions of M. adductor mandibulae externus have been removed. See Fig. 1 for relative scale.

Key: a. boundary of the tendon of origin of M. adductor mandibulae externus ventralis, b. boundary of the subtemporal aponeurosis of origin of M. adductor mandibulae externus rostralis temporalis, c. tendon of insertion of the Pars caudalis, d. secondary tendon of origin of the Pars caudalis.

degree of pinnation (Gans and Bock, 1965) is very high. Because of the very short lengths of the fibres we were unable to generate an index of fibre number for this muscle.

Variations. The pseudotemporalis superficialis shows extreme individual variation, with strong asymmetry in some specimens (Text-fig. 5).

In most specimens, fibres insert only on the lateral surface of the medial flange of the tendon of insertion. In Vireo nanus ${ }^{*}, V$. bairdi, V. vicinior, $V$. solitarius, V. olivaceus, $V$. m. magister, V. altiloquus, Cyclarhis gujanensis, Hylophilus poicilotis, and $H$. pectoralis*, individual specimens have fibres running from the skull wall to the medial surface of this flange. This bipinnate condition of the inner lobe is especially well marked in Cyclarhis gujanensis.

Other variations involve the relative sizes of the three lobes and the orientation of the flanges of the tendon of insertion. The flange to the middle lobe is usually flattened in a paramedial plane, but in some specimens of Vireo and Hylophilus it is oriented at right angles to the midline. Usually when this occurs the two medial aponeuroses of origin 

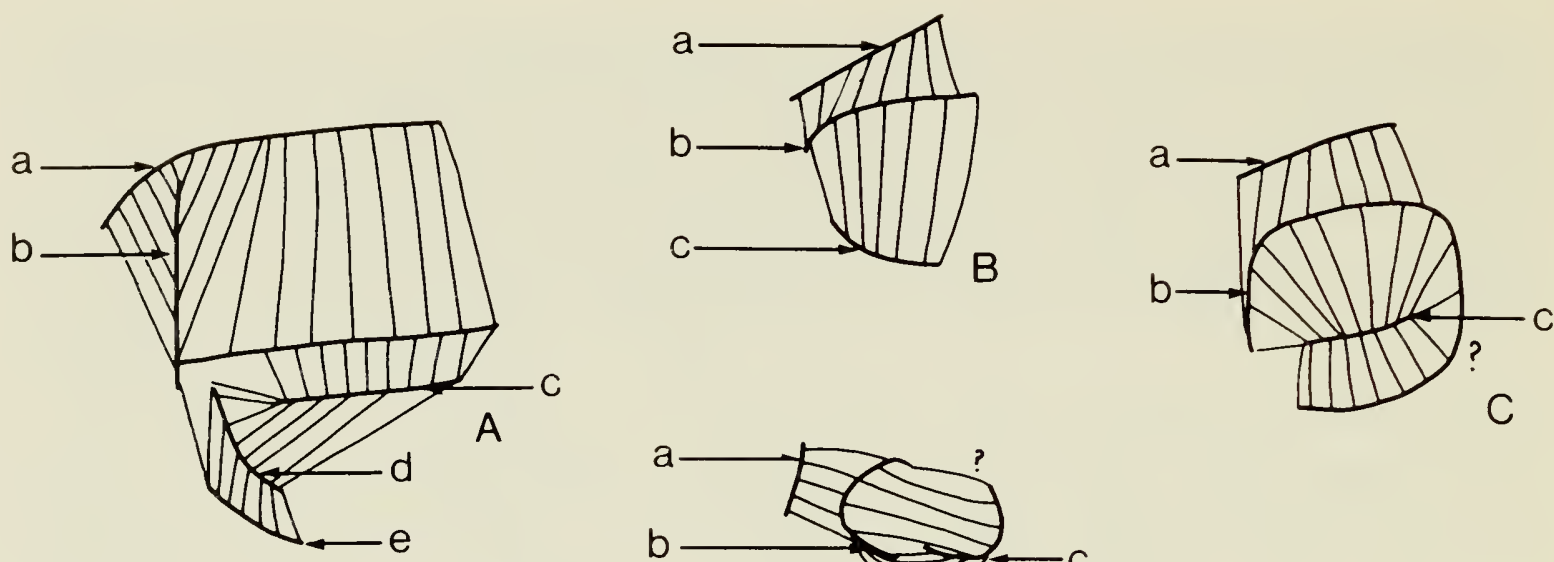

Text-fig. 4 Diagrammatic cross-sections, viewed dorsally, through the central portion of M. adductor mandibulae externus caudalis on the left side in four species, to show tendon arrangements. Not to scale.

Key: a. tendon of origin of M. adductor mandibulae externus ventralis, b. tendon of insertion of M. adductor mandibulae externus caudalis, c. tendon of origin of M. adductor mandibulae externus caudalis, $d$. secondary tendon of insertion, e. secondary tendon of origin.
A Cyclarhis gujanensis insularis (Carnegie 1077)
B Vireo o. olivaceus (Rом 103089)
C Hylophilus pectoralis (Carnegie 1349)
D Hylophilus ochraceiceps (Carnegie 917)

are fused across the front of the lobe, giving rise to fibres inserting on the rostral face of the tendon of insertion. The lateral aponeurosis of origin may be absent. In Vireo atricapillus ( 1 of 2), flavifrons ( 1 of 2), olivaceus, altiloquus, and magister, the flange of the tendon of insertion of the lateral section is oriented in a paramedial plane rather than at about a 45-degree angle to the midline, the more usual state.

\section{M. pseudotemporalis profundus (Figs. 6-12: psp)}

This is a bulky muscle taking origin from the medial and lateral surfaces of the orbital process of the quadrate and inserting broadly on the medial surface of the mandible. Most fibres arise from the caudoventral face of a broad aponeurosis attaching at the tip of the orbital process; others arise fleshily.

Variations. Small numbers of fibres may arise from the rostrodorsal face of the aponeurosis of origin. In Vireo huttoni stephensi (1 of 2), Hylophilus poicilotis, and $H$. pectoralis* fibres arise at its proximolateral edge, and in Vireo vicinior (1 of 4), solitarius plumbeus ( 2 of 6 ), flavifrons, o. olivaceus (1 of 10), m. magister ( 2 of 4), magister caymanensis, and Vireolanius melitophrys*, from its distal edge. Extensive origin from the rostrodorsal face is found in Vireo vicinior (2 of 4) and Cyclarhis gujanensis (Text-fig. 6). In Cyclarhis the aponeurosis is expanded ventrolaterally, with fibres taking origin from both surfaces of the expanded area. In the two specimens of Vireo vicinior fibres arise from the entire rostrodorsal face of the aponeurosis, and insert on the ventral surface of a large aponeurosis attached to the mandible. This aponeurosis of insertion is absent in the other two vicinior dissected, in one of which the muscle is entirely unipinnate. A bipinnate condition for the M. pseudotemporalis profundus is apparently unusual (W. J. Bock, in litt.). 

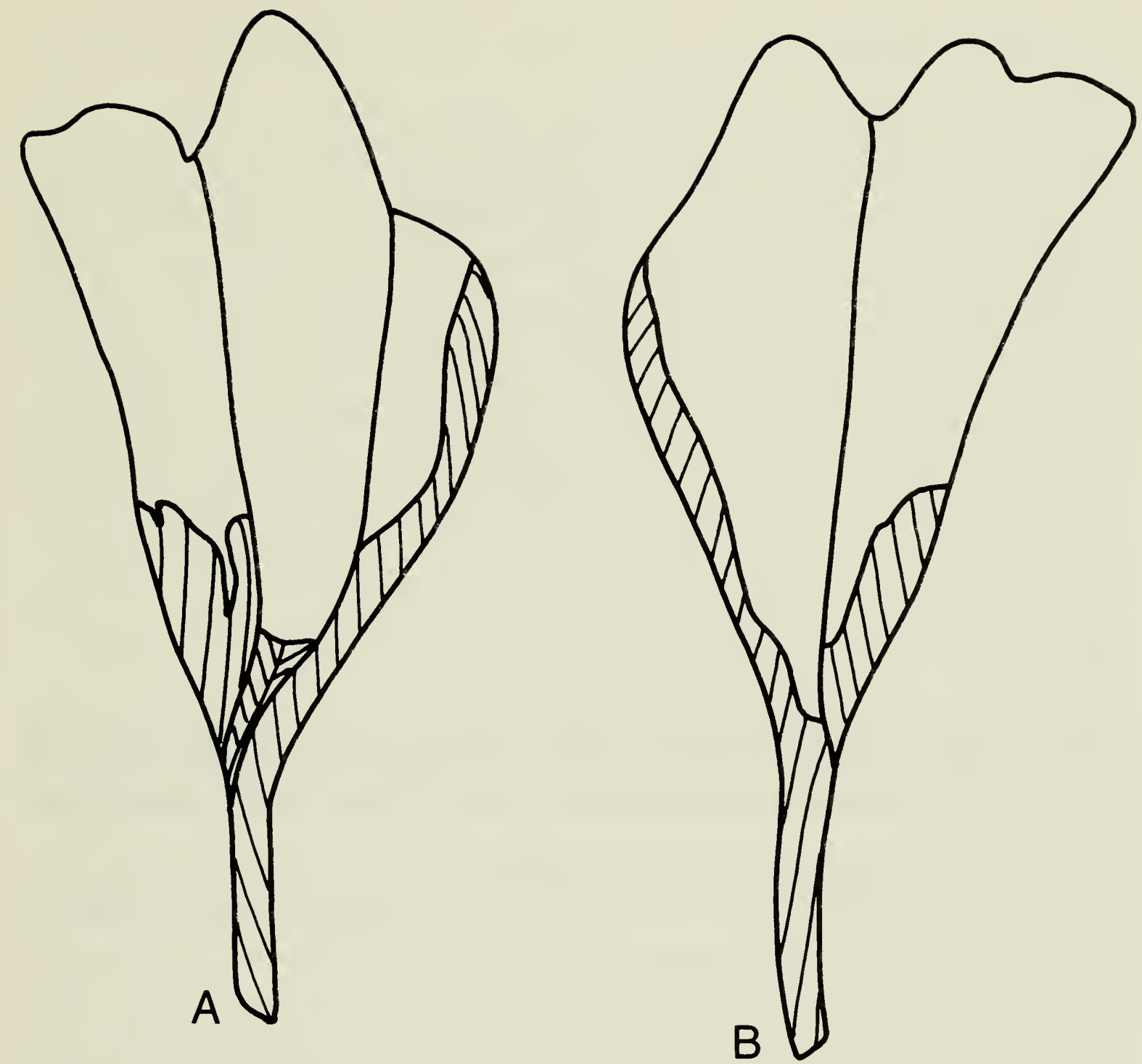

Text-fig. 5 Rostral view of M. pseudotemporalis superficialis from the right and left sides of a single specimen of Hylophilus ochraceiceps (Carnegie 917), showing asymmetry. The left-hand muscle is bilobate, the right-hand muscle is trilobate (the normal condition). See Fig. 12 for relative scale.

A Right side

B Left side

\section{M. adductor mandibulae posterior (Figs. 6-12: amp)}

This is a small, thick muscle arising from the ventral, lateral, and medial surfaces of the orbital process of the quadrate, proximal to the $\mathrm{M}$. pseudotemporalis profundus. The two muscles are separated by the passage of the pterygoideus nerve. It inserts on the dorsal surface of the mandible caudal to the insertion of the $\mathbf{M}$. adductor mandibulae externus caudalis. This muscle is usually entirely parallel-fibred in the Vireonidae, though it is bipinnate in Loxops (Richards and Bock, 1973).

Variations. In Cyclarhis gujanensis the area of origin is expanded over the medial surface of the orbital process. A tiny aponeurosis of origin for a few caudolateral fibres was found in single specimens of Vireo vicinior, solitarius plumbeus, s. cassinii*, $c$. crassirostris*, caribaeus*; Vireolanius melitophrys*, Cyclarhis gujanensis, and 


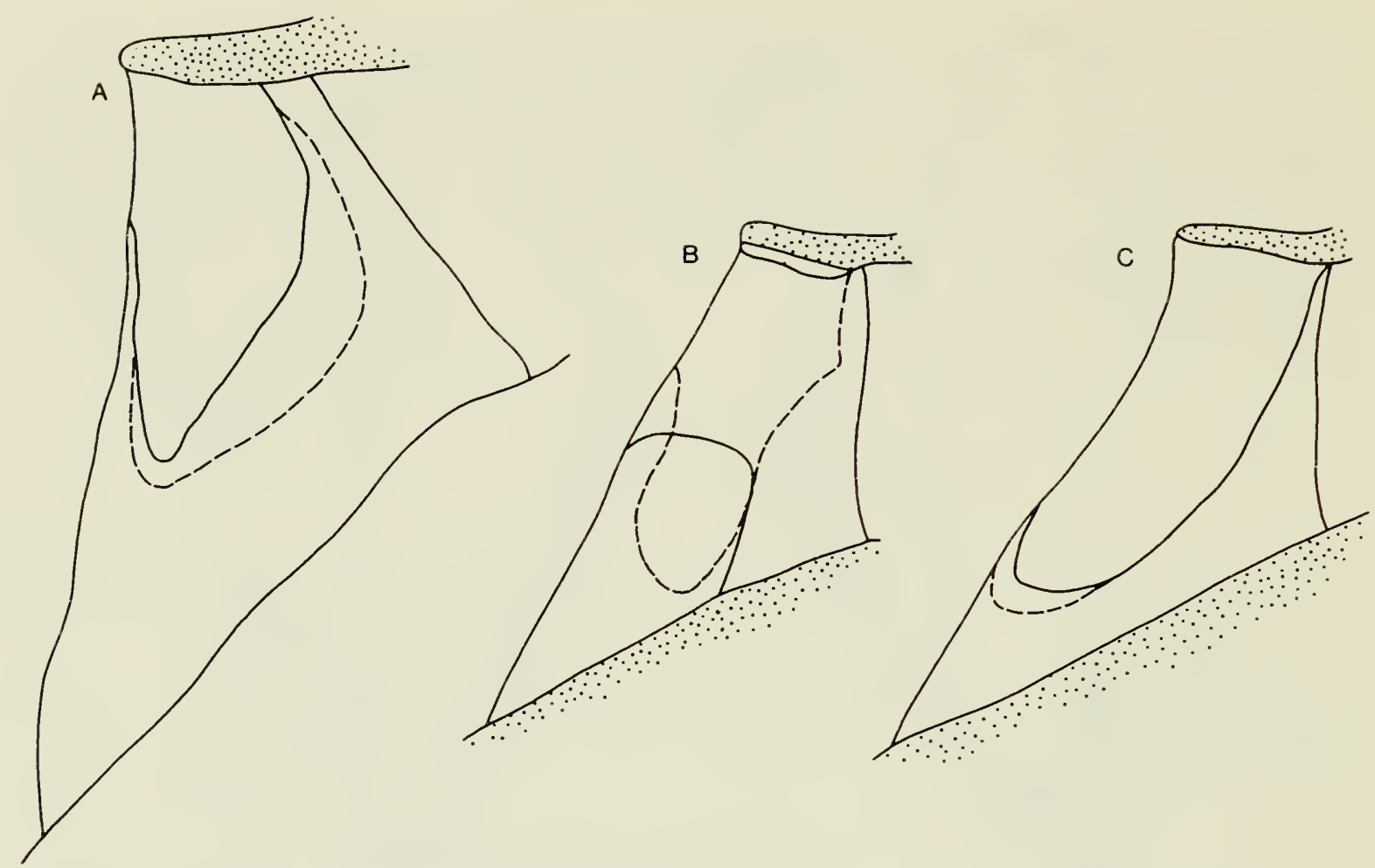

Text-fig. 6 Rostrolateral view of M. pseudotemporalis profundus in various species, to show the occurrence of a bipinnate condition in this muscle. The dashed line indicates the true (concealed) edge of the tendon of origin in the bipinnate portion of the muscle. See Figs. 6 and 9 for relative scale.

A Cyclarhis gujanensis insularis (Carnegie 1077)

B Vireo vicinior (the illustrated condition occurred as an individual variant in this species; see text) (ROM 104480)

C Vireo flavifrons (ROM 102921)

Hylophilus flavipes*. A similar aponeurosis is usual in the Geospizinae (Bowman, 1961). In another Vireo solitarius plumbeus and one $V$. flavifrons, a few lateral fibres inserted by a small aponeurosis. These variations affect only a very small proportion of the muscle.

\section{M. protractor pterygoidei et quadrati (Figs. 6-12: ppq)}

This fan-shaped muscle takes origin fleshily from the lateral surface of the parasphenoid rostrum and the anteromedial portion of the alisphenoid. It is customarily divided into two parts, the anterior (M. protractor pterygoidei) inserting by a tendon on the posterior end of the pterygoid and the posterior (M. protractor quadrati) inserting on the medial surface of the quadrate body. These two portions are indistinguishable in the belly of the muscle in vireos.

Variations. Little variation was noted. In Vireo nanus* the area of insertion is much increased, fibres inserting along the whole of the medial face of the orbital process of the quadrate. In Hylophilus the tendon of insertion is broader than in Vireo, Cyclarhis, or Vireolanius, and the muscle itself is more extensive ventrally. In $H$. pectoralis* and $H$. decurtatus the area of origin is further increased laterally, fibres arising from the skull wall as far as the fossa of origin for the M. pseudotemporalis superficialis. 


\section{M. depressor mandibulae (Figs. 1-15: dm)}

This is a large muscle taking origin from the area of the occipital wing which is posterior to the opening of the tympanic recess. The most medial fibres arise by a small aponeurosis attaching to the edge of the tympanic recess. Insertion is onto the caudal portion of the medial process and the medial side of the retroarticular process of the mandible. Lateral fibres insert on the medial surface of a large aponeurosis. Although the lateral fibres of this muscle are longer than those arising by the aponeurosis of origin, no division into separate parts as in the Geospizinae (Bowman, 1961), Loxops (Richards and Bock, 1973), or Heteralocha (Burton, 1974b) can be made.

Variations. In most specimens examined, the most caudodorsal fibres arise from a layer of connective tissue covering the anterior edge of $\mathrm{M}$. rectus capitis. This layer forms an aponeurosis, extending ventrally, in most individuals. It is best developed, running about half the length of the muscle, in Hylophilus spp., and poorly developed or absent in Vireo huttoni, atricapillus, nelsoni*, brevipennis*, c. crassirostris*, modestus $^{*}$, nanus*, osburni*, vicinior, solitarius, carmioli*, o. olivaceus, o. chivi, m. magister ( 1 of 4 with the aponeurosis), magister caymanensis, and gilvus. In single specimens of Vireo atricapillus and $V$.pallens semiflavus, the rostralmost fibres insert on a medial aponeurosis of insertion attaching to the dorsal edge of the mandible.

The principal aponeurosis of insertion is occasionally infolded in its central portion, forming a raphe which sometimes extends dorsal to the rest of the tendon. In Vireo this raphe is found in V. griseus noveboracensis*, bairdi (2 of 3), b. bellii*, gundlachii*, h. hypochryseus (4 of 6), olivaceus flavoviridis ( 1 of 6$)$, o. chivi ( 1 of 2 ), and $m$. magister (1 of 4). In Hylophilus it is absent only in $H$. aurantiifrons and $H . d$. decurtatus. In $H$. poicilotis and $H$. pectoralis* there are at least three such raphes, the central one deepest. In H. ochraceiceps* there is only a single, exceptionally large and deep, raphe. The raphes attach to an inconspicuous process on the mandible. Similar raphes have been reported in Loxops (Richards and Bock, 1973), and in some sandpipers, being particularly well developed in Gallinago (Burton, 1974a).

The M. depressor mandibulae is broader and more fan shaped in Hylophilus than in Vireo, Cyclarhis, or Vireolanius. In Hylophilus spp., particularly H. poicilotis, the retroarticular process is produced caudad, providing a large additional area of insertion. In one specimen of $H$. poicilotis the rostral edge of the muscle partially covers the M. adductor mandibulae externus rostralis temporalis (Fig. 5).

\section{M. pterygoideus}

This large and complex muscle is divided into the four Partes: dorsalis lateralis (including ventralis lateralis of some authors), ventralis medialis, dorsalis medialis, and retractor.

\section{Pars dorsalis lateralis (Figs. 6-15: pdl)}

Fibres of the dorsalis lateralis take origin from the dorsal side of the transpalatine, and from the dorsal surface of a large aponeurosis attaching to the tip of the transpalatine process. This aponeurosis curves dorsally at its medial edge, forming a boundary with the Pars ventralis medialis. Fibres of this muscle insert over a large area of the ventral 
surface of the mandible, and onto the ventral surface of an extensive aponeurosis attaching to the medial surface of the mandible.

Variations. The name "Pars ventralis lateralis" refers to any fibres taking origin from the ventral surface of the aponeurosis of origin of the Pars dorsalis lateralis and inserting on the mandible. Although a prominent feature in heavy-billed birds such as finches (W. J. Bock, pers. comm.), such fibres are absent in most vireos. When present, their area of origin is largely confined to the lateral portion of the aponeurosis. A small Pars ventralis lateralis was noted in single specimens of Vireo vicinior, $V$. solitarius plumbeus, V.m. magister, and Vireolanius melitophrys*. All three specimens of Cyclarhis gujanensis had a fairly extensive Pars ventralis lateralis, one having fibres arising from almost the entire ventral surface of the aponeurosis of origin. The external edge of the aponeurosis angled dorsally in this species, providing for the attachment of a greater number of fibres.

In many vireos, a flimsy aponeurosis of insertion for a few fibres inserts on a crista on the rostroventral edge of the medial angular process medial to the attachment of the principal tendon of insertion. This aponeurosis is absent in Vireo brevipennis*, nanus*, modestus*, carmioli*, and philadelphicus, and is either weak or absent in $V$. olivaceus. In Hylophilus it is weak or, in $H$. poicilotis, pectoralis*, and $d$. decurtatus, missing. It is well developed, although still providing insertion for only a few fibres, in Vireo flavifrons and $V . m$. magister. In one specimen of $V$. pallens semiflavus this aponeurosis passed ventrad to the tendon of origin rather than dorsad, receiving fibres from the ventral surface of that tendon.

In Vireo vicinior, V. osburni* ${ }^{*}$ V. magister caymanensis, Cyclarhis gujanensis, Vireolanius melitophrys*, and V. pulchellus*, there is further complexity in the Pars dorsalis lateralis. The second aponeurosis of insertion is considerably expanded and strengthened. The dorsomedial edge of the tendon of origin is produced laterally as a large dorsal flange, attached at its rostral end to the transpalatine process and passing between the two aponeuroses of insertion. In this condition the tendon of origin is steeply U-shaped in cross-section, with its open end facing laterally. All fibres from the "inside" of the U insert on the secondary tendon of insertion or the mandible. Only fibres from the dorsal side of the dorsal flange insert on the dorsal tendon of insertion. This condition is least developed in Vireolanius melitophrys*, in which the extra tendinous material is only about half as extensive as in the others. In Vireo gundlachii* and $V . m$. magister ( 1 of 4 ) a dorsal flange of the tendon of origin was present as a very narrow edge (Text-fig. 7).

\section{Pars ventralis Medialis (Figs. 6-15: pvm)}

This strongly bipinnate muscle inserts by a long, flat tendon lying in a paramedial plane and attaching at the medial end of the medial process of the mandible. Externally this tendon receives fibres from the medial face of the vertical portion of the tendon of origin of the Pars dorsalis lateralis, and, rostrally, from the medial edge of the transpalatines and from the interpalatines. Medially, fibres take origin from the interpalatine process and, caudally, from the ventral surface of an aponeurosis attaching to the caudal face of the rostral head of the pterygoid. On the dorsal surface the tendon of insertion has a flange covering some of the lateral fibres in the central portion of the muscle. 

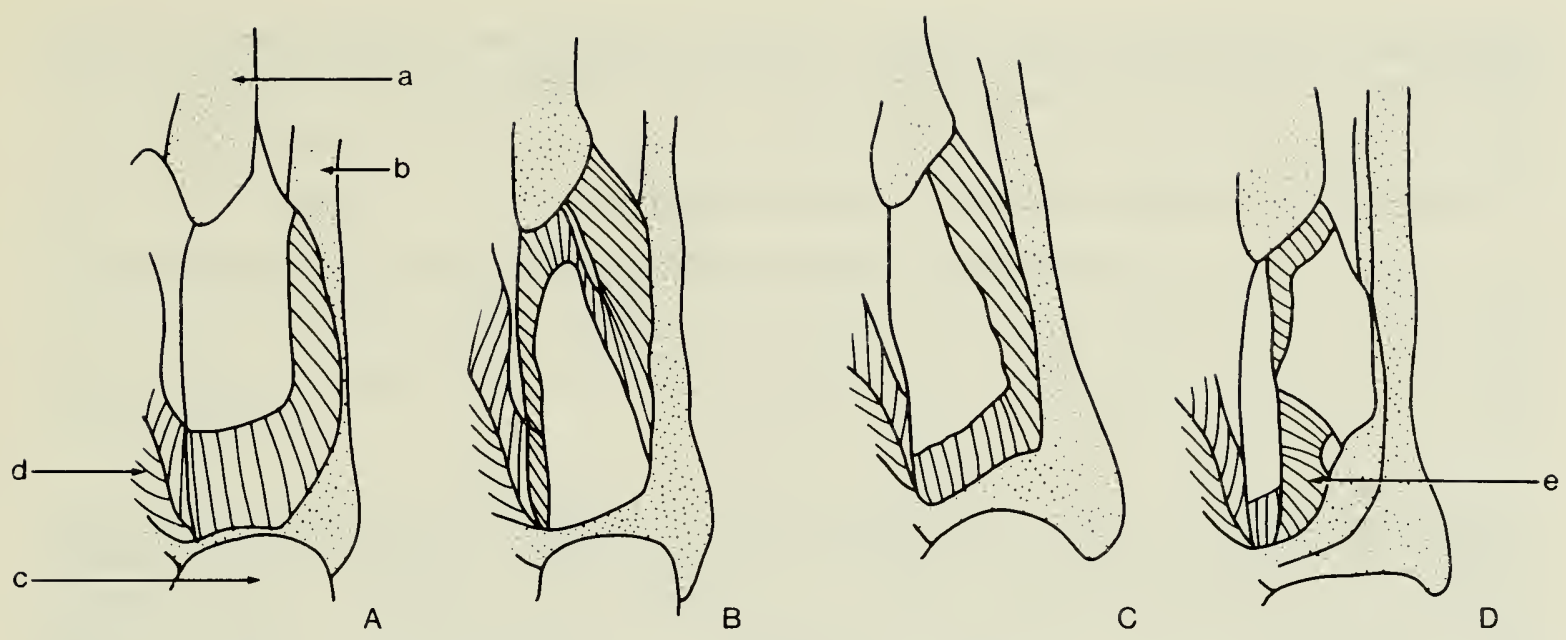

Text-fig. 7 Ventral views of M. pterygoideus dorsalis lateralis in Vireo vicinior (ROM 99458) at sequential stages in dissection, to show the multipinnate structure. See Fig. 14 for relative scale. In all views, the rostral end of the muscle faces the top of the figure.

Key: a. transpalatine process, b. mandible, c. M. depressor mandibulae, d. M. pterygoideus ventralis medialis, e. M. pterygoideus dorsalis medialis anterior.

A Superficial aspect

B View after removal of the superficial flange of the tendon of origin and some superficial fibres. The much expanded secondary tendon of insertion is revealed, and the lateral edge of the dorsal flange of the tendon of origin is also visible.

C View after removal of the secondary tendon of insertion and further fibres, revealing the dorsal flange of the tendon of origin.

D View after removal of most of the remainder of the muscle, revealing the dorsal flange of the tendon of insertion.

Variations. In Hylophilus spp. a very few medial fibres take origin from the ventral surface of the pterygoid, continuous with fibres of the Pars dorsalis medialis posterior.

\section{PARS DORSALIS MEdialis}

This muscle is divided into the Partes dorsalis medialis anterior and dorsalis medialis posterior, lying lateral and medial respectively to the pterygoid.

\section{a. Pars dorsalis medialis anterior (Figs. 6-12: pdma)}

The anterior portion takes origin along the lateral surface of the pterygoid. Its most rostral fibres arise from the dorsal surface of a weak aponeurosis of origin attached to the pterygoid, and insert onto the ventral surface of a tendon attached to the mandible just medial to the major tendon of insertion of the Pars dorsalis lateralis. These two tendons are weakly fused at their edges. Fibres originating caudal to the penetration of the muscle by the pterygoideus nerve arise and insert fleshily.

Variations. The tendon of origin is tenuous and difficult to discern in Hylophilus spp. In Vireo nelsoni*, bairdi, gundlachii ${ }^{*}$, modestus $^{*}$, carmioli ${ }^{*}$, solitarius plumbeus, and m. magister it is large and strongly developed. In Vireo philadelphicus ( 2 of 3 ) and $V . g$. gilvus ( 1 of 2), the tendon of origin arises entirely from the pterygoid foot plate, and no fibres take origin from the pterygoid in the rostral half of the muscle. An intermediate condition exists in V.atricapillus ( 1 of 2$)$ and $V . m$. magister ( 1 of 4$)$.

In Vireo vicinior and Cyclarhis gujanensis, the Pars dorsalis medialis anterior is 
enlarged and takes origin broadly from both the foot plate and the pterygoid, so that in dorsal view it completely obscures the normally visible Pars ventralis medialis.

\section{b. Pars dorsalis medialis posterior (Figs. 6-15: pdmp)}

Most fibres of the posterior section arise from the dorsal face of the internal tendon of origin of the Pars ventralis medialis. They insert on the ventral face of an aponeurosis attached to the distal end of the medial angular process of the mandible, medial to the tendon of insertion of the Pars ventralis medialis.

Variations. Fibres occasionally arise from the pterygoid and insert on the dorsal surface of the tendon of insertion along its rostrolateral edge. The number of such fibres is highest in the deepest-billed forms. We recorded this condition in Vireo huttoni, griseus maynardi (1 of 3 ), pallens semiflavus, c. crassirostris*, b. bellii*, bellii medius*, osburni*, vicinior, solitarius, flavifrons, $h$. hypochryseus (2 of 6), philadelphicus ( 1 of 3), olivaceus flavoviridis ( 1 of 6$)$, o. vividior ( 1 of 2$)$, o. chivi ( 1 of 2), o. gracilirostris*, m. magister (1 of 4), magister caymanensis; Vireolanius spp.*; all Hylophilus spp.; and in Cyclarhis gujanensis.

\section{PARS RETRACTOR (Figs. 13C, 14A, 15C, D: prp)}

This is a small, fleshy muscle arising at the caudal end of the pterygoid foot plate and inserting on the parasphenoid rostrum. It lies medial to the Pars dorsalis medialis posterior.

Variations. No gross variations were noted.

\section{Jaw Ligaments}

The jaw ligaments (Bowman, 1961; Zusi, 1967) were briefly examined and appear to show little variation, although the postorbital ligament is noticeably thick in Vireo hypochryseus and Hylophilus ochraceiceps*.

In most passerines, the $\mathrm{M}$. branchiomandibularis posterior, a tongue muscle, arises from the medial surface of the mandibular ramus. This muscle arises from the lateral surface of the mandible rostral to the insertion of the $\mathrm{M}$. adductor mandibulae externus ventralis in all vireonids examined except for Vireo huttoni, V. osburni*, and Vireolanius melitophrys*. A lateral origin for this muscle has also been recorded in the Zosteropidae, Pycnonotidae, and Meliphagidae; its position of origin differs between two species in Melithreptus (Bock and Morioka, 1971).

\section{Quantitative Results}

A detailed quantitative analysis at the species level was hampered by small sample sizes. The results of the SS-STP tests on the data ranked by subgenus, therefore, were taken as a preliminary guide to the amount and kind of variation present. Cyclarhis 
gujanensis and the species acquired late in the study were not included in these tests, except that Cyclarhis gujanensis was included in the univariate analysis on the data ranked by species. Our quantitative analyses do not take into account tendon arrangements or complexity of fibre arrangement, and therefore cannot be regarded as a mathematical statement of the qualitative muscle descriptions.

\section{Fibre Length}

Significant differences $(\mathrm{P} \leqslant 0.05)$ were established between the subgenera Vireo and Vireosylva for 18 of the 23 uncorrected fibre lengths measured, with Vireo having the smaller mean in every case. The average body weights of Vireosylva spp. are, however, greater than those of Vireo spp. When adjusted by the cube root of weight, appropriate for a linear measure (Amadon, 1943; Bowman, 1961), 10 characters showed significant differences. Nine of these separated Vireo from Vireosylva, and one isolated Hylophilus (Table 3). These results may reflect the poor representation of Hylophilus in the SS-STP analysis (four specimens of three species with weight data).

Table 3 Results of the SS-STP test for fibre length/cube root of weight on Hylophilus and the subgenera Vireo and Vireosylva of the genus Vireo. Horizontal lines connect statistically homogeneous sets. Only characters exhibiting significant differences are graphed.

\begin{tabular}{|c|c|c|c|}
\hline Character & & f SS-STP Test & \\
\hline FLAT & $\begin{array}{c}\text { Hylophilus } \\
1.03 \\
\end{array}$ & $\begin{array}{c}\text { Vireosylva } \\
0.96 \\
\end{array}$ & $\begin{array}{c}\text { Vireo } \\
0.81 \\
\end{array}$ \\
\hline FTEM & $\begin{array}{c}\text { Vireosylva } \\
0.74 \\
\end{array}$ & $\begin{array}{c}\text { Hylophilus } \\
0.73 \\
\end{array}$ & $\begin{array}{c}\text { Vireo } \\
0.53 \\
\end{array}$ \\
\hline FVME & $\begin{array}{c}\text { Vireosylva } \\
0.72 \\
\end{array}$ & $\begin{array}{c}\text { Hylophilus } \\
0.70 \\
\end{array}$ & $\begin{array}{l}\text { Vireo } \\
0.56\end{array}$ \\
\hline FIME & $\begin{array}{c}\text { Vireosylva } \\
0.82 \\
\end{array}$ & $\begin{array}{c}\text { Hylophilus } \\
0.70 \\
\end{array}$ & $\begin{array}{c}\text { Vireo } \\
0.61\end{array}$ \\
\hline FAVE & $\begin{array}{c}\text { Vireosylva } \\
0.80 \\
\end{array}$ & $\begin{array}{c}\text { Hylophilus } \\
0.70 \\
\end{array}$ & $\begin{array}{l}\text { Vireo } \\
0.66\end{array}$ \\
\hline FPPR & $\begin{array}{c}\text { Hylophilus } \\
1.50 \\
\end{array}$ & $\begin{array}{c}\text { Vireosylva } \\
1.40 \\
\end{array}$ & $\begin{array}{l}\text { Vireo } \\
1.26 \\
\end{array}$ \\
\hline FPRP & $\begin{array}{c}\text { Vireosylva } \\
1.24 \\
\end{array}$ & $\begin{array}{c}\text { Vireo } \\
1.15 \\
\end{array}$ & $\begin{array}{c}\text { Hylophilus } \\
1.00\end{array}$ \\
\hline FDLT & $\begin{array}{c}\text { Vireosylva } \\
1.48 \\
\end{array}$ & $\begin{array}{c}\text { Hylophilus } \\
1.45 \\
\end{array}$ & $\begin{array}{c}\text { Vireo } \\
0.99 \\
\end{array}$ \\
\hline FEVM & $\begin{array}{c}\text { Hylophilus } \\
1.30 \\
\end{array}$ & $\begin{array}{c}\text { Vireosylva } \\
1.17 \\
\end{array}$ & $\begin{array}{l}\text { Vireo } \\
1.02 \\
\end{array}$ \\
\hline FADM & $\begin{array}{l}\text { Vireosylva } \\
1.09 \\
\end{array}$ & $\begin{array}{c}\text { Hylophilus } \\
1.05 \\
\end{array}$ & $\begin{array}{l}\text { Vireo } \\
0.90\end{array}$ \\
\hline
\end{tabular}


The nine measurements separating the two subgenera of Vireo represent fibres from three major adductors: the $\mathrm{Mm}$. adductor mandibulae externus, pseudotemporalis profundus, and pterygoideus. The tenth character, FPRP, is for fibres from the protractor pterygoidei, a jaw-opening muscle.

The univariate analysis revealed no clear patterns of variation within subgenera. In Vireo hypochryseus, mean fibre lengths for characters showing significant differences between subgenera are consistently above the approximate confidence intervals for the subgenus Vireo, but within those of Vireosylva. Values for $V$. huttoni usually lie below the lower confidence limit for the subgenus Vireo. Weight-corrected flgures for Cyclarhis gujanensis appear to fall within the range of the subgenus Vireo.

Larger sample sizes permit comparison of Vireo o. olivaceus and V. o. flavoviridis. For the three major adductors listed above, fibre lengths are consistently higher in flavoviridis, the longer-billed subspecies. High values for $V$. o. vividior suggest that the average weight used for correction (from Haverschmidt, 1968) may be low. Smaller sample sizes inhibit comparison between $V$. s. solitarius and $V$. s. plumbeus ( $\mathrm{N}=2$ for the former). Mean values for plumbeus in the major adductors were usually smaller than those for the nominate race.

Three characters showing significance at the subgeneric level are FTEM, FPPR, and FDLT (Text-figs. 8-10).

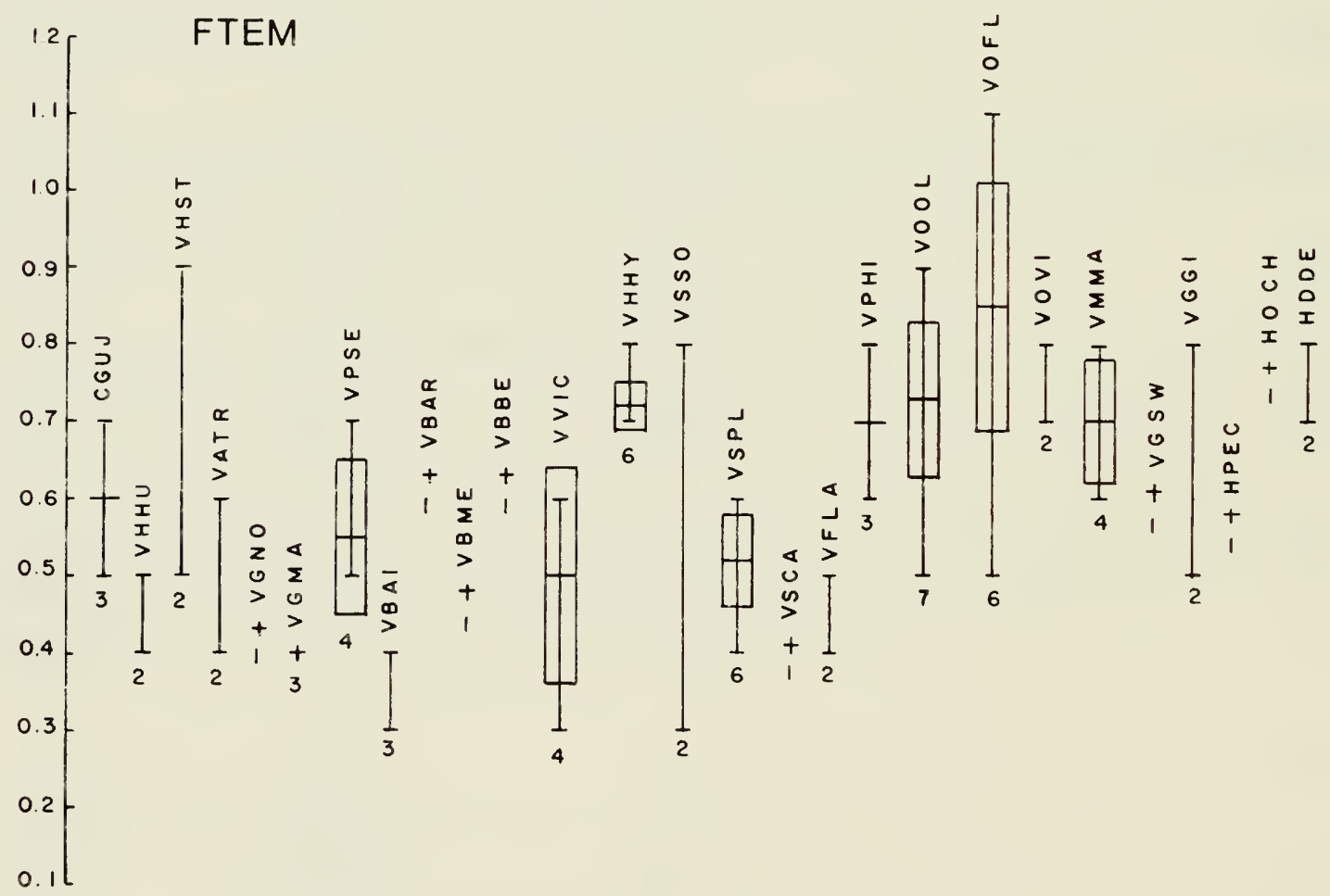

Text-fig. 8 Dice-gram of the character FTEM/cube root of weight in vireonids. Vertical lines enclose the range for each form. Horizontal bars indicate means (where $\mathrm{N}$ is greater than 2). Boxes enclose two standard errors on either side of the mean (where $\mathrm{N}$ is greater than 3 ). Crosses indicate single observations. Sample size and code name (see Table 1) are shown for each form. 


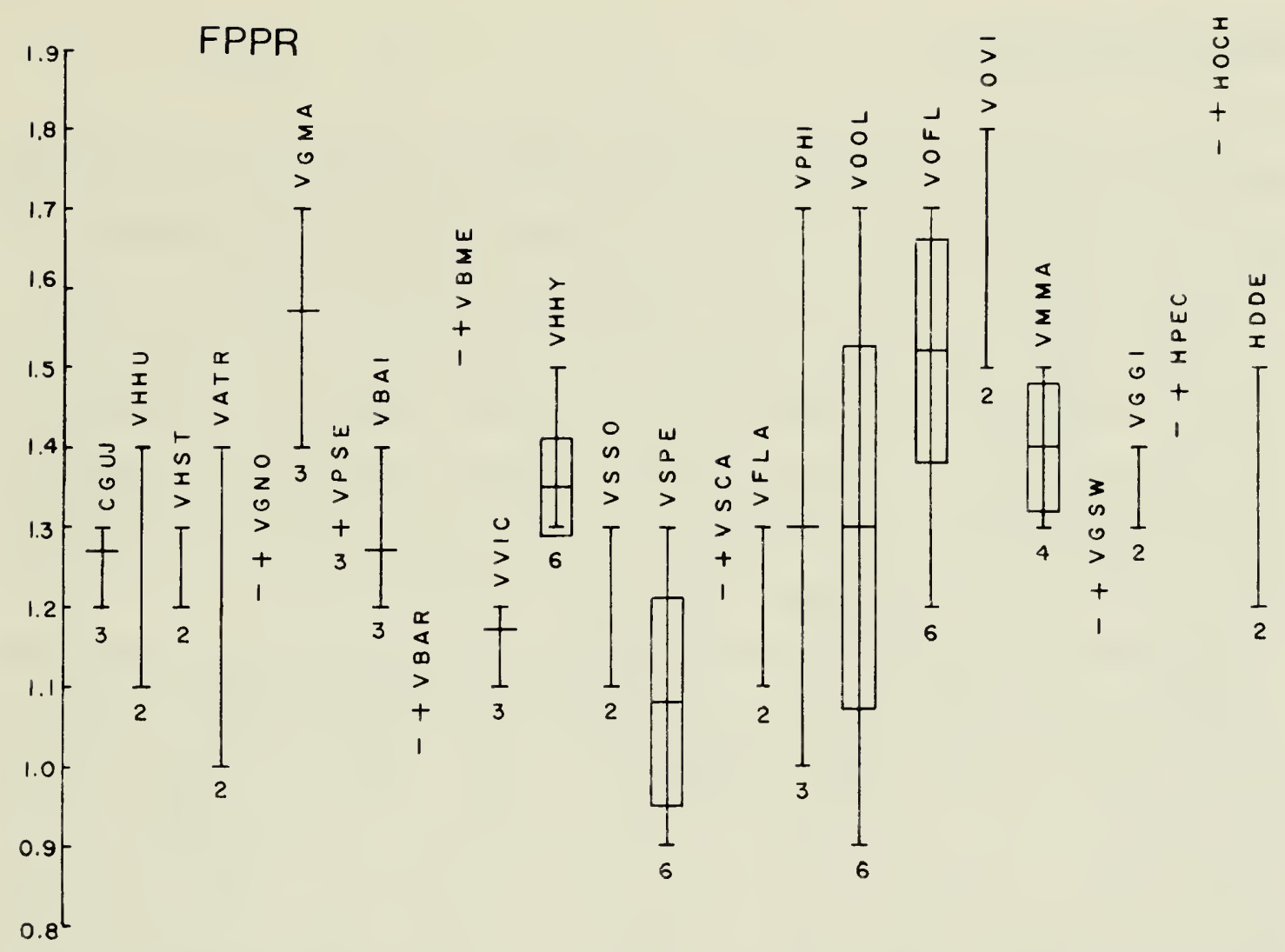

Text-fig. 9 Dice-gram of the character FPPR/cube root of weight in vireonids. For explanation see caption to Text-fig. 8.

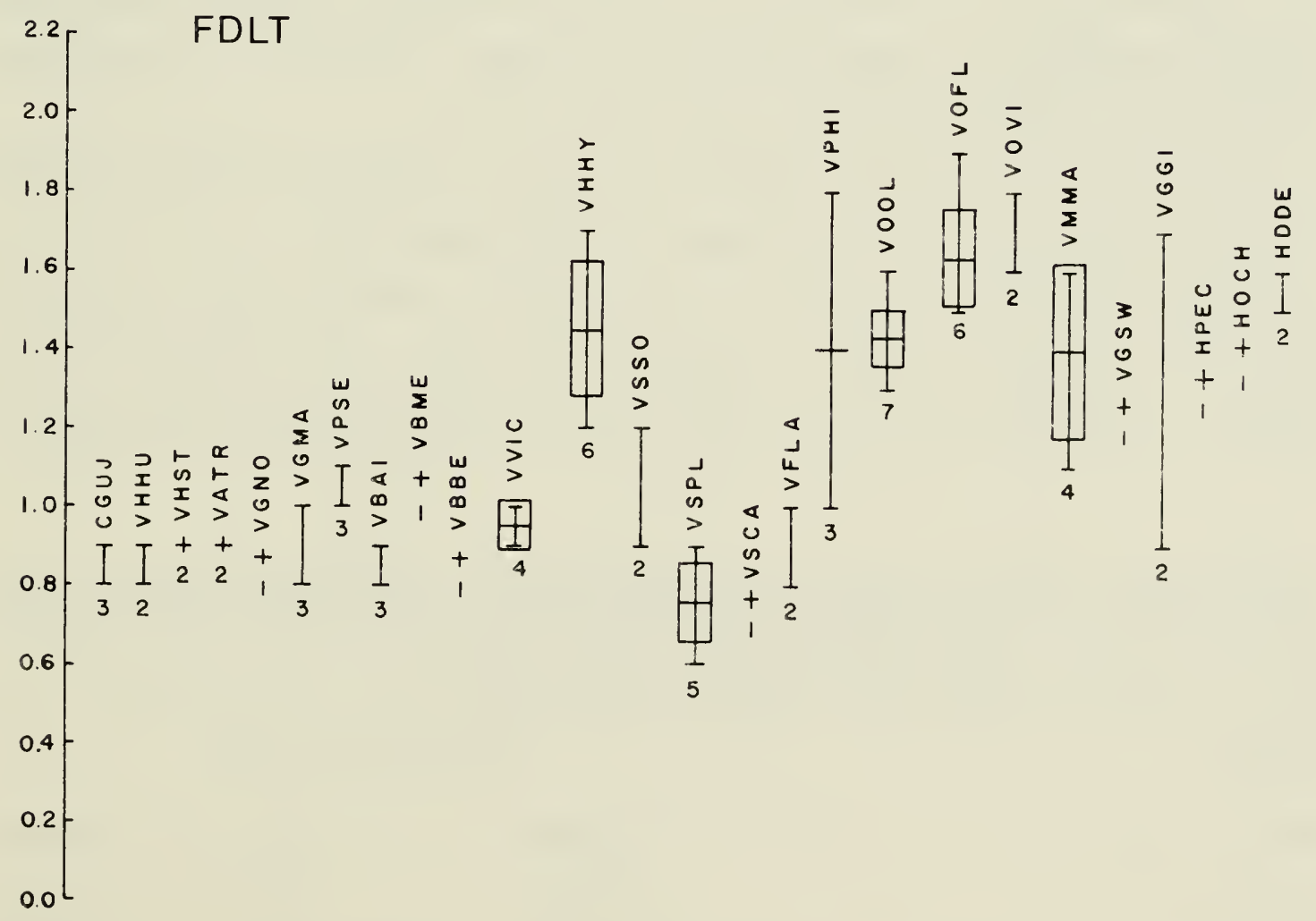

Text-fig. 10 Dice-gram of the character FDLT/cube root of weight in vireonids. For explanation see caption to Text-fig. 8 . 


\section{Fibre-Number Index}

Variation in weight-corrected fibre-number index in Vireo does not correlate with subgeneric allocation. The SS-STP test on corrected data showed significant differences only between the genera Vireo and Hylophilus, for the two jaw-opening muscles (Mm. protractor pterygoidei et quadrati and depressor mandibulae; Table 4).

The fibre-number index for the $\mathbf{M}$. depressor mandibulae varies considerably in Hylophilus, being highest in $\mathrm{H}$. poicilotis. In Cyclarhis gujanensis, corrected means for fibre-number index were higher than those for Vireo, Vireosylva, or Hylophilus in all divisions of the $\mathbf{M}$. adductor mandibulae externus, and in the $M$. pterygoideus dorsalis lateralis and dorsalis medialis anterior. In the M. pseudotemporalis profundus the difference was not as great. Values for the jaw-opening muscles in Cyclarhis lay slightly below those of other taxa (see Text-figs. 11-14).

The degree of interspecific variation present varies among characters, being greatest in major characters for the adductor muscles such as NTEM and NDLT. Variant taxa usually have values above the normal range for a given character. There is no character for which any one species has an unusually low value. NDLT has a higher corrected mean value in Vireo vicinior than in Cyclarhis gujanensis, as does NADM in both $V$. vicinior and $V$. m. magister. For NCDL, Vireo vicinior and $V$. bairdi are the only species with unusually high values; for NPPR, V. vicinior, bairdi, and flavifrons have higher values than do other species. Fibre number in the jaw-opening musculature exhibits little variation within Vireo. V. atricapillus, a species with low mean values in the jaw adductors, has the highest mean value for NDEP.

Among the species of the subgenus Vireo analysed, the lowest mean values for the major adductors are found in V. huttoni, atricapillus, and griseus, the highest in bairdi and vicinior. $V$. solitarius plumbeus yields mean values up to twice as high as those of $V$. $s$. solitarius or $V$. s. cassinii in every muscle exhibiting extensive interspecific variation except the $M$. pseudotemporalis profundus. Values for $V$. hypochryseus resemble those of typical species of Vireo and Vireosylva.

Interspecific variation in fibre-number index is less marked in Vireosylva than in Vireo, except for V. m. magister which has very large adductors. V. o. olivaceus and $V$. $o$. flavoviridis resemble each other closely in fibre-number index.

Considerable individual variation was noted for fibre number, possibly reflecting the imprecision of the index used. In several species (e.g., Vireo bairdi and $V . m$. magister), the highest values for NAME, for example, were more than twice the smallest. NPVM showed extreme variation in many forms, notably in Hylophilus $d$.

Table 4 Results of the SS-STP test for fibre-number index/cube root of weight on Hylophilus and the subgenera Vireo and Vireosylva of the genus Vireo. Horizontal lines connect statistically homogeneous sets. Only characters exhibiting significant differences are graphed.

\begin{tabular}{|c|c|c|c|}
\hline Character & \multicolumn{3}{|c|}{ Results of SS-STP Test } \\
\hline NPPQ & $\begin{array}{c}\text { Hylophilus } \\
13.1 \\
\end{array}$ & $\begin{array}{c}\text { Vireo } \\
7.6 \\
\end{array}$ & $\begin{array}{c}\text { Vireosylva } \\
7.0 \\
\end{array}$ \\
\hline NDEP & $\begin{array}{c}\text { Hylophilus } \\
31.1\end{array}$ & $\begin{array}{c}\text { Vireo } \\
14.8 \\
\end{array}$ & $\begin{array}{c}\text { Vireosylva } \\
14.4 \\
\end{array}$ \\
\hline
\end{tabular}




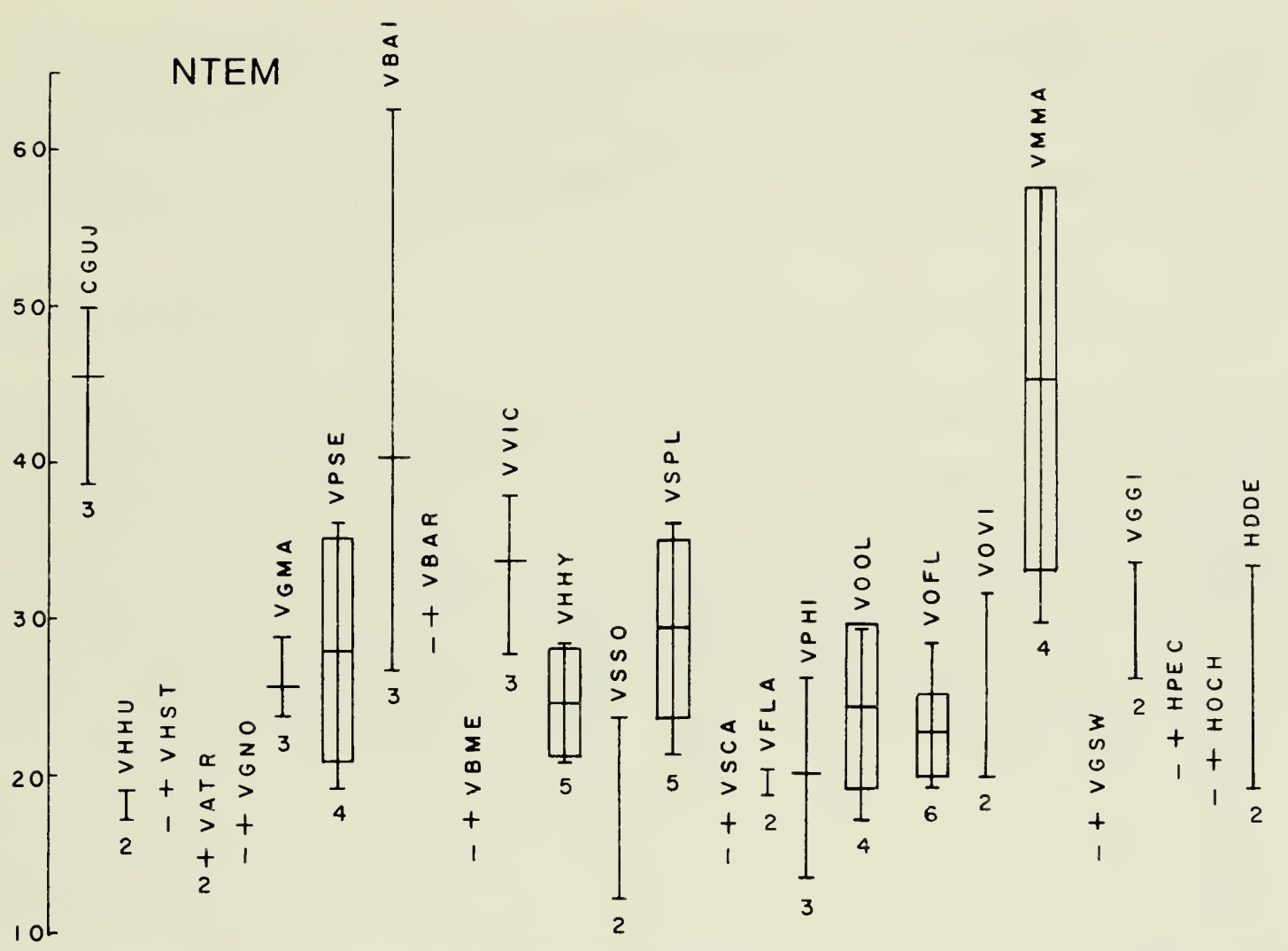

Text-fig. 11 Dice-gram of the character NTEM/cube root of weight in vireonids. For explanation see caption to Text-fig. 8 .
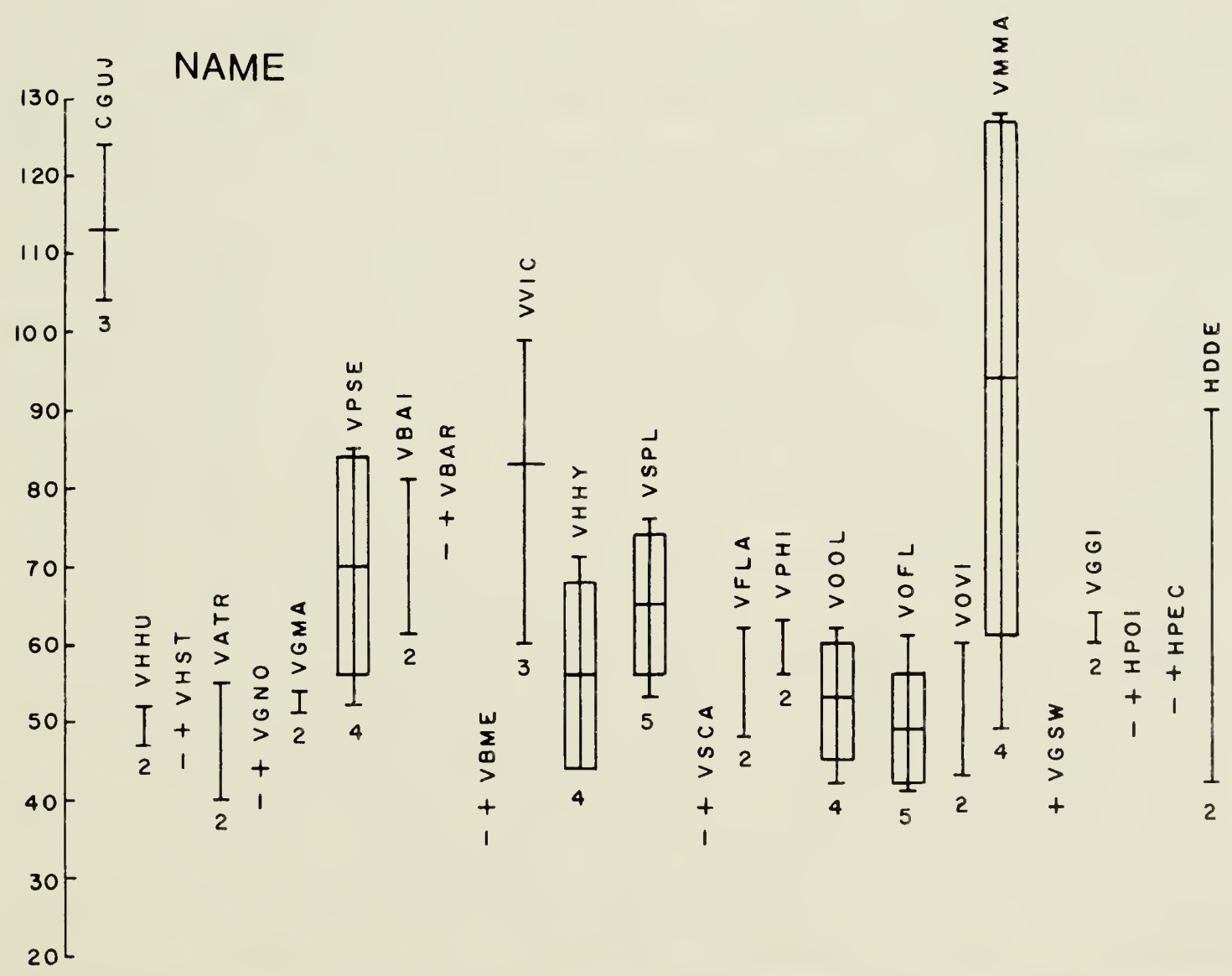

Text-fig. 12 Dice-gram of the character NAME/cube root of weight in vireonids. For explanation see caption to Text-fig. 8. 


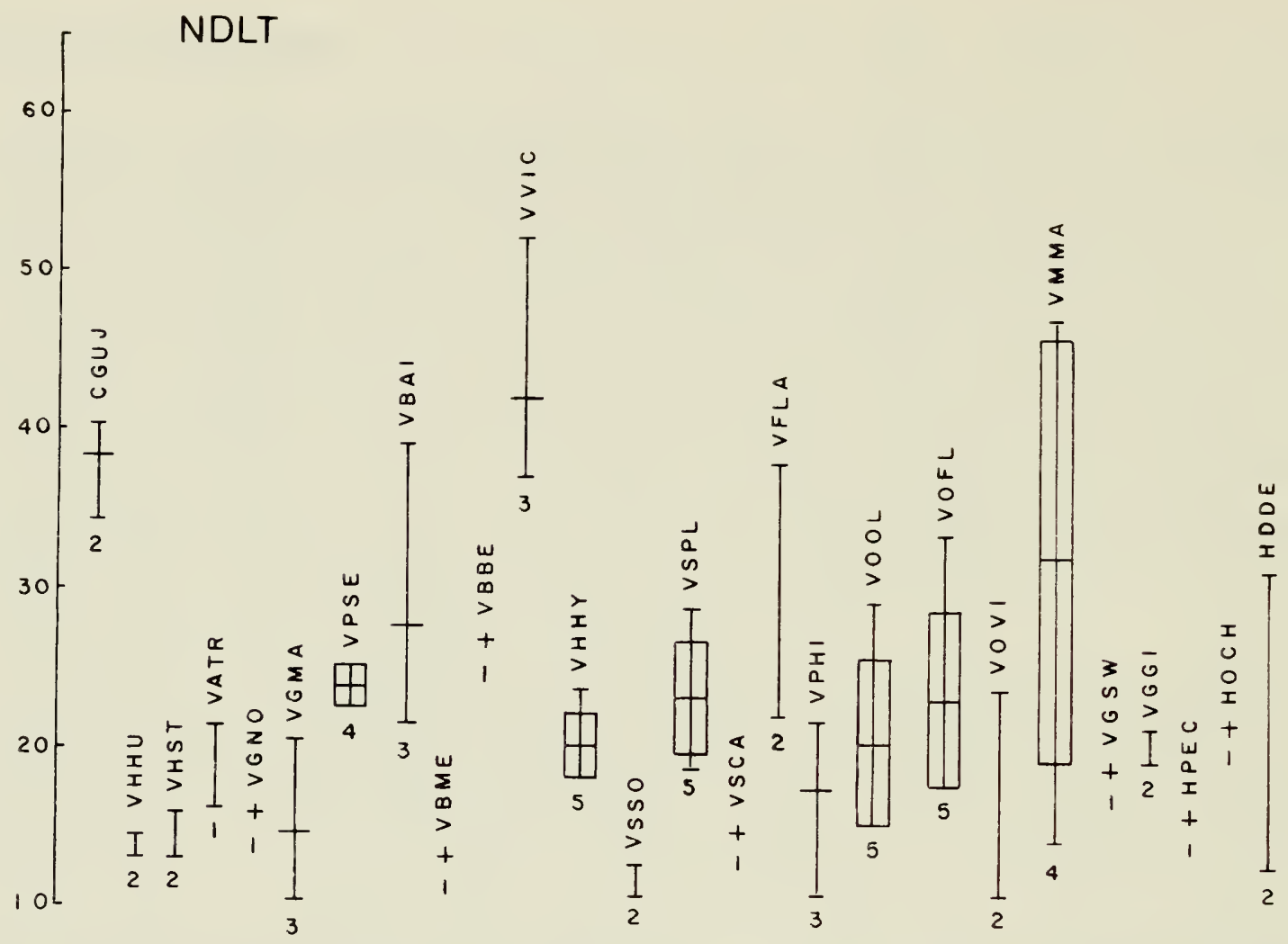

Text-fig. 13 Dice-gram of the character NDLT/cube root of weight in vireonids. For explanation see caption to Text-fig. 8.
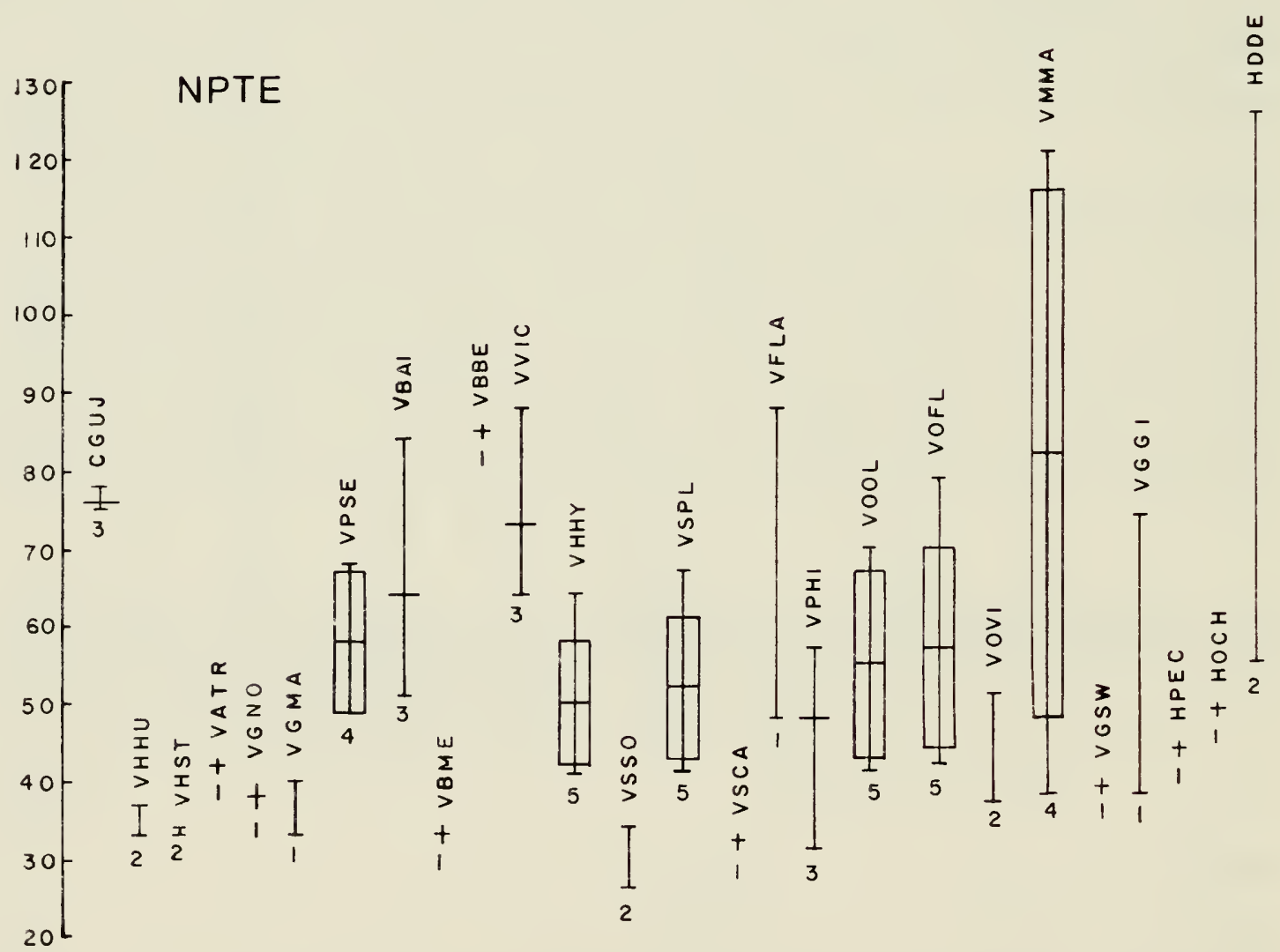

Text-fig. 14 Dice-gram of the character NPTE/cube root of weight in vireonids. For explanation see caption to Text-fig. 8 . 
decurtatus. Within the genus Vireo, individual variation is the most marked in the $\mathbf{M}$. adductor mandibulae externus (particularly the Pars rostralis temporalis) and pterygoideus (particularly the Pars dorsalis lateralis), and is least marked in the $\mathrm{M}$. adductor mandibulae posterior. The M. pseudotemporalis superficialis was not analysed.

\section{Angle of Pinnation}

Measurements of angle of pinnation proved of little use. Extensive individual variation, much of it probably reflecting distortion or injury to the muscles during acquisition or preservation, masked interspecific differences. Since angle of pinnation changes during excursion of the tendons (Gans and Bock, 1965), stretching will affect the measurement. In the SS-STP test on corrected data, a few characters (AACD, APOA, APOP) showed significant differences between Vireo and Vireosylva. It is unlikely, however, that a weight correction is meaningful for an angular measurement.

\section{Discussion}

Except in the M. adductor mandibulae externus caudalis and the M. pterygoideus dorsalis lateralis, gross, species-specific qualitative variation is limited in the jaw musculature of the Vireonidae. The commonest such variants involve changes in pinnateness (i.e., from unipinnate to bi- or multipinnate) accompanying changes in fibre number. Additional tendons or aponeuroses of origin, for example that arising from the temporal crista in the $\mathbf{M}$. adductor mandibulae externus rostralis temporalis, may permit fibre length to remain constant as fibre number increases. The structure of the M. adductor mandibulae externus caudalis in Vireo osburni, Cyclarhis gujanensis, and Vireolanius spp. probably developed by the addition of layers of fibres and tendons caudally as fibre number increased. A similar structure in the Pars caudalis has been found in large-billed Geospizinae (Bowman, 1961). The complex structure of the M. pterygoideus dorsalis lateralis in Vireo vicinior, V. magister caymanensis, V. osburni, Cyclarhis gujanensis, and Vireolanius spp., however, did not in our opinion arise in this manner, but originated instead through internal extensions of the tendons, with fibre transferences as the tendon of origin and internal, secondary tendon of insertion expanded. The presence of a weak internal aponeurosis of insertion in many vireos, particularly in Vireo flavifrons and V.m. magister, probably represents an intermediate stage in the evolution of the multipinnate condition.

The assumption that increased complexity of pinnateness always represents a derived condition is unwarranted (Gans and Bock, 1965; Bock, 1974). In the Vireonidae, however, this assumption appears to be valid for at least some characters and species. For example, Vireo magister caymanensis, which has a multipinnate $\mathbf{M}$. pterygoideus dorsalis lateralis, is almost certainly an island derivative of $V . m$. magister in which this muscle is almost entirely unpinnate. The multipinnate condition presumably arose independently several times in the Vireonidae, as those species exhibiting it are highly unlikely, on the basis of behavioural (Barlow, unpubl.) and other morphological evidence, to be members of a monophyletic assemblage within the family. 
An increase in fibre number may result either in an increase in muscle volume or an increase in pinnateness, although the two are not mutually exclusive. If increased pinnateness is not accompanied by increased muscle volume, fibre length must decrease. The best-adapted muscle ought to be the one requiring the least metabolic energy to produce the desired effect (Bock, 1974). As fibre length does not affect the force generated in contraction, and longer fibres require more energy to contract than short ones, shortening of fibres will increase the efficiency of force generation in a muscle. Reduction of fibre length, however, may be restricted by the size of the excursions necessary. These will be greater for a muscle inserting farther from the centre of rotation, and particularly for a one-joint as opposed to a two-joint muscle. Bock (1974) has analysed the two-joint M. pseudotemporalis superficialis and the onejoint M. pseudotemporalis profundus, showing that the position and nature of attachments of these muscles permit the former to be multipinnate and extremely shortfibred, but not the latter. A two-joint, but not a one-joint muscle, can produce considerable bone rotation with little or no isotonic shortening. Thus, in the jaw musculature, the $\mathrm{Mm}$. pseudotemporalis superficialis, adductor mandibulae externus, and pterygoideus are two-joint and complexly pinnate, whereas the $\mathrm{Mm}$. pseudotemporalis profundus, adductor mandibulae posterior, and much of the $\mathrm{M}$. protractor pterygoidei et quadrati are one-joint, and largely parallel-fibred or unipinnate. In the M. pseudotemporalis profundus increased pinnateness does not produce a large increase in fibre number. The two-joint muscles are also those showing the greatest variations in tendon number and area. For the major adductors, species exhibiting increased pinnateness (e.g., $V$. vicinior) do not have correspondingly shorter fibres, although limited data for races of Vireo solitarius suggest that reduction in fibre length may have accompanied increased fibre number for these muscles in $V$. s. plumbeus. It may be dangerous to rely on comparisons between species in attempting to correlate changes in fibre length with those in fibre number; mechanical differences such as in the proportions and weights of the bony elements moved, or ecological differences, may affect these parameters discordantly.

Increased pinnateness and shortening of fibres may also be in part a response to restrictions on available space for expansion of most jaw muscles resulting from the presence of the eye and its associated structures, and of other jaw, neck, or tongue muscles. In the Mm. adductor mandibulae externus and pterygoideus increased pinnateness is accompanied by an overall size increase which is impossible in the $M$. pseudotemporalis superficialis because of its position within the orbit. The muscle most free from packing problems, the $\mathrm{M}$. adductor mandibulae externus rostralis temporalis, appears to be also the most variable in overall volume (although it also varies in degree of pinnateness within Vireo). In Hylophilus the temporal fossa is relatively small in all species dissected. The portion of the skull over which caudodorsal shifts in the position of the temporal crista occur in Vireo is occupied by the large M. depressor mandibulae in Hylophilus. The M. depressor mandibulae is likewise relatively free from spatial restrictions, and its increased fibre number in Hylophilus spp. as compared to Vireo has not been accompanied by increased pinnateness. Although the infolded raphes of aponeurotic tissue in some species may add to the internal strength of the M. depressor mandibulae, or perhaps may assist in the distribution of force vectors, they do not increase pinnateness. Richards and Bock (1973) suggest that similar raphes in the M. depressor mandibulae of Loxops may, by subdividing the muscle, increase its force. 


\section{Individual Variation}

Although some of the individual variation recorded in this study, particularly in fibre-number index, may be attributable to measurement errors, much of it is real. Major qualitative differences between the right and left sides of the same specimen have been described (Text-fig. 5). Some individual variants, such as that of the $M$. pseudotemporalis profundus in Vireo vicinior or of the $\mathbf{M}$. depressor mandibulae in Hylophilus poicilotis, exhibit character states unknown in other vireos. Sample sizes are too small to test for the effects of differences owing to age, sexual dimorphism, or geographic variation. However, one species with a highly variable fibre-number index, Vireo bairdi, is endemic to Isla de Cozumel where it is abundant (Paynter, 1955) and almost certainly forms a homogeneous population. Interspecific differences in this species cannot be attributed to geographic variation.

Much of this variation in form may be of little adaptive significance. As long as a muscle performs adequately, details of its fine structure can probably vary randomly (cf. Raikow, 1975). The M. pseudotemporalis superficialis, which exhibits great intraspecific qualitative variation, may contract isometrically (Bock, 1967, 1974). The tendons of this muscle, therefore, would not alter their relationships to one another appreciably during contraction. Even if its contraction is isotonic (C. Gans, pers. comm.), excursion of the tendons within this extremely short-fibred muscle must be slight and problems of drag arising from inefficient tendon arrangements minimal. As long as such arrangements do not significantly affect fibre length or number, therefore, they may not modify function significantly.

\section{Functional Consequences of Variation}

An increase in fibre number increases muscle force (Gans and Bock, 1965). An increase in fibre length allows a muscle to contract over a greater distance during one cycle, thus increasing muscle speed (Vander et al., 1975).

For comparisons in this discussion, muscles with higher fibre number will be referred to as "stronger", those with lower fibre number as "weaker".

Increased strength in the jaw adductors may permit the taking of larger or more heavy-bodied prey. Those vireos with especially strong or complexly pinnate adductors (Vireo bairdi, gundlachii, crassirostris, osburni, vicinior, solitarius plumbeus, flavifrons, magister, altiloquus) have relatively deep bills (Appendix 1), particularly deep in osburni and vicinior as well as in Cyclarhis and Vireolanius. Bill depth is directly related to the biting or crushing forces that can be brought to bear on an object held between the mandibles (Bock, 1966). Vireo solitarius plumbeus has both a deeper bill and stronger adductors than do other races of the species dissected here (fibre number indices for $V$. s. solitarius are rather low for its bill depth). Those species with a multipinnate $\mathbf{M}$. adductor mandibulae externus caudalis and/or a multipinnate $\mathrm{M}$. pterygoideus dorsalis lateralis (Vireo vicinior, V. osburni, V. magister caymanensis, Cyclarhis gujanensis, Vireolanius melitophrys, $V$. pulchellus) have particularly deep bills. The M. pterygoideus is a strong retractor of the upper mandible. The Pars caudalis, which inserts at a steeper angle to the mandible, and closer to the centre of its rotation than other sections of the $\mathbf{M}$. adductor mandibulae externus, acts most efficiently when the bill is almost closed or closed. Increases in their strengths will 
increase the crushing forces applied through the bill and therefore are logical correlates of increased bill depth. Bill width and bill length, neither of which are directly responsible for biting forces (Bock, 1966), are not clearly correlated with high fibre number in the jaw adductors. High fibre numbers are found, for example, in both short-billed (e.g., Vireo vicinior) and long-billed forms (e.g., V. magister caymanensis).

Fibre length appears to be partially correlated with bill length. Many long-fibred forms are long-billed. Vireo olivaceus flavoviridis is both longer-billed than $V . o$. olivaceus and has consistently longer fibres in the major adductors. In contrast, these races differ little in weight-corrected fibre-number indices. V. philadelphicus, however, has a short bill and long muscle fibres.

\section{Ecological Consequences of Variation}

The genus Vireo is divisible into short-fibred and long-fibred species with respect to the major adductors. These divisions correspond to the subgenera Vireo and Vireosylva respectively except for the long-fibred $V$. hypochryseus. Long-fibred birds have long and/or fine bills. Short-fibred species vary more in bill shape than long-fibred forms, from the warblerlike bill of Vireo atricapillus to the short, stout bill of $V$. vicinior and the large, heavy bill of $V$. osburni. Birds with short-fibred muscles also vary more in fibre-number index for the major adductors. In the long-fibred group, high fibrenumber indices occur only in $V$. magister and $V$. altiloquus, which have long, heavy bills.

Hamilton $(1958,1962)$ divided the species of Vireo into thicket and arboreal foragers. In the first group he included griseus, pallens, bairdi, nelsoni, bellii, vicinior, carmioli, latimeri, nanus, and osburni, and in the second solitarius, flavifrons, atricapillus, huttoni, olivaceus, magister, altiloquus, philadelphicus, gilvus, and hypochryseus, placing the last in Vireosylva. This classification is an oversimplification. "Thicket foragers" such as Vireo griseus (Nolan and Wooldridge, 1962), V. bellii (Barlow, 1962), and V. latimeri (Wetmore, 1916) gather at least some of their food high in trees. V. atricapillus is actually a thicket forager (Hamilton, 1962: 48; Barlow, 1977). V. carmioli is apparently an arboreal forager (Barlow, pers. obs.; Orenstein, pers. obs.). Within these two groups preferred habitats vary considerably. $V$. bairdi, V. latimeri, and $V$. pallens semiflavus inhabit second-growth woods and low scrub, although V. p. ochraceus prefers mangroves (Paynter, 1955; L. Davis, 1957). $V$. vicinior usually occupies the most xeric habitat of any vireo (cf. Barlow and Johnson, 1969), foraging mostly below $3 \mathrm{~m}$ but occasionally to $10 \mathrm{~m}$, while $V$. osburni occurs mostly in humid closed-canopy broadleaf forest, foraging from ground level to $12 \mathrm{~m}$ (Cruz, 1980; Lack, 1976), exceptionally to $20 \mathrm{~m}$ (Barlow, unpubl.). The "arboreal foragers" also show a broad range of preferred habitats, from tropical low bushes and mangroves for Vireo magister (Paynter, 1955) to conifer woods for $V$. solitarius (Bent, 1950) and V. huttoni mexicanus (Barlow, 1980; W. Davis, 1945). The two races of $V$. huttoni dissected here live largely in mixed oak-coniferous woodland (Barlow, 1980; Barlow and Williams, 1970).

Hamilton's distinction between thicket and arboreal foraging is not equivalent to our division by fibre lengths, nor can it be related to bill shape or jaw muscle structure. Vireo also differs from Parus, for which Snow (1954) found a correlation between bill shape and habitat preference, coniferous forest species having a longer, finer beak than 
those of broad-leafed woodlands. Large fibre indices and heavy bills may occur in both coniferous forest vireos (Vireo solitarius plumbeus) and those of scrubby tropical thickets ( $V$. bairdi).

Foraging technique, we believe, has had a greater effect on the evolution of the feeding apparatus in Vireo than habitat or stratum preference. A bird that captures food while hovering, or from a moving substrate, requires greater accuracy of aim, and speed and dexterity of movement, than one that forages from a perch. Conversely, while invertebrates on leaves are unlikely to be heavy-bodied there is no such restriction on those on branches. A leaf forager would therefore be less likely to require increased crushing power than a branch forager. Heavy jaw musculature may be disadvantageous for a leaf forager because of the additional metabolic cost of maintaining unnecessarily large muscle masses. Loxops virens (Drepanididae), a twig and leaf forager, has weaker adductors than L. maculata, which takes slightly larger insects on larger branches and trunks (Richards and Bock, 1973).

James (1976) found differences in foraging technique among Vireo flavifrons, $V . o$. olivaceus, and V. g. gilvus. V. flavifrons acquired most of its food by stalking on branches. The other two species fed mostly by gleaning insects from leaves, frequently while hovering. Vireo flavifrons has a deep bill and short-fibred, strong adductors. The other two species have slender bills and longer-fibred adductors. Longer muscle fibres, providing an increased contraction distance in an equivalent time period, enable the bill to snap shut more rapidly. Bock (cited in Morioka, 1974: 15) points out the presumably similar situation in swifts (Apodidae), in which long-fibred adductors "may be an adaptation for closing the bill rapidly". The skulls of Vireo olivaceus and V. gilvus are narrower than that of $V$. flavifrons, bringing the eyes closer together and therefore bringing the field of binocular vision closer to the bird (assuming that the relative orientation of the eyes does not change). This may improve accuracy in prey capture. The longer bill of $V$. olivaceus enhances binocular vision at the bill tip. Ficken et al. (1971) have postulated that the pre-ocular stripe present in long-billed (= long-fibred) species may aid in sighting down the bill, a possibly related adaptation.

The limited information available on foraging in other vireos supports the hypothesis that jaw-muscle and bill variations are related to foraging site and methods of prey capture. Among short-fibred species of Vireo, V. h. huttoni, atricapillus, griseus noveboracensis, and $b$. bellii feed from both leaves and twigs (Bent, 1950; Barlow, 1962; Nolan and Wooldrige, 1962). These species are not strong muscled, nor is $V$. carmioli, which forages among small twigs in the outer foliage of trees (Orenstein, pers. obs.).

$V$. nanus of Hispaniola reportedly relies conspicuously on flycatching (Wetmore and Swales, 1931; Hamilton, 1962). It has lengthened rictal bristles, noticeably large and bulging eyes (on the specimen dissected), and a bill broadened so that the jugal bars are almost parallel. Its jaw musculature shows few qualitative modifications; the $\mathbf{M}$. adductor mandibulae externus is small and weak, and only the M. protractor, a jaw-opening muscle, is unusually large. A comparison of corrected fibre lengths for the single specimen dissected (not included in the quantitative analyses) shows relatively high values for FTEM (0.72) and FPPR (1.53), though not for FDLT $(0.81$; compare Text-figs. 8-10). An apparent increase in fibre length has occurred in those adductors that insert at a steep angle to the mandible. These presumably are important in those early stages of bill-closing for which speed is essential to an aerial flycatcher. Long fibres and a weak jaw musculature are characteristic of swifts and, to a lesser extent, 
swallows (Hirundinidae; Morioka, 1974), though their shift in insertion of the adductors closer to the mandibular hinge was not noted in $V$. nanus.

Vireo osburni, V. magister caymanensis, Cyclarhis gujanensis, and the two Vireolanius spp. inhabit forest of varying age and complexity, but their foraging techniques are similar. All search foliage and branches for prey to a greater or lesser extent. It is, however, unknown if they take more heavy-bodied insects than do weak-muscled species. Vireo vicinior, however, a species with a stout bill and large adductors, forages by hawking and foliage gleaning in about 75 per cent of all bouts $(\mathrm{N}=300)$. It rarely hovers $(2 \%)$ but catches flies surprisingly frequently (23\% of all bouts; Barlow, 1980). The role of the heavy jaw musculature in V. vicinior is unclear, but it may be related to the nature of prey in its xeric habitat.

Vireo philadelphicus is a leaf forager and hoverer like olivaceus and gilvus (Barlow, 1980; Bent, 1950). V. olivaceus gracilirostris of Fernando de Noronha forages largely by hawking insects from the undersides of leaves (Storrs Olson, pers. comm.). The single specimen dissected of this particularly long- and slender-billed race did not differ significantly in its jaw musculature from $V$. o. flavoviridis, although corrected quantitative comparisons could not be made as no weight data were available. Barlow (unpubl.) has observed the little-studied $V$. hypochryseus leaf foraging, as might be expected from its long bill and long-fibred adductors.

$V$. altiloquus and the closely related V. magister (Paynter, 1955; Hamilton, 1962) glean for arthropods in a manner resembling that of $V$. olivaceus (Barlow, unpubl.; Cruz, 1980), despite their much stronger jaw musculature and deeper bills. These species are more frugivorous than most vireos. Berries formed 58 per cent of the food of V.a. altiloquus on Puerto Rico (Wetmore, 1916) and 51.4 per cent in this race in Jamaica (Cruz, 1980), and plant material, mostly fruit, comprised 49 per cent of the diet of $V$. magister caymanensis (Johnston, 1975). In V. altiloquus barbatulus, a small-billed race, vegetable food comprised only 12 per cent of the diet in May and June (Chapin, 1925), which is high for most vireos but apparently low for the species. Frugivory, however, may not explain the increased fibre-number indices in these species. V. o. flavoviridis is apparently highly frugivorous in Panama and perhaps completely so on the wintering grounds in the Amazon basin (Morton, 1977). Three stomachs of $V$. olivaceus flavoviridis taken by the first author in Guanacaste, Costa Rica, in April 1971 contained more vegetable than animal remains, and a full stomach of Hylophilus decurtatus obtained at the same time contained only vegetable material.

\section{Evolution within the Genus Vireo}

Hamilton (1962) considered that interspecific competition for food among Vireo spp. has largely resulted in spatial or stratal separation. Both stratal separation and foraging differences have been documented by Johnston (1975) for $V$. crassirostris and $V$. magister on Grand Cayman, and for V. crassirostris and V. altiloquus on the other two Cayman Islands. V. crassirostris was found mostly below $4 \mathrm{~m}$ whereas the Vireosylva spp. fed most often between 5 and $15 \mathrm{~m}$. Overlap occurred between 3 and $5 \mathrm{~m}$. On Grand Cayman V. crassirostris ate 77 per cent animal food, V. magister 51 per cent.

Hamilton himself, however, cites examples of habitat co-occupancy without stratal separation (e.g., between Vireo modestus and V. osburni on Jamaica). V. flavifrons overlaps broadly in foraging stratum with $V$. o. olivaceus in broadleaf deciduous forest, and with $V$. gilvus in open woodlands (James, 1976). V. vicinior may be 
syntopic with $V$. atricapillus, $V$. bellii arizonae, and $V$. solitarius plumbeus (Barlow, 1967; Barlow et al., 1970). These species apparently minimize resource competition by means of differing foraging methods (Barlow, 1980; James, 1973), reflected in the morphological variation of the feeding apparatus.

Text-fig. 15 illustrates types of adaptive shifts that may have occurred in the evolution of the genus Vireo. Direct competition for food between the ancestors of

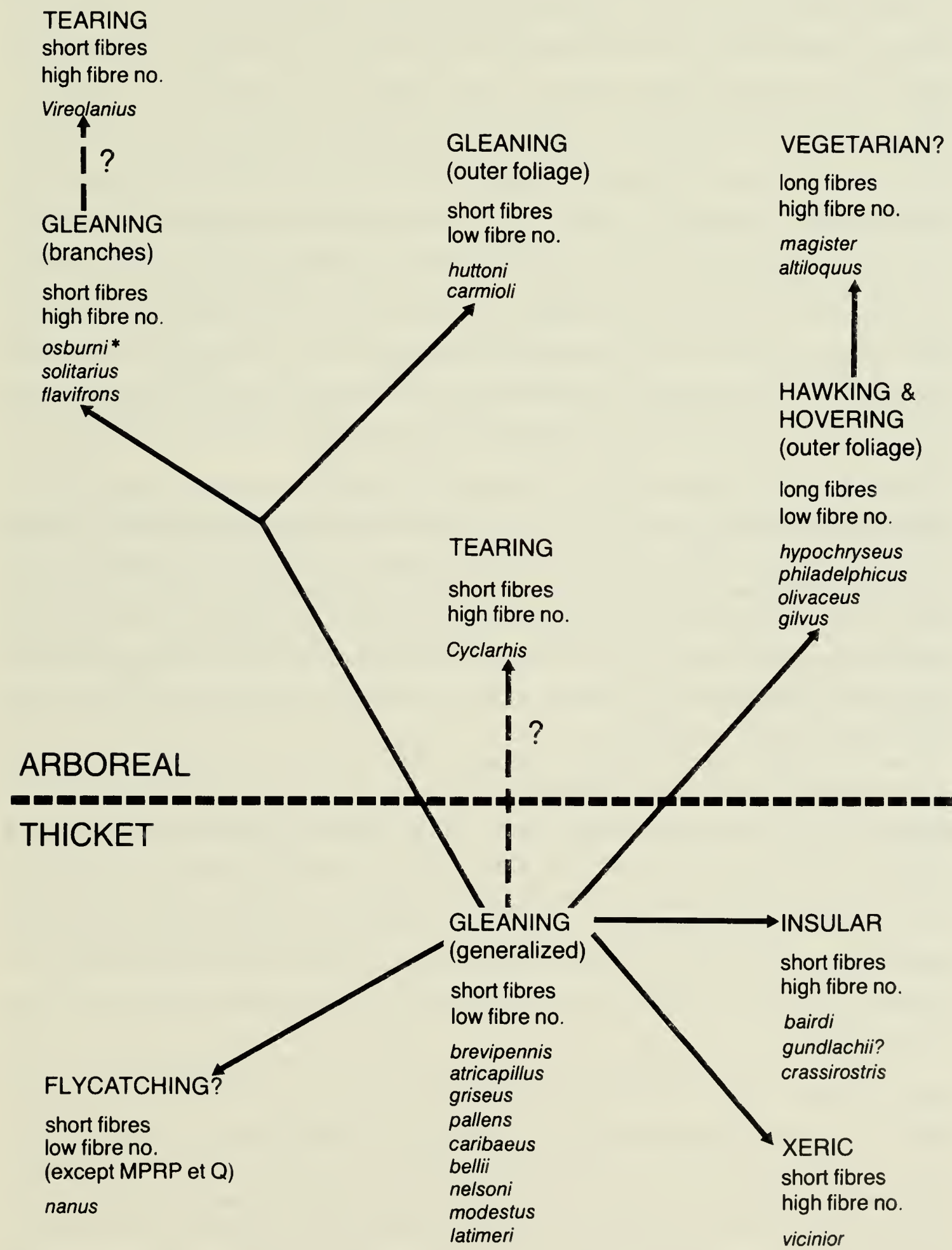

Text-fig. 15 Possible adaptive shifts in the genus Vireo (see text). This figure is not intended as a phylogenetic hypothesis. Vireo vicinior, for example, is almost certainly closely related to $V$. solitarius and may represent a secondary invasion of thicket habitat. Vireo osburni* forages in thickets as well as in trees (Barlow, pers. obs.; Cruz, 1980). 
Vireo and Vireosylva may have influenced differentiation in foraging type. Proto-Vireo may have tended towards twig and small leaf gleaning, while proto-Vireosylva became adapted to foraging in broad-leafed vegetation with increased use of hawking (i.e., aerial sallying after prey on a leaf or branch) and hovering, with an associated increase in fibre length in the major adductors. Foraging type may be related to stratal separation, as hawking is perhaps better suited to the open canopy of deciduous trees than to thickets. Thicket foragers in the subgenus Vireo thus minimize direct competition with the arboreal Vireosylva spp. Wide-ranging thicket foragers (e.g., V. griseus, V. pallens, $V$. bellii) do not have deep bills or strong jaw musculature, and regularly forage from leaves. Thicket foragers with strong jaw musculature ( $V$. bairdi, $V$. crassirostris and, presumably, $V$. gundlachii) are island isolates, except for the xeric habitat-dwelling $V$. vicinior. Of arboreal foragers in the subgenus Vireo, both $V$. flavifrons, which shares the habitat stratum of $V$. olivaceus, and $V$. solitarius plumbeus, which overlaps with western $V$. gilvus spp., have strong jaw adductors. In both cases competition is minimized by differences in foraging site and technique. The montane $V$. carmioli, which forages in the outer foliage of trees in the manner of Vireosylva spp., is the only vireo in its range at high elevations, where it is abundant. It overlaps with $V$. gilvus leucophrys only at middle elevations, but is less numerous there (Slud, 1964: 310). V. huttoni, another small-billed, weak-muscled arboreal forager, has an inflated skull and is the only non-migratory temperate-latitude vireo. It may forage in a manner that avoids direct competition with Vireosylva spp.

On the evidence of bill shape, plumage, and, particularly, relative lengths of the adductor fibres, we believe that Vireo hypochryseus is better placed in Vireosylva than in Vireo (Hamilton, 1958, 1962). Phenetic assessment based on skeletal patterns of 37 taxa of vireos (Barlow, unpubl.) supports its affinity with Vireosylva. This species may be the most primitive living member of its subgenus. Its skull is not as strongly narrowed as in other Vireosylva spp. Further, it is endemic to Mexico, the region of the greatest mainland diversity of the genus and a possible candidate for an ancestral radiating point (Barlow, 1980).

Vireo philadelphicus is frequently syntopic with $V$. olivaceus. These species have similar songs and maintain mutually exclusive territories, enabling them to forage in a similar manner without competing directly for food (Barlow and Power, 1970; Barlow and Rice, 1977; Rice, 1978a, 1978b). Their differences in bill length are not reflected by any observed differences in foraging behaviour. $V$. olivaceus and $V$. gilvus only partially overlap in habitat (James, 1976). There is nothing in the jaw musculature of $V$. philadelphicus or $V$. gilvus to support the suggestion of Hamilton (1962) that they are related to Hylophilus. The M. depressor mandibulae, for example, is typical of Vireo in both species.

Vireo altiloquus and $V$. magister are probably derived from olivaceus stock, perhaps from a long-billed form such as V. o. flavoviridis (Paynter, 1955; Hamilton, 1958, 1962). V. magister caymanensis has a very large head relative to its body size. Its complex M. pterygoideus dorsalis lateralis is difficult to explain. This form is an isolate on a small island, however, and may occupy a broader niche than does the nominate race. A stronger jaw musculature may permit the taking of a wider range of food items, as Grant (1965) has argued for bill size. The most divergent members of the genus Vireo with respect to bill shape, V. nanus, V. osburni, and V. olivaceus gracilirostris, are island endemics. 


\section{Other Vireonid Genera}

Cyclarhis and Vireolanius appear to be correctly placed close to or within the Vireonidae (Barlow and James, 1975). This conclusion is supported by phenetic studies based on skeletal characters (Barlow, unpubl.) and by characters in the appendicular musculature (Raikow, 1978: 26). Configurations of the jaw musculature, particularly of Mm. adductor mandibulae externus rostralis temporalis and depressor mandibulae, in both genera are more similar to Vireo than are those of Hylophilus. The differences are explainable as adaptations correlated to the enlargement of the bill and the increased robustness of the skull. These birds present at most only slightly more extreme examples of developments present in the deeper-billed vireos, especially Vireo osburni. In foraging behaviour they resemble some Vireo spp. Cyclarhis gujanensis feeds largely on insects from the crown and middle layers of low trees, but may occasionally forage to within $1 \mathrm{~m}$ of the ground (Barlow, unpubl.). Its large bill is adapted to tearing open cocoons. It also uses it to tear apart large prey items held down with the foot (Snow, 1964). Many vireos will hold a large invertebrate down with the foot while hammering at it with the bill, as will other birds such as tits (Paridae). Vireolanius pulchellus is a bird of the rain forest canopy, V. melitophrys of montane forest; they forage in much the same way as does Cyclarhis (Skutch, 1964; Barlow and James, 1975). Foraging techniques in both genera resemble that of Vireo solitarius plumbeus.

Little is known about the foraging behaviour of greenlets. They have been characterized as forming a more homogeneous group than do Vireo spp. (Bond, 1964). Their enlarged depressor musculature suggests that these birds open their bills against force. The pointed, almost wedge-shaped bill of Hylophilus seems almost ideal for thrusting into an object and opening against resistance. Such foraging methods have been noted in other groups (Beecher, 1951a; Burton, 1974b). They include gaping inside ripe fruit, spreading debris on the ground to hunt for insects, and gaping inside tubular flowers to improve access to the nectaries. Some neotropical species gape between the bases of bromeliad leaves to reach insects deep in the plant (J. Hubbard, pers. comm.). Richards and Bock (1973) have described an enlarged M. depressor mandibulae in the extinct drepanidid Loxops sagittirostris, a species that possessed a straight, wedgeshaped bill similar to (although relatively larger than) that of Hylophilus spp. This bird apparently fed on insects concealed in bark crevices, the leaf bases of arboreal epiphytes, and other places presumably exposed by prying and gaping actions.

It is probable, on the basis of what is known of other birds, that the higher fibre number in the depressors and wedge-shaped bills of Hylophilus spp. are adaptations for gaping during foraging. Unfortunately, we find no evidence that Hylophilus spp. do any of these things; instead, the few species studied appear to be warblerlike leaf foragers (Wetmore, 1943; Skutch, 1960). Beecher (1951b, 1953) claimed that $H$. poicilotis was a nectar-feeder, but apparently without supporting field evidence. Foraging of $H$. flavipes in Venezuela resembles that of Vireo bellii (Barlow, pers. obs.). Limited observations by the first author on $H$.d. decurtatus and $H$. ochraceiceps in Costa Rica revealed no gaping behaviour. Both species appeared to be leaf gleaners. The only suggestion of gaping behaviour in Hylophilus is the report of Skutch (1960) that $H$. $d$. decurtatus pries for insects inside dried, rolled-up leaves. It may have to gape to spread such leaves enough to expose prey. Until more information is available it is therefore premature to say what function enlarged depressor musculature serves in Hylophilus. 
In Costa Rican rain forest and humid subtropical forest sites at Rincón de Osa and San Vito de Java respectively, where the deep-billed, heavy-muscled Hylophilus ochraceiceps and the thin-billed, relatively weak-muscled $H$. $d$. decurtatus coexisted, ochraceiceps is a bird of the interior forest understory. $H$. $d$. decurtatus, a bird of the canopy, is seen in understory only in edge situations where ochraceiceps does not occur. In the dry forest of Guanacaste, where ochraceiceps is absent, decurtatus occurs almost exclusively in forest understory or lower canopy (Orenstein, pers. obs.). This may imply a stratal separation related to bill shape within this genus, based on competitive exclusion.

\section{Taxonomic Significance of the Jaw Musculature}

The considerable amount of individual variation found in the vireos shows that interspecific comparisons must be made with large enough sample sizes to ensure certainty in the citation of species-specific characters. Only after the range of variation within a genus has been determined can intergeneric comparisons be safely made. Modifications of Mm. adductor mandibulae externus caudalis and pterygoideus dorsalis lateralis would probably have been regarded as features peculiar to Cyclarhis and Vireolanius had heavy-billed vireos such as Vireo osburni and V. vicinior not been dissected.

The major differences noted among the jaw musculatures of Vireo spp. seem related to differences in foraging technique. They may be the result of rapid, recent change and of little use in determining intrageneric relationships. Jaw-muscle characters do, however, provide taxonomic guidance for some problems of relationship in vireos. Differences in fibre length support the separation of Vireo and Vireosylva, with $V$. hypochryseus transferred to the latter subgenus, but the jaw musculature provides no evidence for placing the arboreal short-fibred species $V$. solitarius, flavifrons, huttoni, carmioli, and osburni in a subgenus Lanivireo. There is no evidence in the jaw musculature for the recognition of the genera Lawrencia for Vireo nanus or Laletes for $V$. osburni respectively. These species seem to represent extremes of the basic Vireo pattern. Vireo brevipennis has jaw musculature similar to that of $V$. griseus and lacking any distinctive features. For this and other reasons (Barlow, unpubl.), there seems no need to recognize a genus Neochloe for this species. The jaw muscles are useful in shedding light on these specific problems, but their chief importance in this study has been as indicators of the range and kind of morphological variation that has occurred in the Vireonidae as a whole. 


\section{Acknowledgements}

We are grateful to Dennis M. Power for help with statistical techniques; to J. A. Dick, R. D. James, P. L. McLaren, and L. Ferguson for help in the field; and to Ms. Carol Goodwin, who offered advice on drawing techniques and prepared most of the final illustrations and graphs. Thomas Petiet assisted in the preparation of Text-fig. 15. Trudy Rising organized and typed an early draft of the text.

We especially thank Dr. Walter J. Bock, of the Department of Biological Sciences, Columbia University, who gave the first author invaluable assistance on dissection technique and interpretation of anatomical results, and allowed him access to unpublished material. J. M. Speirs, R. S. Parsons, and J. D. Rising of the Department of Zoology, University of Toronto, and A. S. Gaunt of Ohio State University, offered valuable suggestions in the course of the study. J. P. Hubbard, R. L. Zusi, H. B. Tordoff, E. Eisenmann, P. R. Grant, and Mary LeCroy also provided advice and assistance. We also especially thank J. A. Dick, R. D. James, and Dr. and Mrs. W. E. Lockhart, Jr., for a myriad of services which made possible successful completion of this project.

We also thank Mary H. Clench of the Carnegie Museum, Eleanor H. Stickney of the Yale-Peabody Museum, and R. F. Johnston of the Museum of Natural History, University of Kansas, for the loan of anatomical specimens. Storrs Olson of the National Museum of Natural History provided specimens and field information for Vireo olivaceus gracilirostris. Dean Amadon of the American Museum of Natural History and R. W. Storer of the Museum of Zoology, University of Michigan, permitted measurement of study skins in their collections. George Nace of the University of Michigan provided access to an IBM editing typewriter for revision and typing of the final manuscript.

The second author is indebted to the following government agencies that provided permits allowing acquisition of specimens for scientific study. Environment Canada, Canadian Wildlife Service; Arizona Game and Fish Department; Texas Parks and Wildlife Department; U.S.D.I., Fish and Wildlife Service; U.S.D.I., National Park Service. Especially helpful were members of the U.S. Park Service at Big Bend National Park, Brewster Co., Texas. We similarly thank government agencies in the Bahamas, Belize, Cayman Islands, Colombia, Costa Rica, La Guyane Française, Guadeloupe, Guyana, Jamaica, Mexico, Montserrat, and Venezuela.

Financial support for this study was provided by National Research Council Grant No. A-3472 to the second author for study of evolutionary rates in vireos, by a Grant-in-Aid of Research to him from the department of University Affairs, and from the Colin Gordon Fund of the departments of Ornithology and Mammalogy of the Royal Ontario Museum.

This study is a revision of an M.Sc. thesis (Orenstein, 1970) undertaken by the first author under the supervision of the second author at the University of Toronto. 


\section{Literature Cited}

AMADON, D.

1943 Bird weights as an aid to taxonomy. Wilson Bulletin 55:164-167.

BALDWIN, S. P., H. C. OBERHOLSER, and L. G. WORLEY

1931 Measurements of birds. Scientific Publications of the Cleveland Museum of Natural History $2: 1-165$.

BARLOW, J. C.

1962 Natural history of the Bell Vireo (Vireo bellii Audubon). University of Kansas Publications, Museum of Natural History 12:241-296.

1967 Nesting of the Black-capped Vireo in the Chisos Mountains, Texas. Condor 69:605-608.

1977 Effects of habitat attrition on vireo distribution and population density in the northern Chihuahuan desert. In Wauer, R. H. and D. H. Riskind, eds., Transactions of the Symposium on the Biological Resources of the Chihuahuan Desert Region-United States and Mexico. U.S. Dept. of the Interior, National Park Service, Transactions and Proceedings Series 3:591-596.

1980 Patterns of ecological interactions among migrant and resident vireos on the wintering grounds. In Keast, A. and E. S. Morton, eds., Migrant birds in the neotropics: ecology, behavior, distribution, and conservation. Washington, D.C., Smithsonian Institution Press, pp. 79-107.

BARLOW, J. C. and R. D. JAMES

1975 Aspects of the biology of the Chestnut-sided Shrike-vireo. Wilson Bulletin 87:320-334.

BARLOW, J. C., R. D. JAMES, and N. WILLIAMS

1970 Habitat co-occupancy among some species of the subgenus Vireo (Aves: Vireonidae). Canadian Journal of Zoology 48:395-398.

BARLOW, J. C. and R. R. JOHNSON

1969 The gray vireo, Vireo vicinior Coues (Passeriformes: Vireonidae) in the Sierra del Carmen, Coahuila, Mexico. Canadian Journal of Zoology 47:151-152.

BARLOW, J. C. and D. M. POWER

1970 An analysis of character variation in red-eyed and Philadelphia vireos (Aves: Vireonidae) in Canada. Canadian Journal of Zoology 48:673-680.

BARLOW, J. C. and J. RICE

1977 Aspects of the comparative behavior of red-eyed and Philadelphia vireos. Canadian Journal of Zoology 55:528-542.

BARLOW, J. C. and N. WILLIAMS

1970 The Hutton vireo (Vireo huttoni stephensi Brewster) in the Bradshaw Mountains, Arizona. Canadian Journal of Zoology 48:1447-1448.

BAUMEL, J. J., A. S. KING, A. M. LUCAS, J. E. BREAZILE, and H. C. EVANS, eds.

1979 Nomina Anatomica Avium. London, Academic Press. 637 pp.

BEECHER, W. J.

1950 Convergent evolution in the American orioles. Wilson Bulletin 62:51-86.

1951 a Adaptations for food-getting in American blackbirds. Auk 68:411-440.

1951b Convergence in the Coerebidae. Wilson Bulletin 63:274-287.

1953 A phylogeny of the Oscines. Auk 70:270-333. 
BENT, A.C

1950 Life histories of North American wagtails, shrikes, vireos and their allies. Bulletin of the United States National Museum 197:1-411.

BERGER, A. G.

1969 Appendicular myology of passerine birds. Wilson Bulletin 81:220-223.

BLAKE, E. R.

1968 Families Cyclarhiidae, Vireolaniidae and Vireonidae. In Paynter, R. A., Jr., ed., Check-list of the birds of the world, vol. 14. Cambridge, Museum of Comparative Zoology, pp. $103-138$.

BOCK, W. J.

1966 An approach to the functional analysis of bill shape. Auk 83: 10-51.

1967 Consequences of pinnateness of the $m$. pseudotemporalis superficialis in passerine birds. American Zoologist 7:775-776. [Abstract]

1968 Mechanics of one- and two-joint muscles. American Museum Novitates 2319:1-45.

1969 Comparative morphology in systematics. In Systematic biology. Washington, National Academy of Sciences, pp. 411-448.

1974 The avian skeletomuscular system. In Farner, D. S. and J. R. King, eds., Avian biology, vol. 4. New York, Academic Press, pp. 119-251.

BOCK, W. J. and H. MORIOKA

1971 Morphology and evolution of the ectethmoid-mandibular articulation in the Meliphagidae (Aves). Journal of Morphology 135:13-50.

BOCK, W. J. and C. R. SHEAR

1972 A staining method for gross dissection of vertebrate muscles. Anatomischer Anzeiger 130:222-227.

BOND, J.

1964 Vireo. In Thomson, A. L., ed., A new dictionary of birds. London, Nelson, pp. 858-859. BOWMAN, R. I.

1961 Morphological differentiation and adaptation in the Galapagos finches. University of California Publications in Zoology 58:1-305.

BURTON, P. J. K.

1974a Feeding and the feeding apparatus in waders. London, British Museum (Natural History). $150 \mathrm{pp}$.

1974b Anatomy of head and neck in the Huia (Heteralocha acutirostris) with comparative notes on other Callaeidae. Bulletin of the British Museum (Natural History), Zoology 27:1-48.

CHAPIN, E. A.

1925 Food habits of the vireos, a family of insectivorous birds. United States Department of Agriculture, Bulletin 1355:1-42.

CRUZ, A.

1980 Feeding ecology of the Black-whiskered Vireo and associated gleaning birds in Jamaica. Wilson Bulletin 92:40-52.

DA VIS, L. I.

1957 Observations on Mexican birds. Wilson Bulletin 69:364-367.

DAVIS, W. B.

1945 Notes on Veracruzan birds. Auk 62:272-286. 
FICKEN, R. W. , P. E. MATTHIAE, and R. HOREVICH

1971 Eye marks in vertebrates: aids to vision. Science 173:936-938.

GANS, C. and W. J. BOCK

1965 The functional significance of muscle architecture: a theoretical analysis. Ergebnisse der Anatomie 38:115-142.

GRANT, P. R

1965 The adaptive significance of some size trends in island birds. Evolution 19:355-367.

HAMILTON, T. H.

1958 Adaptive variation in the genus Vireo. Wilson Bulletin 70:307-346.

1962 Species relationships and adaptations for sympatry in the avian genus Vireo. Condor 64:40-68.

HA VERSCHMIDT, F.

1968 Birds of Surinam. Edinburgh, Oliver and Boyd. 445 pp.

HUDSON, G. E.

1948 Studies on the muscles of the pelvic appendage in birds. II: the heterogeneous order Falconiformes. American Midland Naturalist 39:102-127.

JAMES, R. D

1973 Ethological and ecological relationships of the Yellow-throated and Solitary Vireos (Aves: Vireonidae) in Ontario. Ph.D. Thesis, University of Toronto. 243 pp.

1976 Foraging behavior and habitat selection of three species of vireos in southern Ontario. Wilson Bulletin 88:62-75.

JOHNSTON, D. W.

1975 Ecological analysis of the Cayman Island avifauna. Bulletin of the Florida State Museum, Biological Sciences 19:235-300.

LACK, D.

1976 Island biology illustrated by the land birds of Jamaica. Oxford, Blackwell. 445 pp.

MANN, C. F., P. J. K. BURTON, and I. LENNERSTEDT

1978 A reappraisal of the systematic position of Trichastoma poliothorax (Timaliinae, Muscicapidae). Bulletin of the British Ornithologists' Club 98:131-140.

MERZ, R. L.

1963 Jaw musculature of the Mourning and White-winged Doves. University of Kansas Publications, Museum of Natural History, 12:521-551.

MORIOKA, H.

1974 Jaw musculature of swifts (Aves, Apodidae). Bulletin of the National Science Museum, Tokyo, 17:1-16.

MORTON, E. S

1977 Intratropical migration in the Yellow-green Vireo and Piratic Flycatcher. Auk 94:97-106.

NOLAN, V., JR. and D. P. WOOLDRIDGE

1962 Food habits and feeding behavior of the White-eyed Vireo. Wilson Bulletin 74:68-73.

ORENSTEIN, R. I.

1970 Variation in the jaw musculature of some members of the avian family Vireonidae. M.Sc. Thesis, University of Toronto. 203 pp. 
PAYNTER, R. A., JR.

1955 The ornithogeography of the Yucatán Peninsula. Peabody Museum of Natural History, Yale University, Bulletin 9:1-347.

RAIKOW, R. J.

1975 The evolutionary reappearance of ancestral muscles as developmental anomalies in two species of birds. Condor 77:514-517.

1978 Appendicular myology and relationships of the New World nine-primaried oscines (Aves: Passeriformes). Bulletin of the Carnegie Museum of Natural History 7:1-43.

RICE, J. C

1978a Behavioural interactions of interspecifically territorial vireos. I. Song discrimination and natural interactions. Animal Behaviour 26:527-549.

$1978 \mathrm{~b}$ Behavioural interactions of interspecifically territorial vireos. II. Seasonal variation in response intensity. Animal Behaviour 26:550-561.

RICHARDS, L. P. and W. J. BOCK

1973 Functional anatomy and adaptive evolution of the feeding apparatus in the Hawaiian Honeycreeper genus Loxops (Drepanididae). American Ornithologists' Union, Ornithological Monographs 15:1-173.

RIDGWAY, R.

1904 Birds of North and Middle America. Bulletin of the United States National Museum 50 (3): $128-232$.

SKUTCH, A. F.

1960 Life histories of Central American birds, vol. 2. Pacific Coast Avifauna 34. Berkeley, Cooper Ornithological Society. 593 pp.

1964 Shrike-vireo. In Thomson, A. L., ed., A new dictionary of birds. London, Nelson, pp. 736-737.

SLUD, P.

1964 The birds of Costa Rica: distribution and ecology. Bulletin of the American Museum of Natural History 128:1-430.

SNOW, D. W.

1954 The habitats of Eurasian tits (Parus spp.). Ibis 96:565-585.

1964 Pepper-shrike. In Thomson, A. L., ed., A new dictionary of birds. London, Nelson, p. 616.

SOKAL, R. R. and F. J. ROHLF

1969 Biometry: the principles and practice of statistics in biological research. San Francisco, W. H. Freeman. 776 pp.

VANDER, A. J., J. H. SHERMAN, and D. S. LUCIANO

1975 Human physiology: the mechanisms of body function. New York, McGraw-Hill. 614 pp.

WETMORE, A.

1916 Birds of Puerto Rico. United States Department of Agriculture, Bulletin 326:1-140.

1943 The birds of southern Veracruz, Mexico. Proceedings of the United States National Museum 93: 215-340.

WETMORE, A. and B. H. SWALES

1931 The birds of Haiti and the Dominican Republic. Bulletin of the United States National Museum 155:1-483. 
ZUSI, R. L.

1967 The role of the depressor mandibulae muscle in kinesis of the avian skull. Proceedings of the United States National Museum 123:1-28.

ZWEERS, G. A.

1974 Structure, movement and myography of the feeding apparatus of the Mallard (Anas platyrhynchos L.). A study in functional anatomy. Netherlands Journal of Zoology 24:323-467.

ZWEERS, G. A., A. F. CH. GERRITSEN, and P. J. VAN KRANENBERG-VOOGD

1977 Mechanics of feeding of the Mallard (Anas platyrhynchos L., Aves, Anseriformes): the lingual apparatus and the suction-pressure pump mechanism of straining. Contributions to vertebrate evolution, v.3. Basel, S. Karger. 109 pp. 


\section{Appendix 1 Bill Measurements (means only)}

Means of measurements are presented in millimetres for all taxa dissected except Vireo olivaceus vividior. All measurements were taken from the base of the bill as recommended by Baldwin et al. (1931). Figures for bill proportions represent means of proportions for each specimen measured.

Specimens were measured in the collections of the Royal Ontario Museum, American Museum of Natural History, and the Museum of Zoology, University of Michigan. The code names given in the left-hand column are those used in computer analyses. Other abbreviations are as follows:

BL bill (culmen) length, BW bill width, BD bill depth, $\mathrm{N}$ sample size.

BL BW $\quad \mathrm{BD} \quad \mathrm{BL} / \mathrm{BW} \quad \mathrm{BL} / \mathrm{BD} \quad \mathrm{BD} / \mathrm{BW} \quad \mathrm{N}$

\begin{tabular}{|c|c|c|c|c|c|c|}
\hline CGUJ & 15.68 & 8.07 & 9.18 & 1.95 & 1.66 & 1.17 \\
\hline VMEL & 17.76 & 8.74 & 8.10 & 2.03 & 2.20 & 0.93 \\
\hline VPUL & 15.80 & 8.17 & 8.55 & 1.93 & 1.88 & 1.05 \\
\hline VBRE & 9.83 & 5.23 & 3.90 & 1.91 & 2.52 & 0.74 \\
\hline VHHU & 9.34 & 5.04 & 3.73 & 1.86 & 2.55 & 0.74 \\
\hline VHST & 9.86 & 5.57 & 4.64 & 1.77 & 2.12 & 0.84 \\
\hline VATR & 9.65 & 4.29 & 3.26 & 2.28 & 2.96 & 0.77 \\
\hline VGNO & 10.61 & 5.57 & 4.11 & 1.91 & 2.59 & 0.74 \\
\hline VGMA & 10.95 & 5.98 & 4.36 & 1.84 & 2.52 & 0.73 \\
\hline VPSE & 11.14 & 5.56 & 4.34 & 2.01 & 2.58 & 0.78 \\
\hline VCRI & 11.30 & 5.20 & 3.93 & 2.18 & 2.88 & 0.79 \\
\hline VBAI & 11.69 & 5.53 & 4.69 & 2.12 & 2.50 & 0.86 \\
\hline VGUN & 12.67 & 5.63 & 4.83 & 2.25 & 2.62 & 0.86 \\
\hline VCCR & 11.86 & 5.69 & 4.77 & 2.08 & 2.48 & 0.84 \\
\hline VBAR & 10.57 & 5.64 & 4.17 & 1.88 & 2.54 & 0.74 \\
\hline VBME & 9.56 & 4.97 & 3.98 & 1.93 & 2.41 & 0.80 \\
\hline VBBE & 10.37 & 5.21 & 3.87 & 2.00 & 2.68 & 0.75 \\
\hline VVIC & 9.65 & 5.64 & 5.16 & 1.71 & 1.86 & 0.92 \\
\hline VNEL & 9.90 & 4.80 & 3.65 & 2.08 & 2.74 & 0.76 \\
\hline VHHY & 12.11 & 5.93 & 4.88 & 2.07 & 2.49 & 0.82 \\
\hline VMOD & 10.32 & 5.48 & 3.93 & 1.89 & 2.63 & 0.72 \\
\hline VNAN & 9.05 & 5.95 & 3.65 & 1.52 & 2.49 & 0.62 \\
\hline VLAT & 11.44 & 5.70 & 4.73 & 2.01 & 2.43 & 0.83 \\
\hline VOSB & 13.4 & 6.8 & 6.7 & 1.99 & 2.01 & 0.99 \\
\hline VCAR & 8.67 & 5.04 & 3.96 & 1.72 & 2.20 & 0.79 \\
\hline VSSO & 9.94 & 5.61 & 4.70 & 1.78 & 2.12 & 0.84 \\
\hline VSPL & 10.88 & 6.13 & 5.07 & 1.77 & 2.15 & 0.83 \\
\hline VSCA & 10.05 & 5.18 & 4.36 & 1.94 & 2.31 & 0.84 \\
\hline VFLA & 10.77 & 5.83 & 4.96 & 1.85 & 2.16 & 0.85 \\
\hline
\end{tabular}




\begin{tabular}{lccccccr}
\multicolumn{1}{c}{ Appendix 1 continued } & BL & BW & BD & BL/BW & BL/BD & BD/BW & N \\
VPHI & 9.14 & 4.83 & 3.51 & 1.90 & 2.62 & 0.73 & 30 \\
VOOL & 12.67 & 5.87 & 4.76 & 2.16 & 2.68 & 0.81 & 30 \\
VOFL & 14.35 & 6.39 & 5.18 & 2.27 & 2.75 & 0.81 & 8 \\
VOCH & 13.45 & 5.65 & 4.75 & 2.38 & 2.84 & 0.84 & 4 \\
VOGR & 14.60 & 5.40 & 4.10 & 2.70 & 3.57 & 0.76 & 2 \\
VMMA & 15.44 & 6.60 & 6.01 & 2.34 & 2.57 & 0.91 & 7 \\
VMCA & 15.05 & 5.87 & 5.16 & 2.57 & 2.92 & 0.88 & 4 \\
VABA & 16.13 & 6.77 & 5.67 & 2.39 & 2.86 & 0.84 & 12 \\
VGSW & 9.95 & 4.87 & 3.77 & 2.05 & 2.65 & 0.78 & 15 \\
VGGI & 10.67 & 5.28 & 4.05 & 2.03 & 2.65 & 0.77 & 15 \\
HPOI & 11.08 & 4.86 & 4.66 & 2.29 & 2.38 & 0.96 & 5 \\
HPEC & 10.8 & 5.0 & 4.8 & 2.16 & 2.25 & 0.96 & 1 \\
HAUR & 12.2 & 5.5 & 4.7 & 2.22 & 2.60 & 0.81 & 1 \\
HFLA & 11.3 & 6.5 & 5.5 & 1.74 & 2.06 & 0.85 & 1 \\
HOCH & 12.75 & 5.18 & 5.23 & 2.47 & 2.44 & 1.01 & 4 \\
HDDE & 11.60 & 5.22 & 4.37 & 2.23 & 2.67 & 0.84 & 6
\end{tabular}



Abbreviations Used in Figs. 1-15
amec $\quad$ M. adductor mandibulae externus caudalis
amerl $\quad M$. adductor mandibulae externus rostralis lateralis
amerm $\quad M$. adductor mandibulae externus rostralis medialis
amert $\quad M$. adductor mandibulae externus rostralis temporalis
amev $\quad M$. adductor mandibulae externus ventralis
amp $\quad$ M. adductor mandibulae posterior
dm M. depressor mandibulae
pdl M. pterygoideus dorsalis lateralis
pdma M. pterygoideus dorsalis medialis anterior
pdmp M. pterygoideus dorsalis medialis posterior
ppq $\quad$ M. protractor pterygoidei et quadrati
prp $\quad$ M. pterygoideus retractor
psp M. pseudotemporalis profundus
pss $\quad$ M. pseudotemporalis superficialis
pvl M. pterygoideus "ventralis lateralis"
pvm $\quad$ M. pterygoideus ventralis medialis 

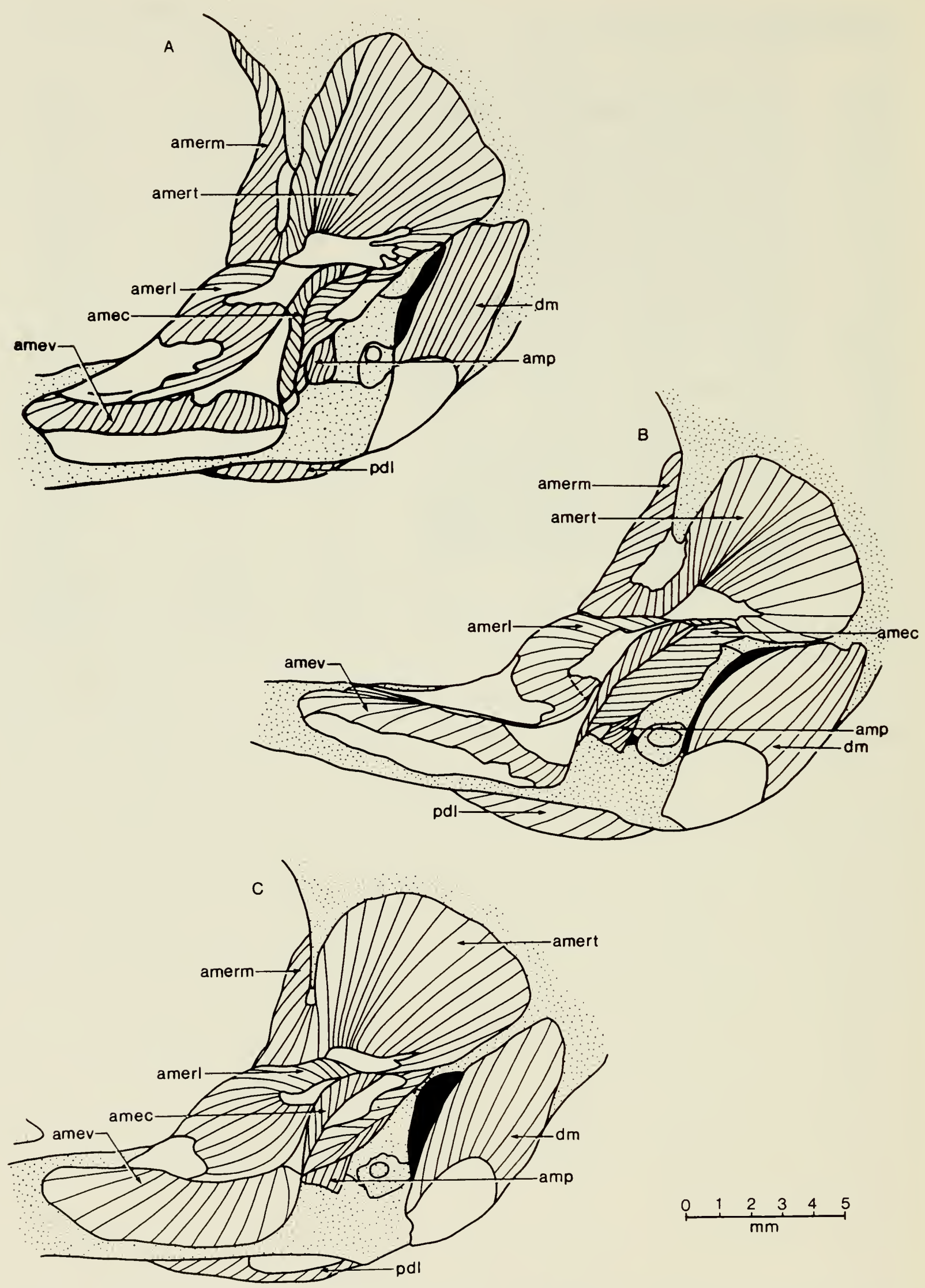

Fig. 1 Lateral view of the superficial jaw musculature in Cyclarhis and Vireolanius. The jugal bar, eye, connective tissues, and ligaments have been removed. Bone is stippled; tendons and aponeuroses are blank; fibre patterns are indicated by lines (Note: the temporal aponeurosis of origin of amert is not shown.)

A Cyclarhis gujanensis insularis (Carnegie 1077)

B Vireolanius melitophrys (ROM 112919)

C V.pulchellus (ROM 112335) 

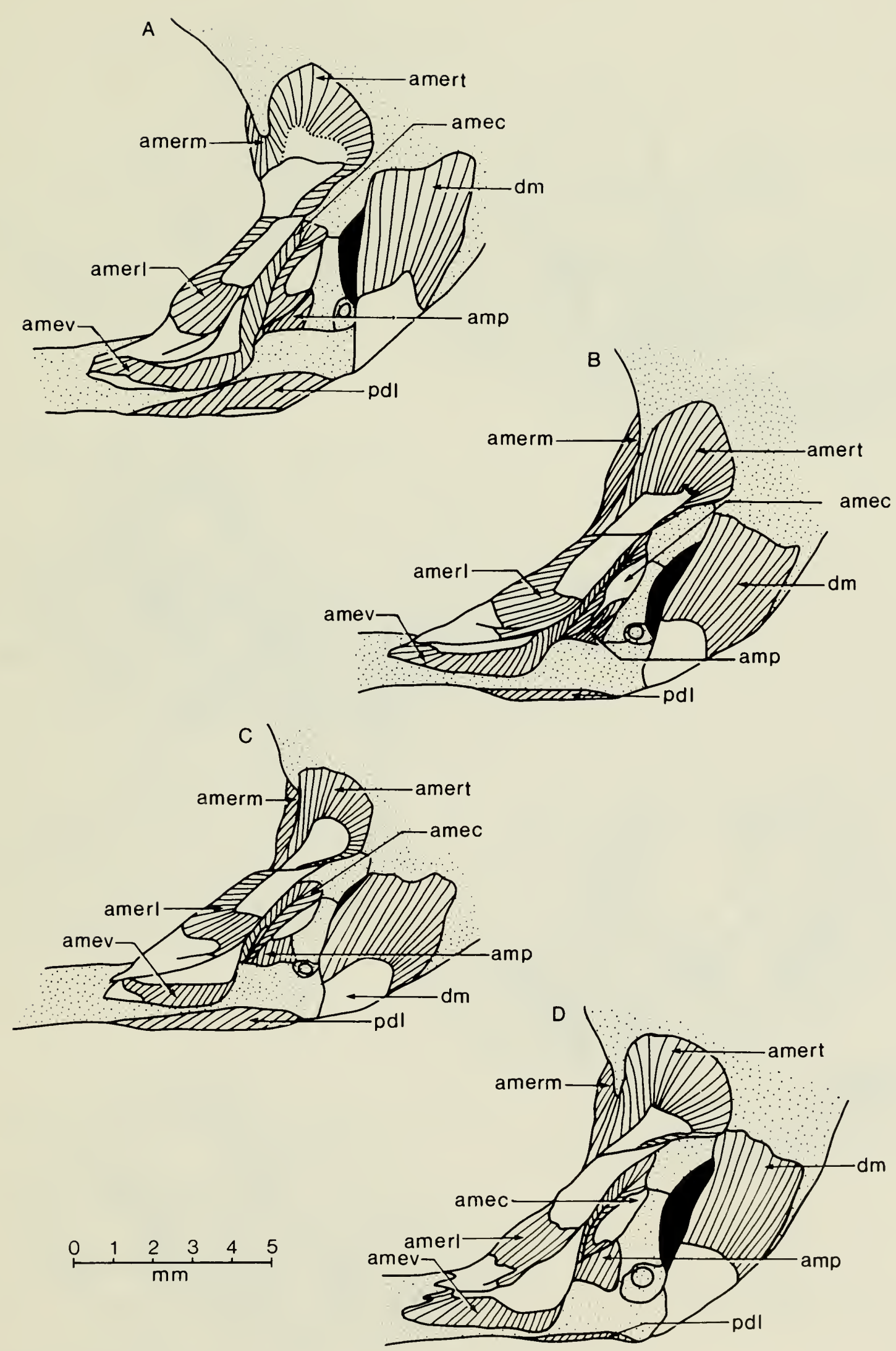

Fig. 2 Lateral view of the superficial jaw musculature in some species of Vireo.

A Vireo brevipennis (ROM 109629) (the dotted line indicates damage to the specimen)

B V.h. huttoni (ROM 106037)

C V.atricapillus (ROM 104450)

D V. griseus maynardi (KU 3889) 

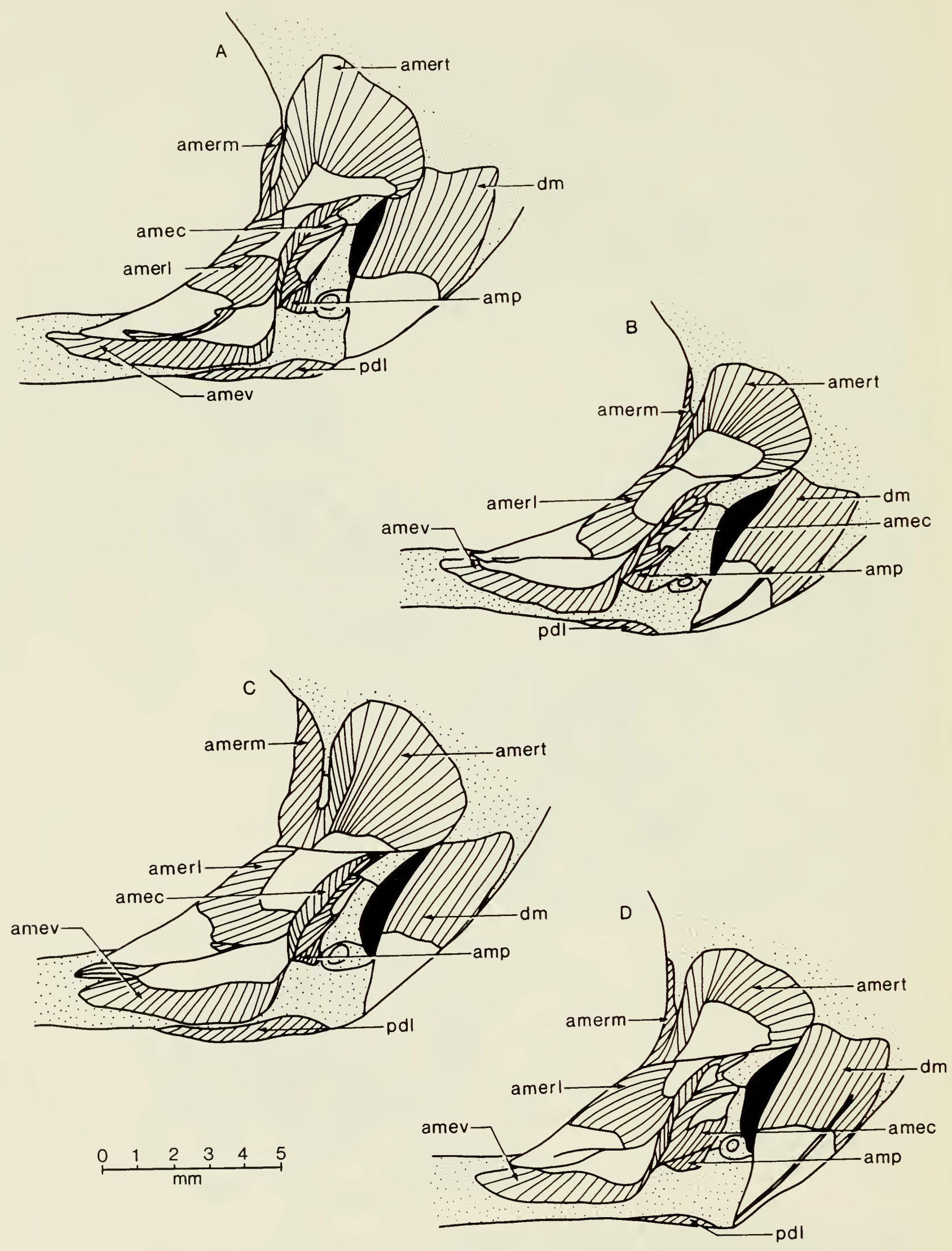

Fig. 3 Lateral view of the superficial jaw musculature in some species of Vireo.

A Vireo bairdi (Yale 6363)

B V. b. bellii ( $\mathrm{KU} 40376)$

C V. vicinior (ROM 99458)

D V.h.hypochryseus (ROM 105617) 


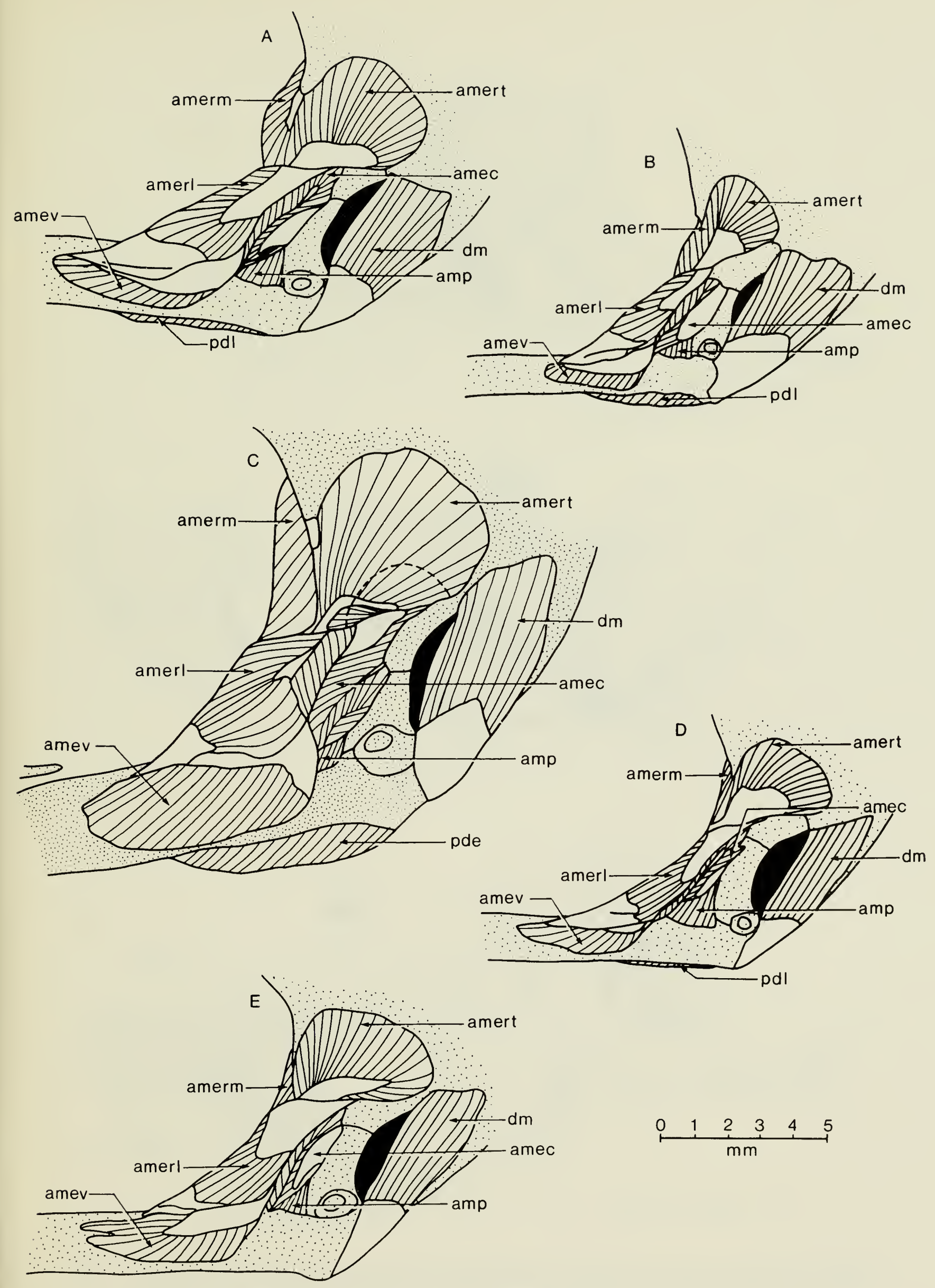

Fig. 4 Lateral view of the superficial jaw musculature in some species of Vireo.

A Vireo solitarius plumbeus (ROM 100591)

B V.nanus (ROM 112421)

C V. osburni (ROM 113173) (the dashed line delimits amec)

D V.philadelphicus (ROM 97688)

E V.o. olivaceus (ROM 103089) 

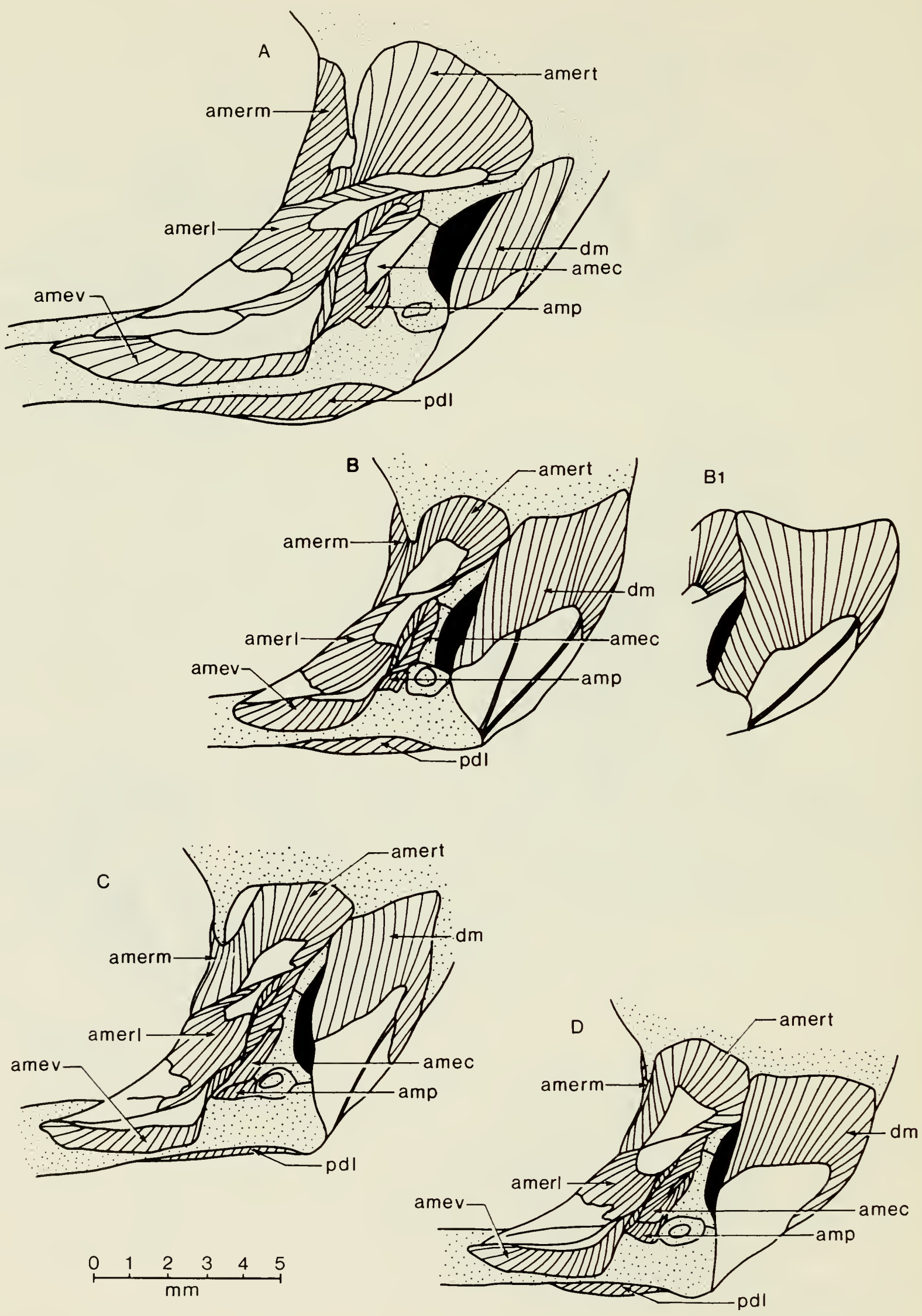

Fig. 5 Lateral view of the superficial jaw musculature in some species of Vireo and Hylophilus.
A Vireo magister caymanensis (ROM 109363)
B Hylophilus poicilotis (Yale 2924)
$\mathrm{B}_{1} H$. poicilotis (Yale 2626, for comparison)
C H.ochraceiceps (Carnegie 917)
D H.d.decurtatus (ROM 104309) 

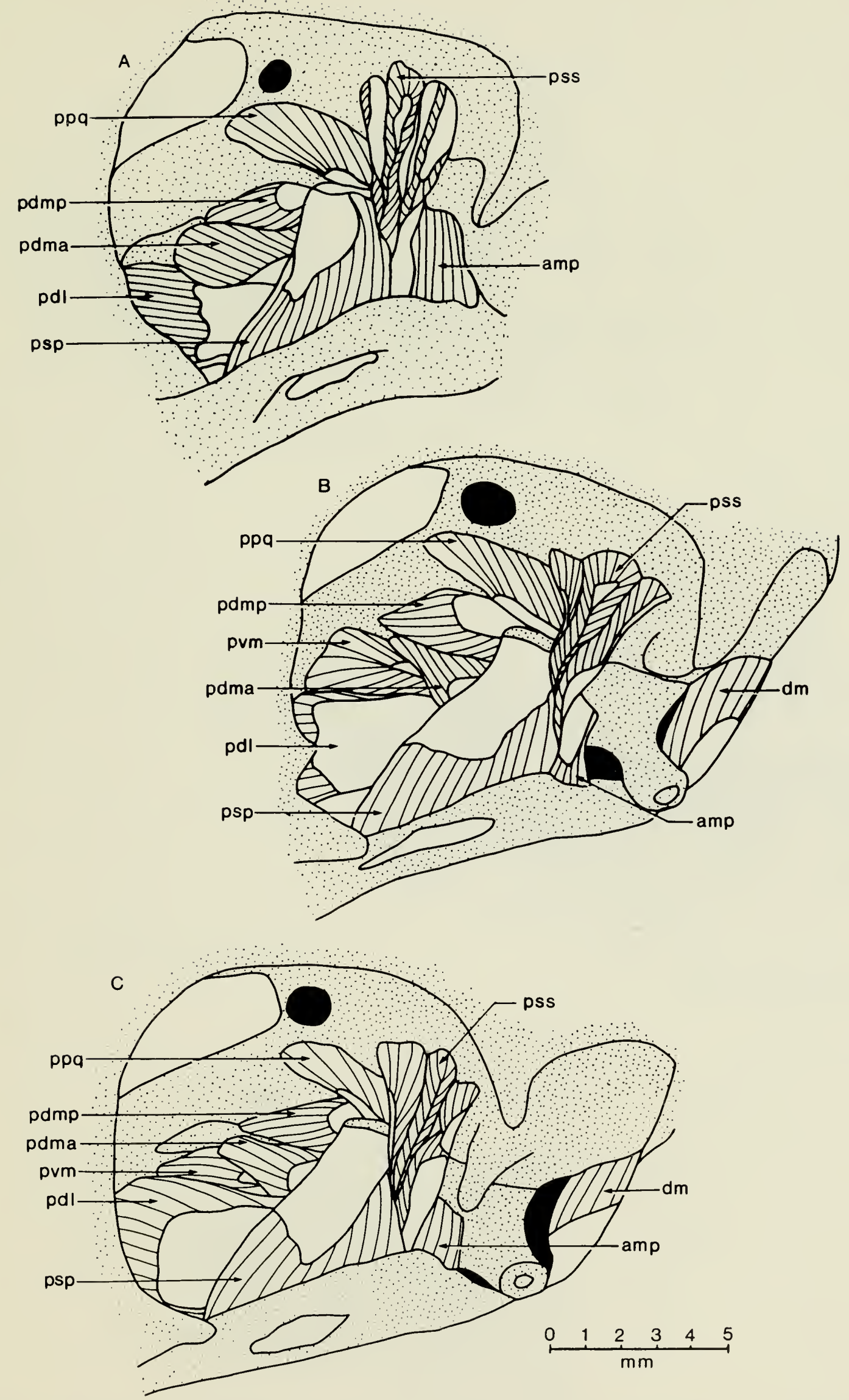

Fig. 6 Internal jaw musculature in Cyclarhis and Vireolanius as viewed within the orbit, after the removal of the eye, jugal bar, intrinsic eye musculature, and connective tissues. The $\mathrm{M}$. adductor mandibulae externus has been removed.

A Cyclarhis gujanensis insularis (Carnegie 1077)

B Vireolanius melitophrys (ROM 112919)

C V.pulchellus (ROM 112335) 

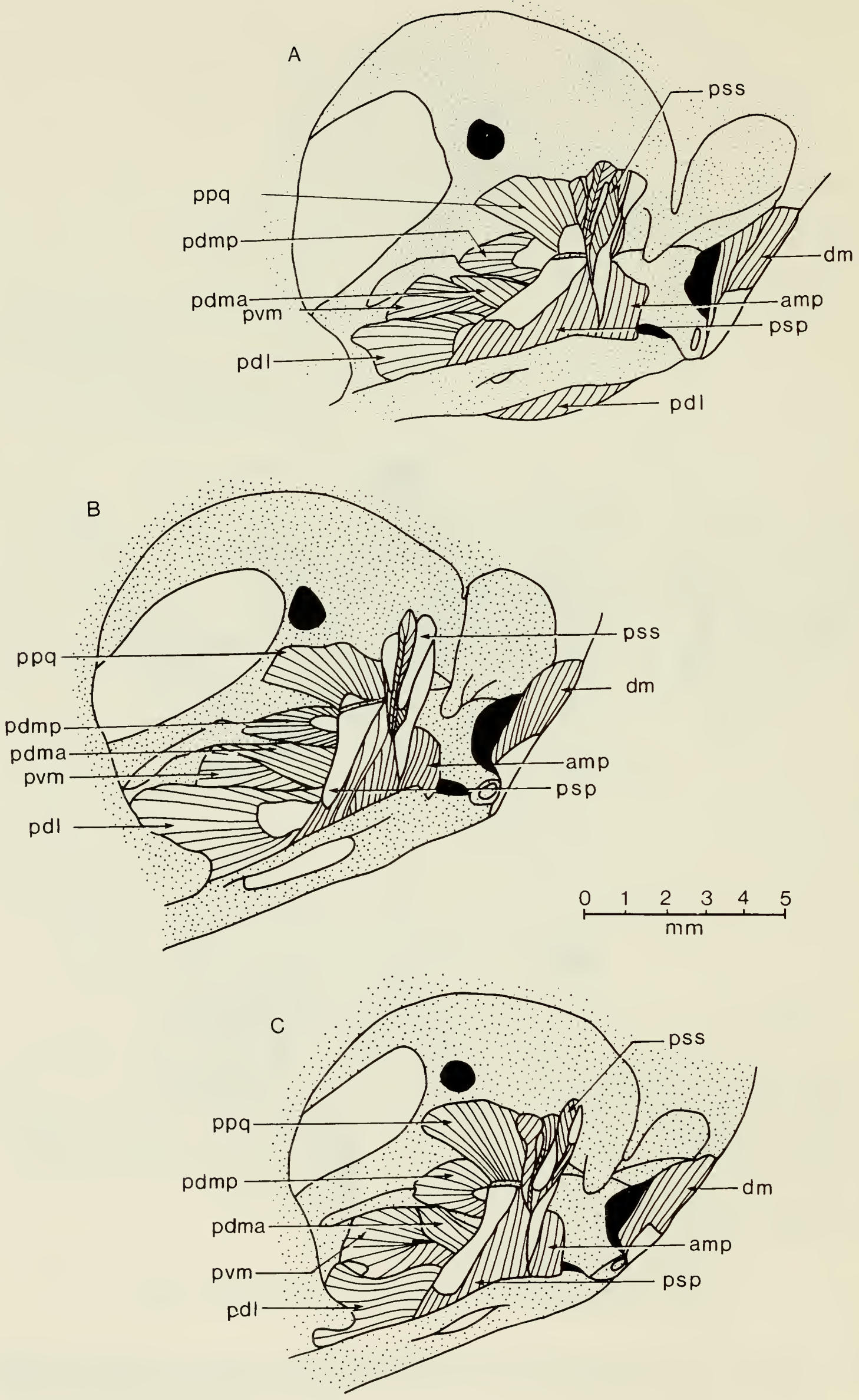

Fig. 7 Internal jaw musculature in some species of Vireo.
A Vireo brevipennis (ROM 109629)
B V.h. huttoni (ROM 104459)
C V.atricapillus (ROM 99456) 

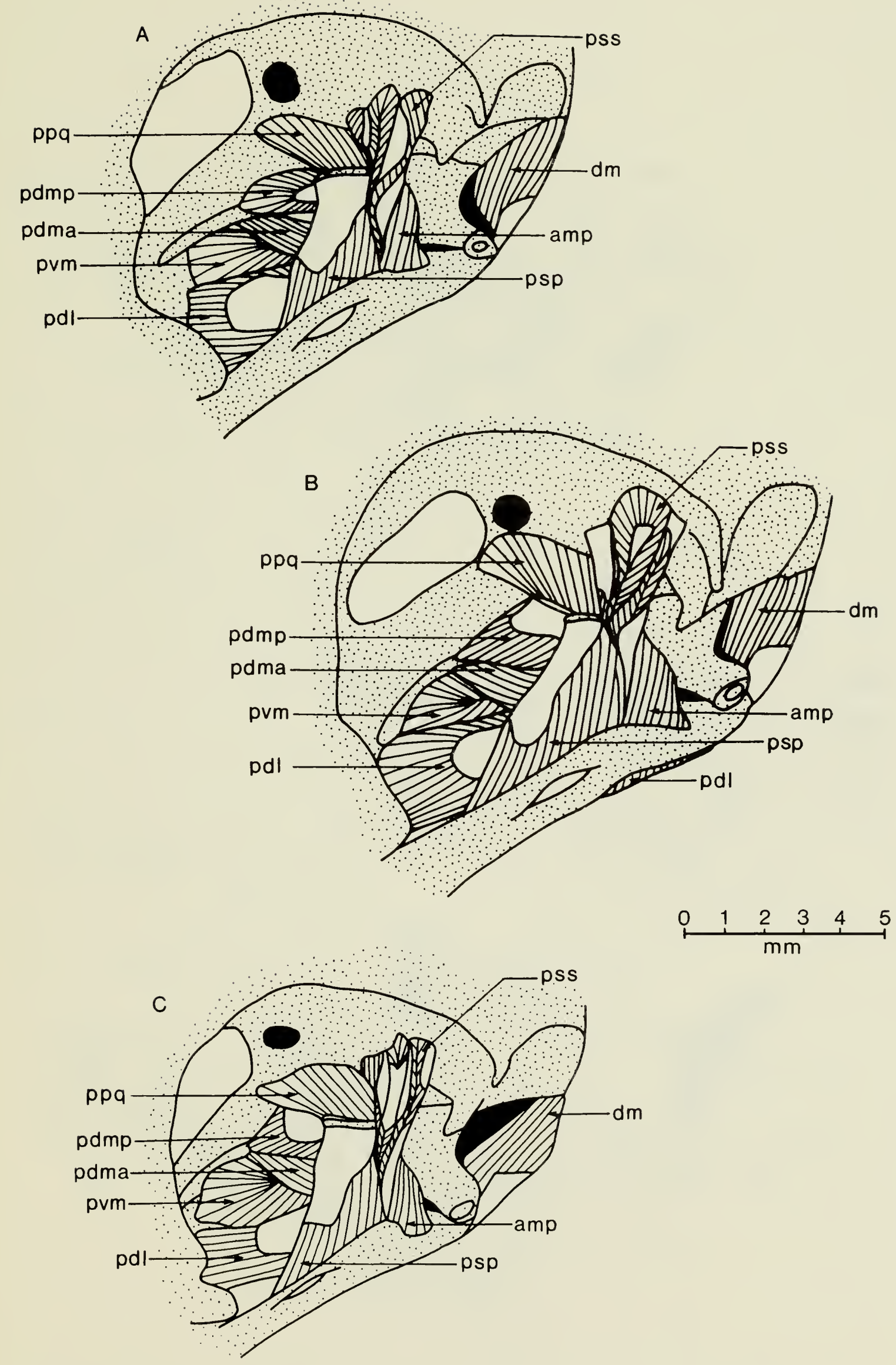

Fig. 8 Internal jaw musculature in some species of Vireo.

A Vireo griseus maynardi (KU 3889)

B V. bairdi (Yale 6363)

C V.b. bellii (KU 40376) 

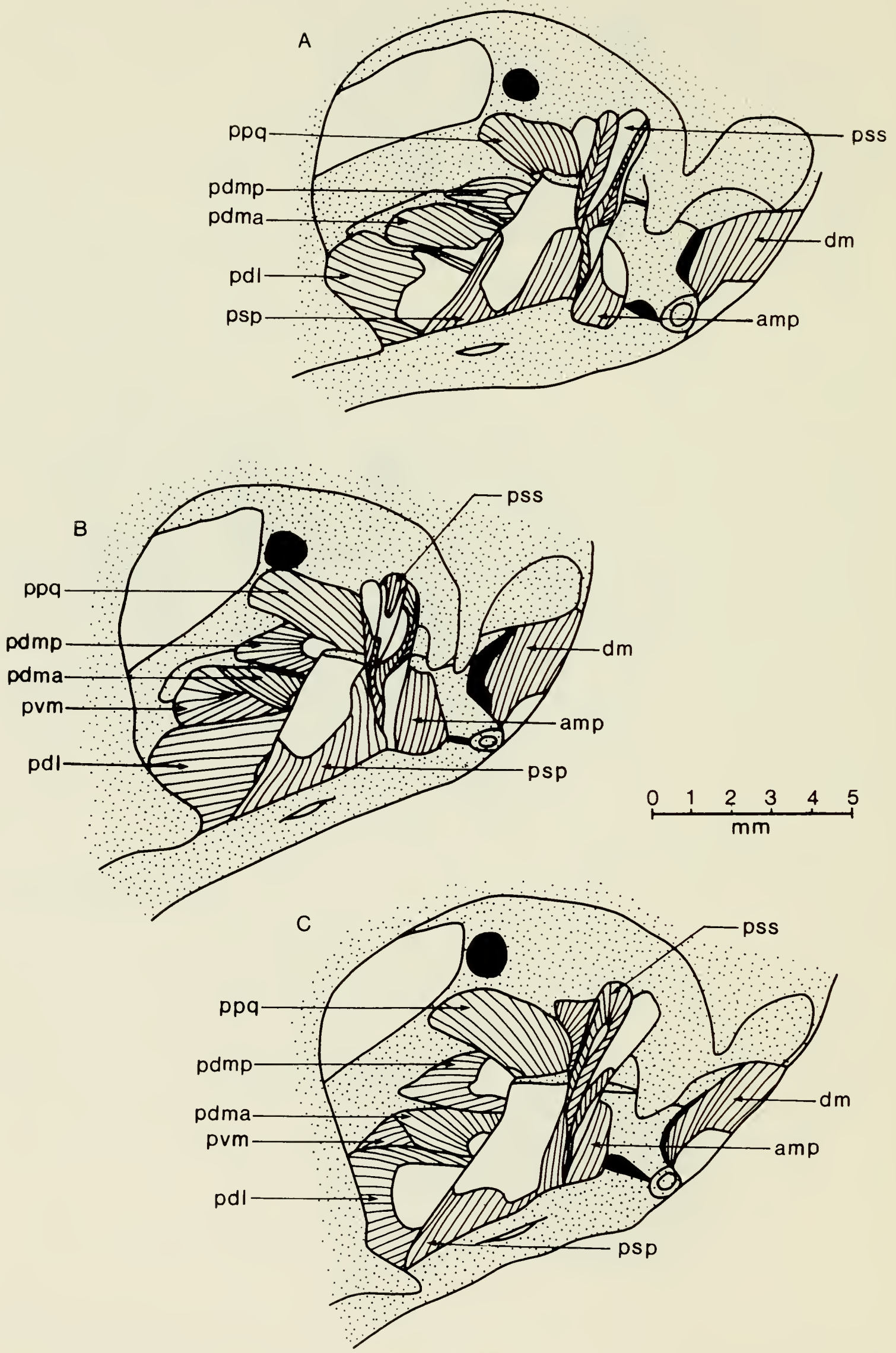

Fig. 9 Internal jaw musculature in some species of Vireo.
A Vireo vicinior (ROM 99458)
В V.h.hypochryseus (ROM 105617)
C V. solitarius plumbeus (ROM 100591) 

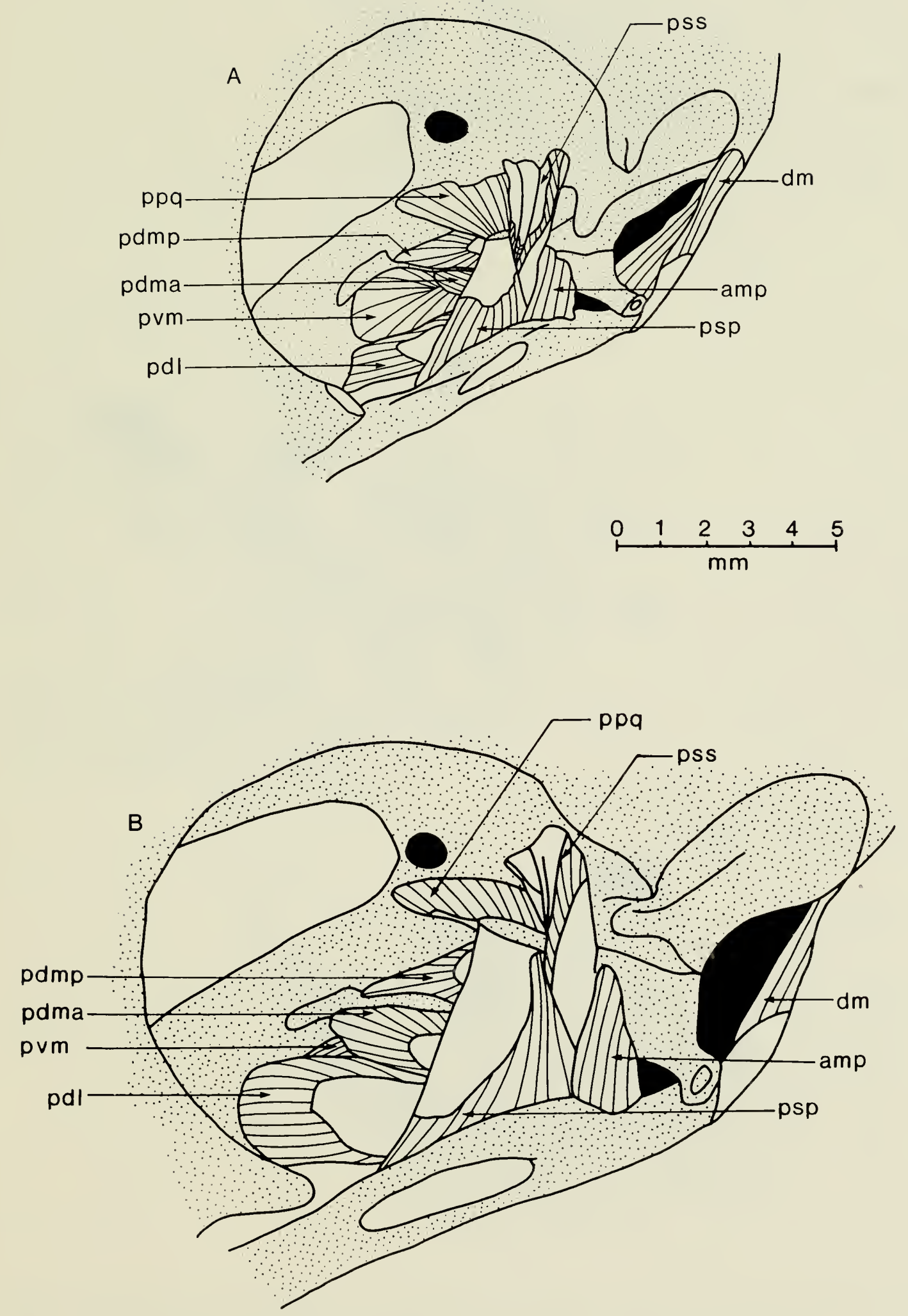

Fig. 10 Internal jaw musculature in some species of Vireo.

A Vireo nanus (ROM 112421)

B V.osburni (ROM 113173) 

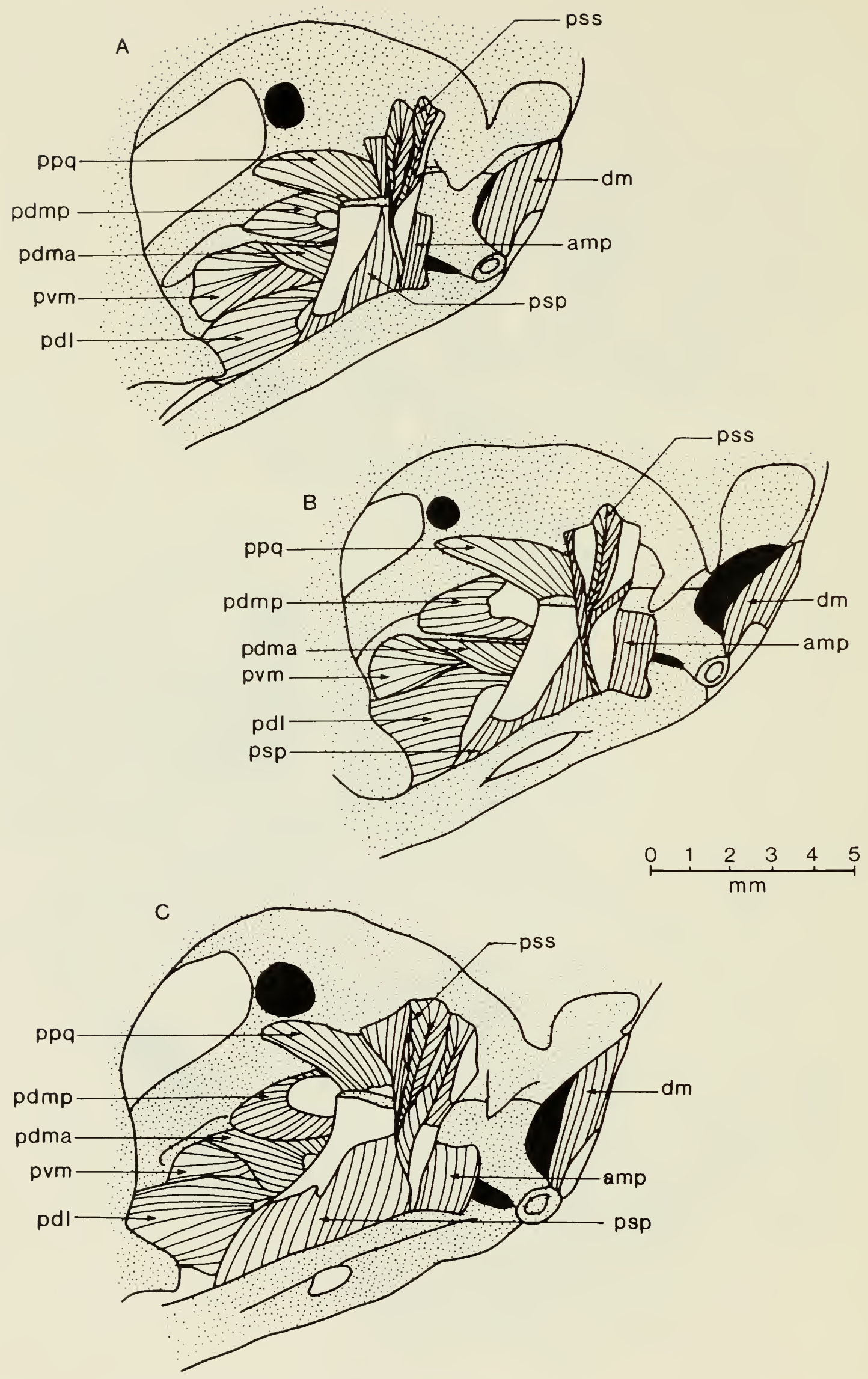

Fig. 11 Internal jaw musculature in some species of Vireo.

A Vireo philadelphicus (Rом 97688)

B V. olivaceus chivi (Carnegie 357)

C V. magister caymanensis (ROM 109363) 

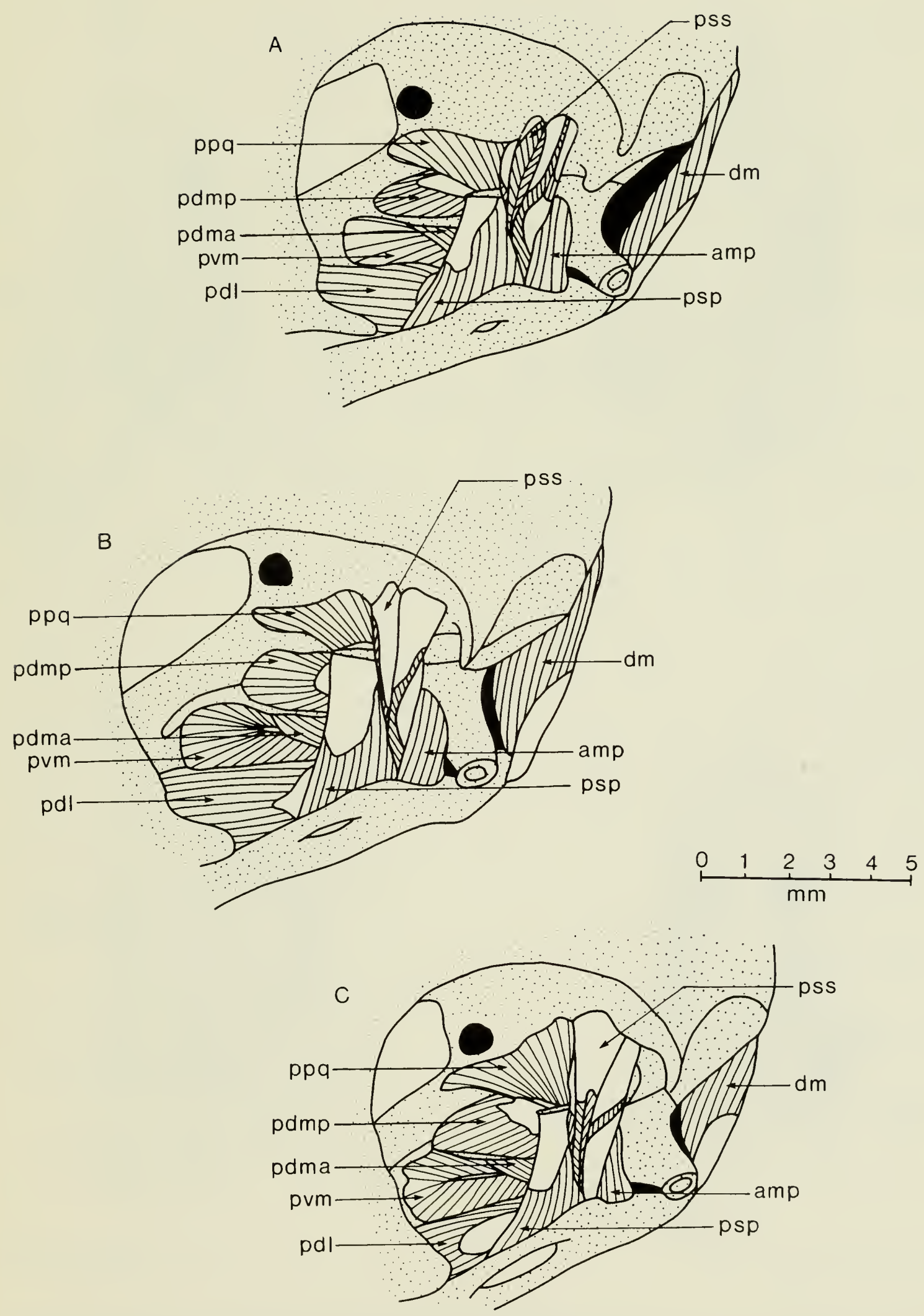

Fig. 12 Internal jaw musculature in some species of Hylophilus.

A Hylophilus poicilotis (Yale 2924)

B H. ochraceiceps (Carnegie 917)

C H.d.decurtatus (ROM 104309) 

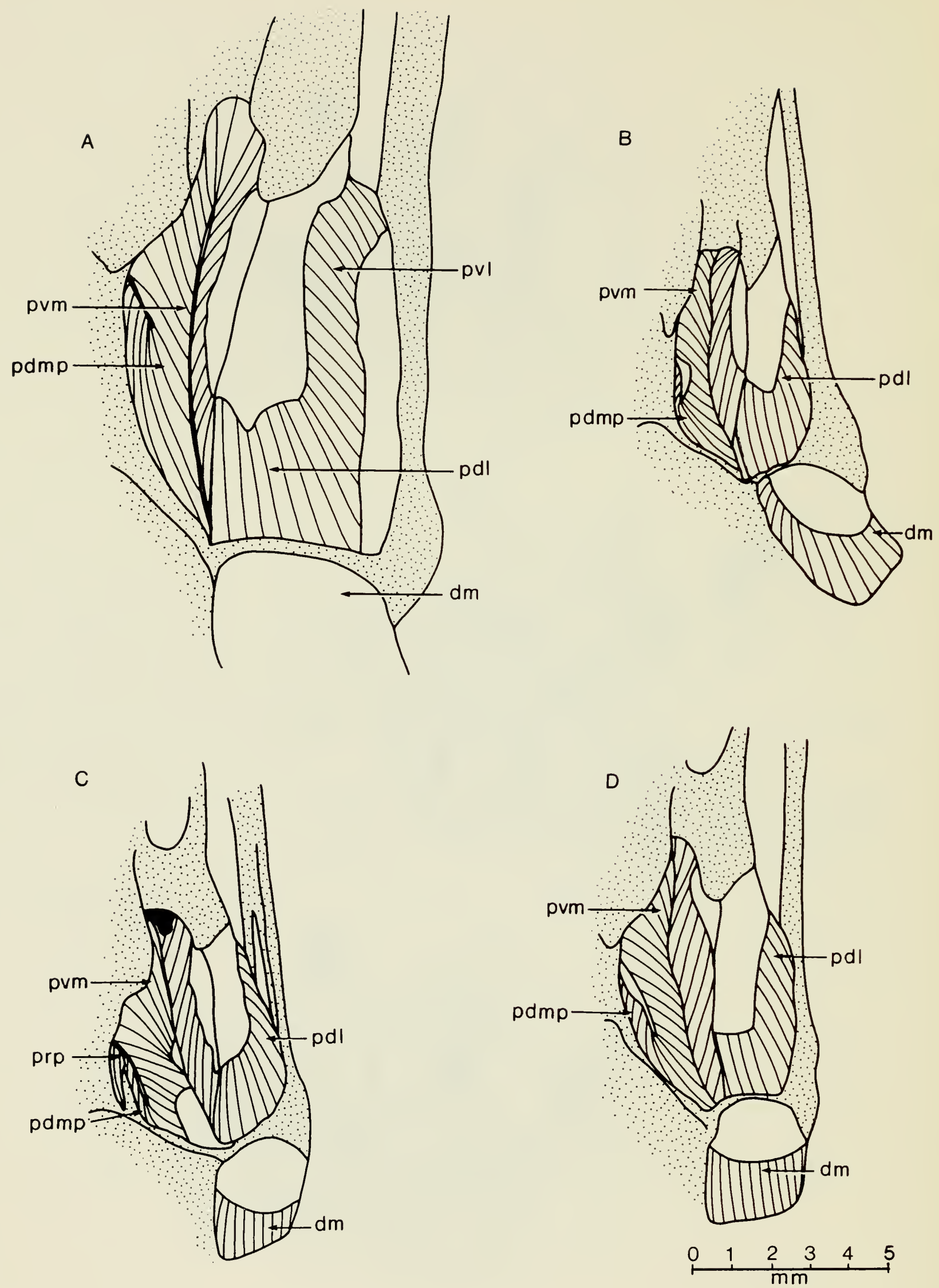

Fig. 13 Ventral view of the jaw musculature of the left side in some species of Cyclarhis and Vireo. The soft palate, connective tissue, and muscles surrounding the Eustachian tube have been removed.

A Cyclarhis gujanensis insularis (Carnegie 1077)

B Vireo huttoni stephensi (ROM 104459)

C V.atricapillus (ROM 99456)

D V. griseus maynardi (KU 3889) 

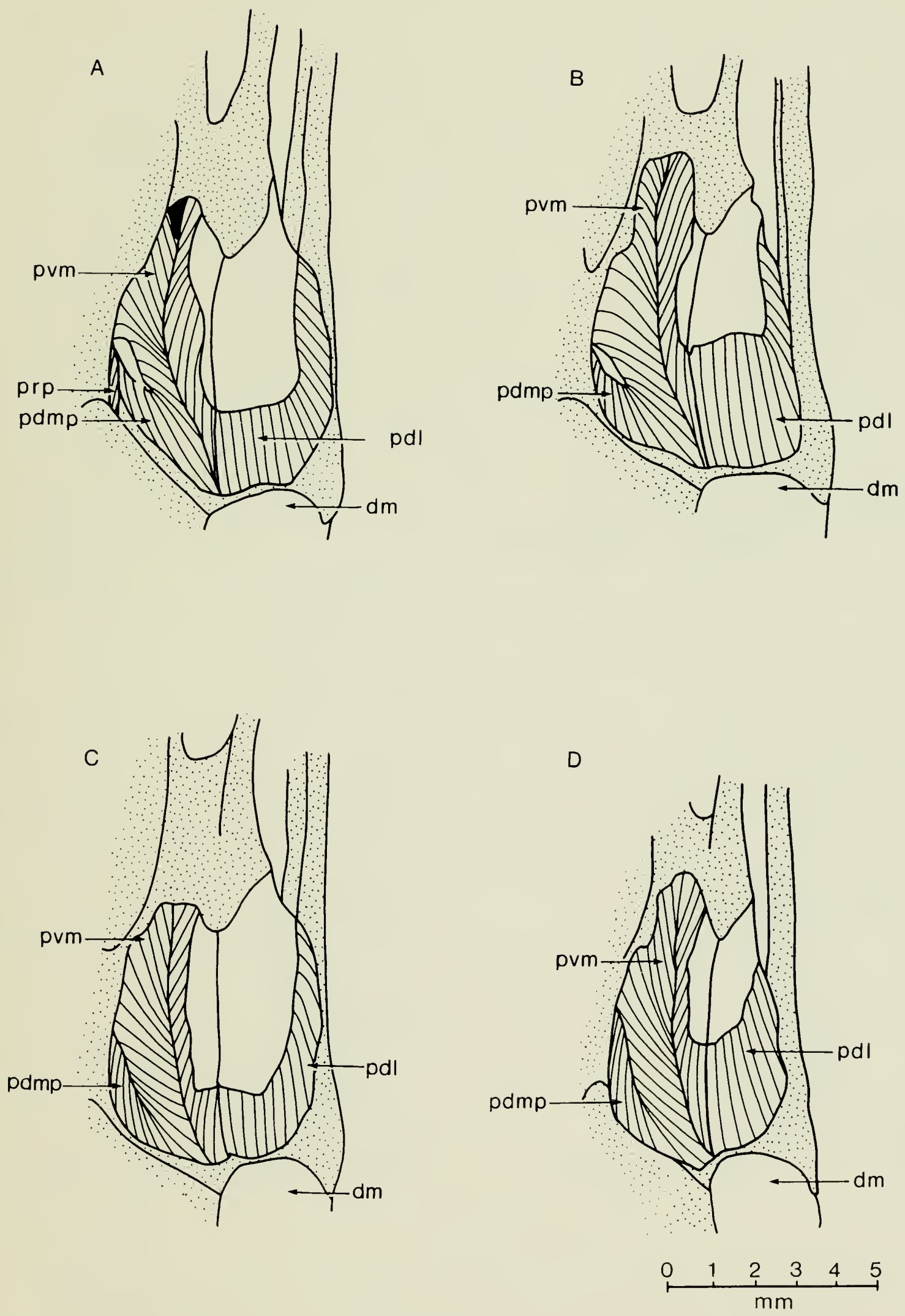

Fig. 14 Ventral view of the jaw musculature of the left side in some species of Vireo.

A Vireo vicinior (ROM 99458)

B V.h.hypochryseus (ROM 105617)

C V. solitarius plumbeus (ROM 100591)

D V.philadelphicus (ROM 97688) 

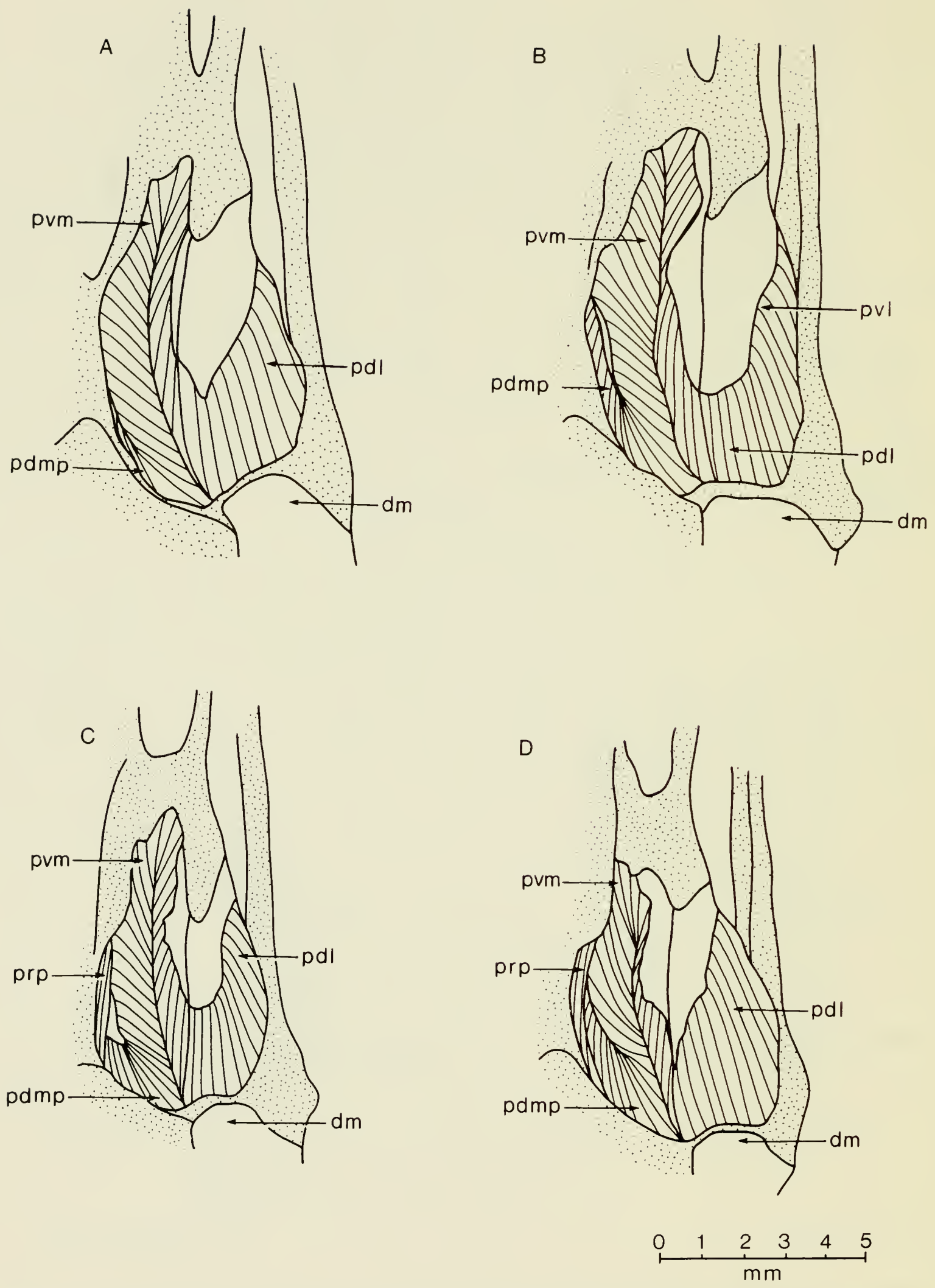

Fig. 15 Ventral view of the jaw musculature of the left side in some species of Vireo and Hylophilus.

A Vireo o. olivaceus (ROM 103089)

B V.m. magister (KU 40814)

C Hylophilus d. decurtatus (ROM 104309)

D H. ochraceiceps (Carnegie 917) 

ISBN 0-88854-276-3 